Aus der Abteilung Anatomie und Zellbiologie

(Komm. Leiter: Prof. Dr. rer. nat. Jörg Wilting)

im Zentrum Anatomie

der Medizinischen Fakultät der Universität Göttingen

\title{
Der Transkriptionsfaktor Hex \\ markiert eine Subpopulation von Endothelzellen \\ bei der Embryonalentwicklung \\ und der Tumorangiogenese
}

\author{
INAUGURAL - DISSERTATION \\ zur Erlangung des Doktorgrades \\ der Medizinischen Fakultät \\ der Georg-August-Universität zu Göttingen
}

vorgelegt von

Katrin Elisabeth Terwelp

aus

Cloppenburg

Göttingen 2010 
Dekan: Prof. Dr. med. C. Frömmel

I. Berichterstatter: Prof. Dr. rer. nat. J. Wilting

II: Berichterstatterin: Prof. Dr. med. Schäfer

III: Berichterstatterlin: -

Tag der mündlichen Prüfung: 16.03.2011 


\section{Inhaltsverzeichnis}

Abbildungsverzeichnis 6

Tabellenverzeichnis 7

1 Einleitung ......................................................................................................... 8

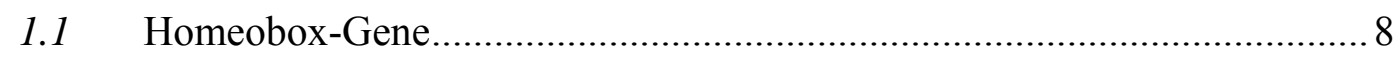

1.1.1 Die Bedeutung der Homeobox .................................................................... 8

1.2 Funktion und Expressionsmuster des Gens Hex .................................... 10

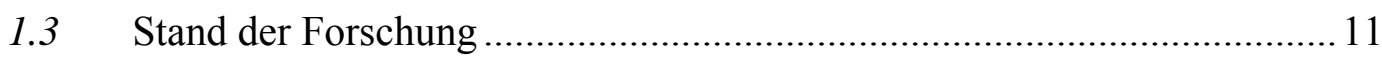

1.4 Fragestellung und Zielsetzung der Arbeit ......................................... 13

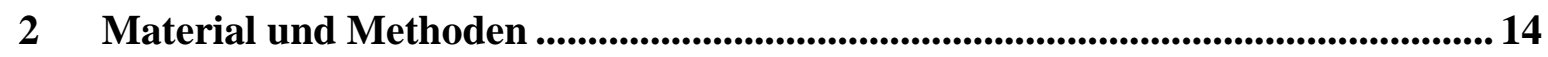

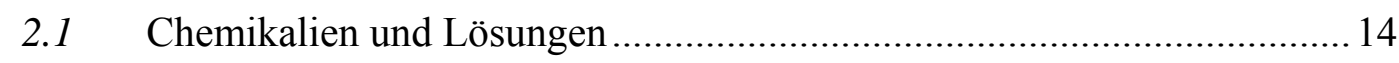

2.2 Verfahren der In-situ-Hybridisierung ............................................ 21

2.3 In-situ-Hybridisierung an Paraffinschnitten ........................................ 22

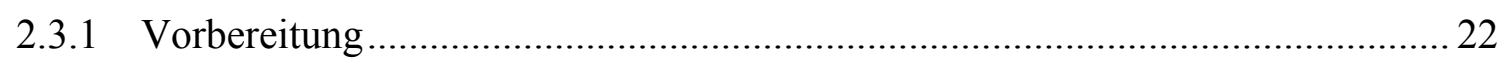

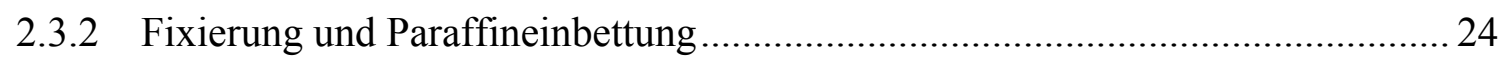

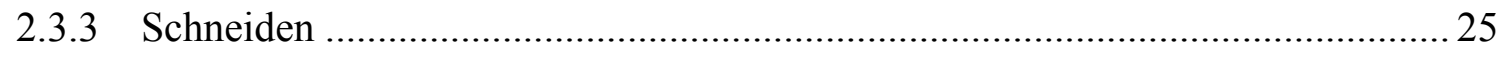

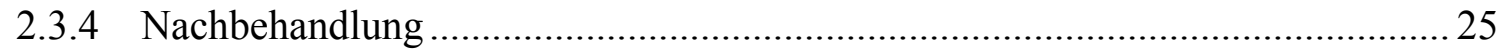

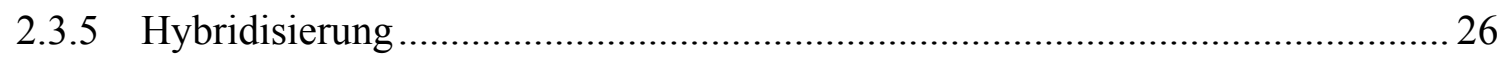

2.3.6 Immundetektion - der Nachweis der Hybridisierungsstellen............................2 27

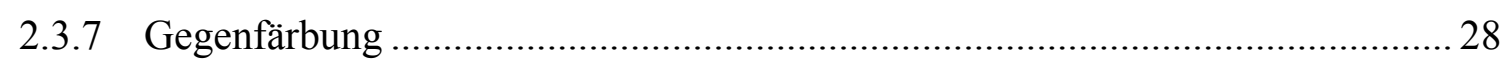

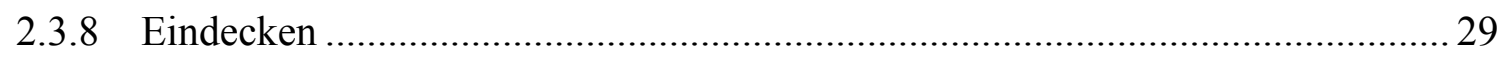

$2.4 \quad$ In-situ-Hybridisierung an whole-mount-Embryonen ..............................2 29

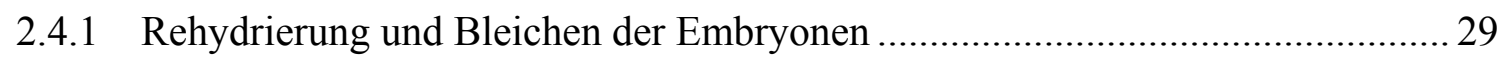

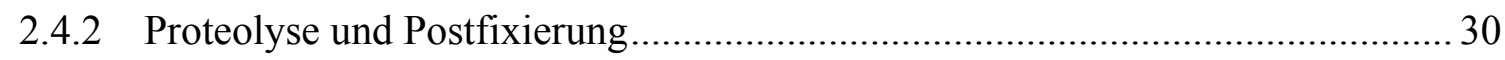

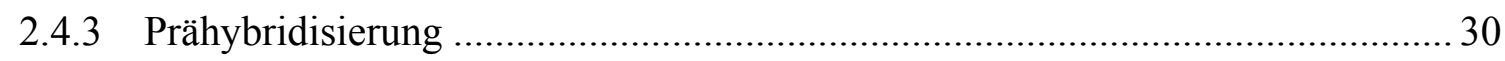

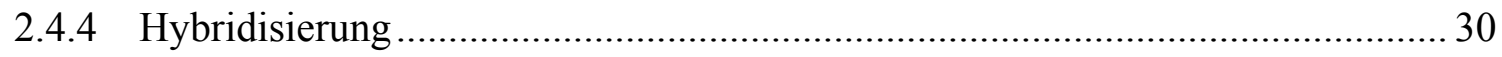


2.4.5 Immundetektion - der Nachweis der Hybridisierungsstellen.

2.4.6 Kryoschnitte

2.5 Experimentelle Gliome auf der CAM

2.5.1 Zellkultur

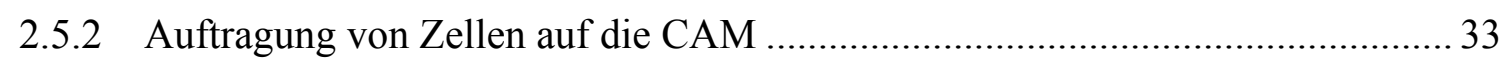

2.5.3 Präparation der Tumoren und Herstellung von Paraffinschnitten ........................ 33

3 Ergebnisse

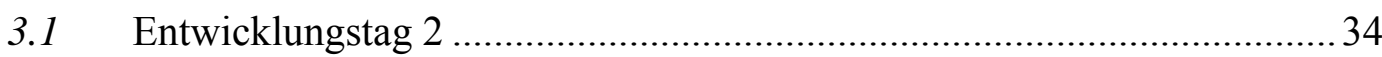

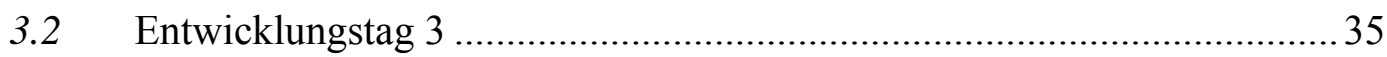

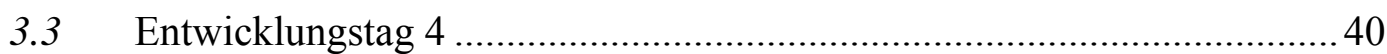

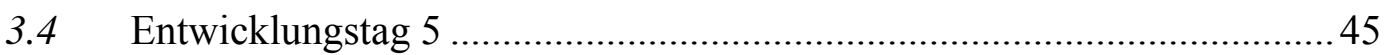

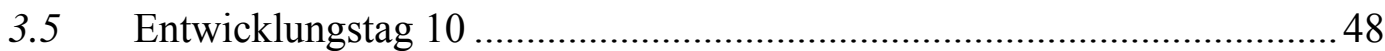

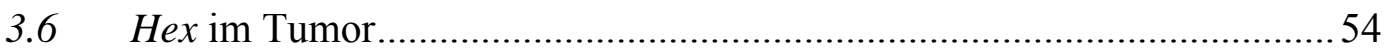

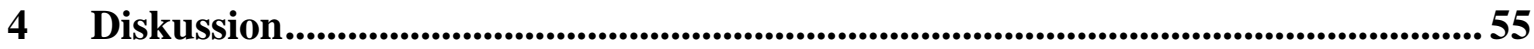

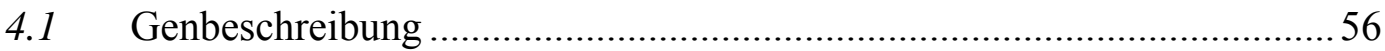

4.2 Vergleich des Hex-Gens von Huhn und Maus .........................................59

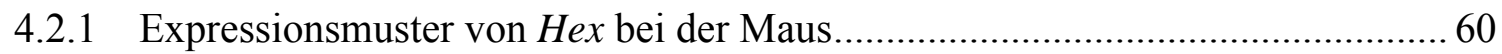

4.3 Vergleich des Hex-Gens von Huhn und Mensch........................................63

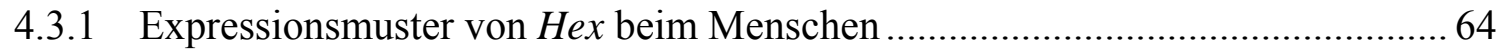

4.4 Vergleich der Ergebnisse des Hex-Expressionsmusters mit anderen Ergebnissen in der Entwicklung 64

4.4.1 Hex in der Leber, im Gallengangssystem und im Pankreas ............................... 65

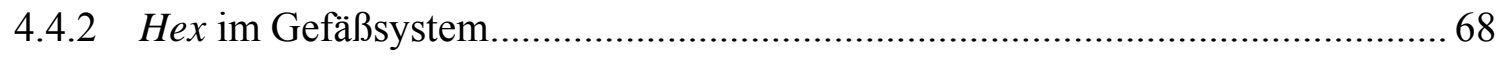

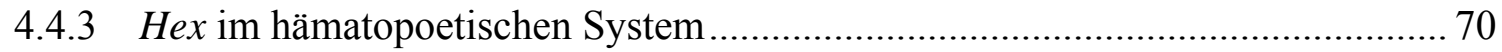

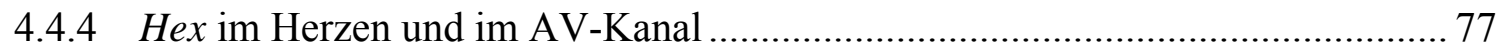

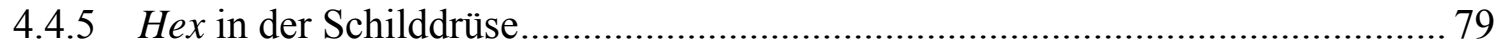


4.4.6 Hex in den Extremitäten und in Hautanhangsgebilden .....

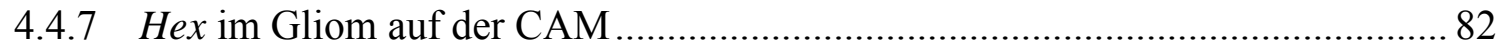

4.5 Bedeutung für den Menschen; Pathologien.............................................. 84

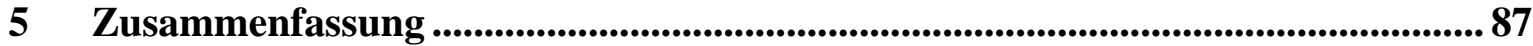

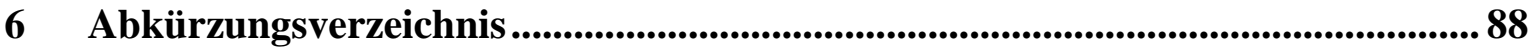

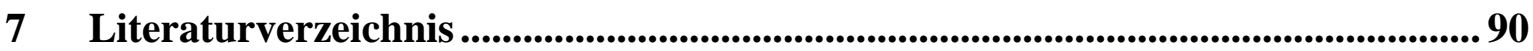

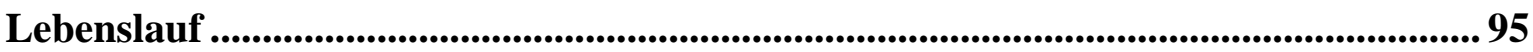




\section{Abbildungsverzeichnis}

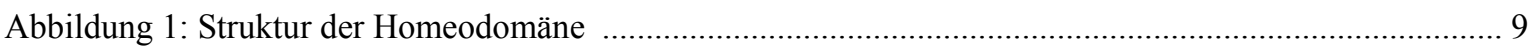

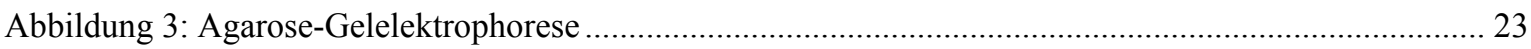

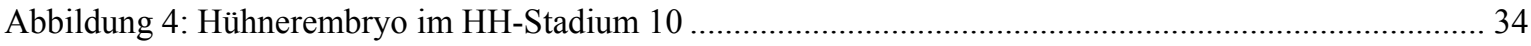

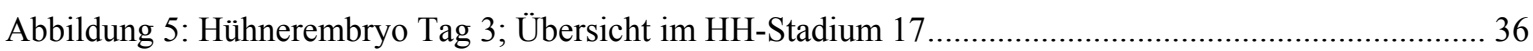

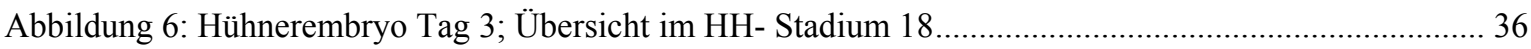

Abbildung 7: Hühnerembryo Tag 3; Leber und Herzanlage .............................................................. 36

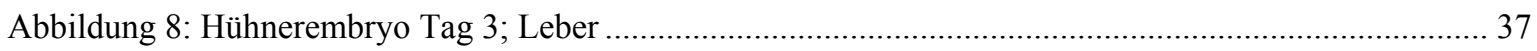

Abbildung 9: Hühnerembryo Tag 3; Leberknospe am Übergang zum Darm.......................................... 37

Abbildung 10: Hühnerembryo Tag 3; Darstellung des Herzens, der Ausflussbahn und des Aortenbodens.... 37

Abbildung 11: Embryo Tag 3; Darstellung der Viszeralbogenarterien .................................................. 38

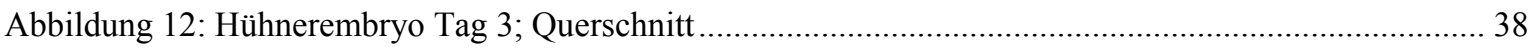

Abbildung 13: Hühnerembryo Tag 3; Vergrößerung der paarigen Aortenanlage aus Abbildung 12 ............. 38

Abbildung 14: Embryo Tag 3; Intersomitische Gefäße............................................................................. 39

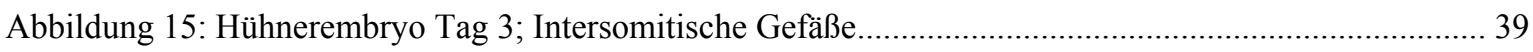

Abbildung 16: Hühnerembryo Tag 3; Perineuraler Gefäßplexus ............................................................. 39

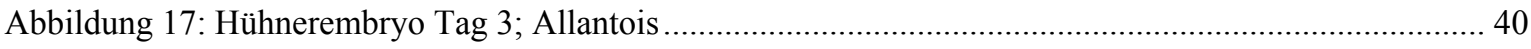

Abbildung 18: Hühnerembryo Tag 4; Übersicht ...................................................................................... 41

Abbildung 19: Hühnerembryo Tag 4; Darstellung der Organanlagen und des Aortenbodens ...................... 41

Abbildung 20: Embryo Tag 4; Darstellung des Herzens und der Ausflussbahn ..................................... 42

Abbildung 21: Hühnerembryo Tag 4; Darstellung des Ventrikels ..............................................................42

Abbildung 22: Hühnerembryo Tag 4; Darstellung der AGM-Zellen ...................................................... 43

Abbildung 23: Hühnerembryo Tag 4; Darstellung der Leberanlage ........................................................... 43

Abbildung 24: Embryo Tag 4; Mesonephros mit Gefäßzeichnung ......................................................... 43

Abbildung 25: Hühnerembryo Tag 4; Darstellung der ventralen Organe und der Schilddrüse..................... 44

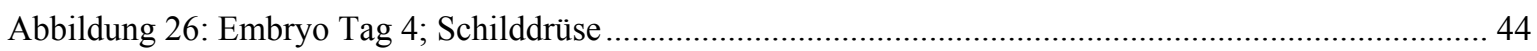

Abbildung 27: Hühnerembryo Tag 4; Darstellung der Allantois .......................................................... 44

Abbildung 28: Hühnerembryo Tag 4; Darstellung der Gefäßzeichnung in den Beinknospen ..................... 45

Abbildung 29: Hühnerembryo Tag 4; Darstellung der Gefäßzeichnung in den Flügelknospen.................... 45

Abbildung 30: Hühnerembryo Tag 5; ventrale Organanlagen in seitlicher Sicht...................................... 46

Abbildung 31: Hühnerembryo Tag 5; ventrale Organanlagen ................................................................ 46

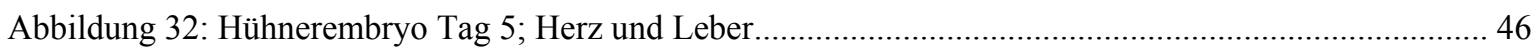

Abbildung 33: Hühnerembryo Tag 5; Querschnitt auf Höhe der Lungenknospen ..................................... 47

Abbildung 34: Hühnerembryo Tag 5; Querschnitt auf Höhe des Mesonephros und des Magens.................. 47

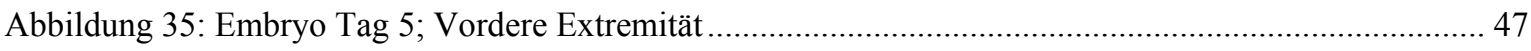

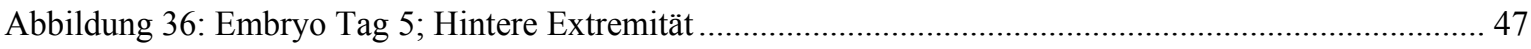

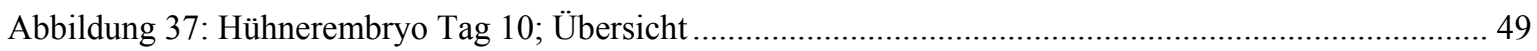

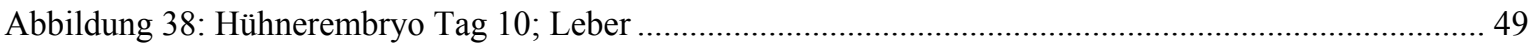

Abbildung 39: Hühnerembryo Tag 10; Lebersinus und Hepatozyten .......................................................49 
Abbildung 40: Hühnerembryo Tag 10; Leber und Ast der V. hepatica.................................................5 50

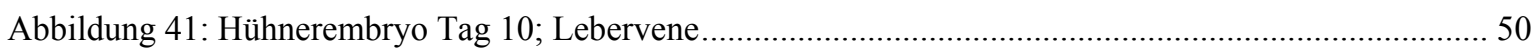

Abbildung 42: Hühnerembryo Tag 10; Leber und Mesenterialgefäße....................................................50

Abbildung 43: Hühnerembryo Tag 10; Lymphgefäße entlang der A. mesenterica .................................... 51

Abbildung 44: Hühnerembryo Tag 10; Hämatopoetische Zellen .............................................................. 51

Abbildung 45: Hühnerembryo Tag 10; Hämatopoetische Zellen im Mesenchym ..................................... 51

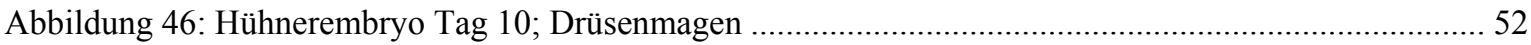

Abbildung 47: Hühnerembryo Tag 10; Gefäßsystem des Drüsenmagens ..................................................5

Abbildung 48: Hühnerembryo Tag 10; Schnitt durch die Ventrikel ..................................................... 52

Abbildung 49: Hühnerembryo Tag 10; Übersicht der Herzwand.............................................................. 52

Abbildung 50: Hühnerembryo Tag 10; Darstellung des Mesonephros und des Metanephros ....................... 53

Abbildung 51: Hühnerembryo Tag 10; Nierentubuli mit peritubulären Kapillaren ................................... 53

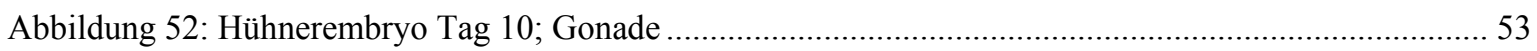

Abbildung 53: Hühnerembryo Tag 10; Perineurales Gefäßsystem und Rückenmark ............................... 54

Abbildung 54: Experimentelles Gliom auf der Chorioallantoismembran .................................................. 54

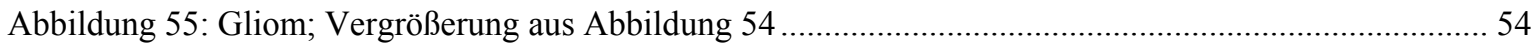

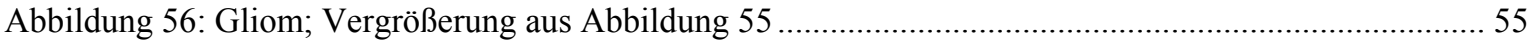

Abbildung 57: Gliom mit Tumorgefäßen; Vergrößerung aus Abbildung 55 ............................................. 55

Abbildung 58: Gensequenz des Homeobox-Gens Hex beim Huhn ......................................................... 56

Abbildung 59: Basensequenzvergleich des Hex-Gens von Maus und Huhn ........................................... 59

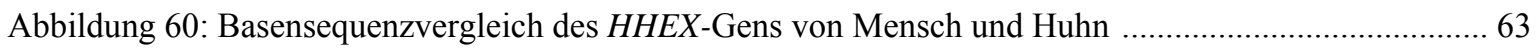

\section{Tabellenverzeichnis}

Tabelle 1: Lokalisation von Hex in verschiedenen Stadien der Hühnchenentwicklung.......................11 


\section{Einleitung}

\subsection{Homeobox-Gene}

Das Hex-Gen (hematopoietically-expressed homeobox gene) gehört zu der Gruppe der Homeobox Gene. Bei dieser Gengruppe wird eine stark konservierte DNA Sequenz, die Homeobox, vorgefunden.

Folgende Synonyme werden für das Gen Hex verwendet:

- Hematopoietically-expressed homeobox Hex

- HHEX

- HOX11L-PEN

- $\mathrm{HMPH}$

- Prh

- $\operatorname{Prhx}$.

Homeobox-Gene umfassen eine große Gruppe von Entwicklungsregulatorgenen, die essentiell für Differenzierung und Wachstum sind (Abate-Shen, 2002). Erstmals wurden sie bei Drosophila melanogaster genauer beschrieben, wo sie wichtig für die Entwicklung der anterioren-posterioren Körperachse sind (Krumlauf, 1994). Das menschliche Genom enthält mindestens 200 Homeobox-Gene (Tupler et al., 2001), die man in zwei Klassen unterteilt. Die Klasse 1, die HOX Gene, umfasst 39 geclusterte Gene, während die HomeoboxGene der Klasse 2 über das gesamte Genom verteilt sind und verschiedenen Genfamilien zuzurechnen sind. Die Mitglieder dieser Genfamilien besitzen neben der Homeobox konservierte Sequenzen, die ihnen weitere funktionelle Eigenschaften verleihen (Abate-Shen, 2002; Owens und Hawley, 2002).

\subsubsection{Die Bedeutung der Homeobox}

Unter der Homeobox versteht man eine konservierte Gensequenz aus 183 Basenpaaren, welche für eine Aminosäuresequenz kodieren, die eine hohe Affinität zur DNA besitzt. Diese Homeodomäne, bestehend aus 61 Aminosäuren, bindet sequenzspezifisch an die DNA und reguliert somit die Genexpression (Gehring et al., 1994). Die Homeodomäne ähnelt einem Helix-Turn-Helix-Motiv (HTH) (Abbildung 1), ist aber im Unterschied zur HTH-Einheit länger und stellt somit eine stabilere Struktur dar, die die DNA spezifisch binden kann (Buske und Humphries, 2000). Die Primärsequenz zeigt in den unterschiedlichen Homeoproteinfamilien Variabilitäten (Abbildung 2). 


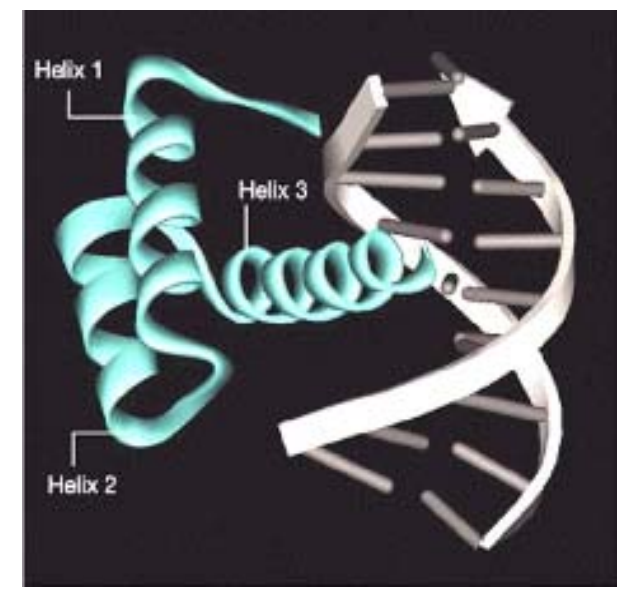

Abbildung 1: Struktur der Homeodomäne (aus: Abate-Shen 2002, S. 780)

Die dreidimensionale Struktur der Homeodomäne ist hochkonserviert und entspricht 3 a Helices, die einen variablen amino-terminalen Arm aufweisen. Die Übereinstimmung der Aminosäuresequenz in den Homeodomänen ist essentiell für den Kontakt mit der DNA.

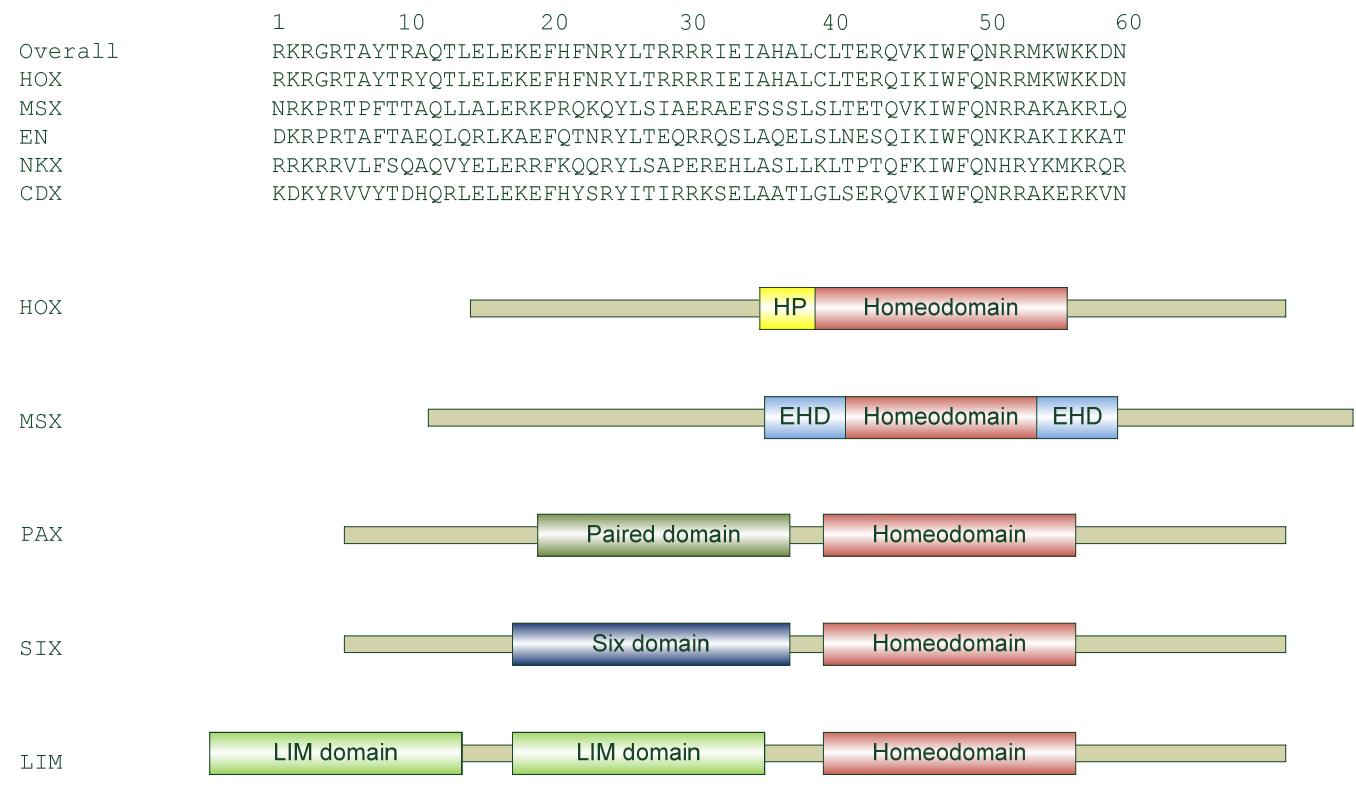

Abbildung 2: Variabilitäten unter den Homeobox-Genen (aus Abate-Shen 2002, S.780)

Die Abbildung zeigt Gemeinsamkeiten und Unterschiede der Primärsequenz der Homeodomäne verschiedener Genfamilien (Abbildung 2 oben) sowie die starken Unterschiede innerhalb der carboxy- und aminoterminalen Enden, die der Homeodomäne direkt benachbart sind (Abbildung 2 unten). Die Sequenzunterschiede scheinen mitverantwortlich für die funktionellen Eigenschaften der einzelnen Genfamilien zu sein. 


\subsection{Funktion und Expressionsmuster des Gens Hex}

Hex codiert für ein Homeodomänprotein, welches sowohl als Transkriptionsrepressor als auch als Transkriptionsaktivator fungiert (Cong et al., 2006). Hex ist im Huhn an der Entwicklung der Organe, die sich vom Vordarm ableiten, z. B. der Schilddrüse, und dem Vorderhirn beteiligt. Außerdem ist das Homeobox-Gen bei der Differenzierung von Gefäßen und hämatopoetischen Zellen von Bedeutung. Darüber hinaus hat Hex Funktionen bei regenerativen Prozessen, die mit Gefäß- und Blutbildung einhergehen (Djavani et al., 2005).

Das Hex-Expressionsmuster in den frühen Stadien der Hühnchenentwicklung ist bereits detailliert beschrieben worden. Whole-mount-In-situ-Hybridisierungen beim Huhn zeigten zum Zeitpunkt des Legens cHex-Transkripte in den posterioren Marginalzonenzellen, in Koller's Sickle und in allen Zellen des sich bildenden Hypoblasten, bis sich die Schicht vollständig ausgebildet hat. Während der Gastrulation (Stadium 4 nach Hamburger und Hamilton 1951) wird cHex in den anterioren Hypoblastzellen exprimiert und schwache Expression kann im prächordalen Mesoderm detektiert werden. Außerdem werden zu diesem Zeitpunkt $\mathrm{cHex}$-Transkripte in vereinzelten Zellhaufen in der lateralen und posterioren Area opaca gefunden, die zukünftige Blutinseln darstellen (Yatskievych et al., 1999). Im HH-Stadium 6 werden cHex-positive Blutinseln im gesamten extraembryonalen Mesoderm beobachtet. Während der nächsten Entwicklungsstunden ist Hex-Expression in der halbmondförmigen Herzanlage zu beobachten. Sagittalschnitte zeigen, dass die Hex-Expression dabei auf das Schlundentoderm beschränkt bleibt und direkt neben dem Epithel des sich bildenden Herzrohrs zu finden ist. Dieser Entodermbereich bildet letztendlich die Leber (Yatskievych et al., 1999). Im HH-Stadium 12 zeigen sich cHex-Transkripte im Endokard, in der Schilddrüsenanlage und in der Leberanlage. Außerdem wurde Expression in den Endothelzellen der dorsalen Aorta, im Bereich der sich bildenden Kardinalvenen und in intersomitischen Gefäße gefunden. Im Stadium 14 HH zeigen sich cHex-Transkripte in der Leber und Schilddrüsenanlage, in der Niere, in der Schwanzknospe und in vereinzelten Blutinseln kaudal der Area pellucida. Im hämatopoetischen System wird Hex in multipotenten Vorläuferzellen, in myeloischen Zellen, in B-Zellen, jedoch nicht in T-Zellen exprimiert (Owens \& Hawley, 2002). 


\subsection{Stand der Forschung}

Die Expression des Homeobox-Gens Hex wurde in einigen Stadien der Embryonalentwicklung schon sehr detailliert untersucht. Dabei wurde bislang besonders die Genexpression in verschiedenen Organanlagen in der Frühphase der Entwicklung beschrieben. In der Spätphase der Embryonalentwicklung beschränken sich die meisten Untersuchungen auf die entodermalen Organe. Tabelle 1 zeigt, in welchen Organen Hex in verschiedenen Stadien der Embryonalentwicklung des Vogels exprimiert wird. Die Stadien beziehen sich auf die Einteilung nach Hamburger und Hamilton (1951). Danach findet in den ersten 33 Stadien die Frühentwicklung des Vogelembryos statt, in der sich die Organanlagen ausbilden und erste Gewebe differenzieren. Die Stadien 34 bis 42 sind durch zunehmende Organdifferenzierung sowie durch Wachstum und Ausreifung geprägt (Hamburger \& Hamilton, 1951). Hex wird in der Frühphase der Entwicklung vor allem im frühen Entoderm, im Bereich des Primitivknotens und des Primitivstreifens exprimiert (Stadium 1-6). Außerdem werden bereits früh Hex-positive Blutinseln beschrieben (Stadium 4-6). In den nachfolgenden Stadien (7-24) ist die Hex-Expression weiterhin im Entoderm und den sich ableitenden Organen wie Leber und Darmrohr beschrieben worden. Des Weiteren zeigt sich eine HexExpression in den Gefäßen, vor allem im Ausflusstrakt des Herzens und im Sinus venosus, in Blutinseln und im Endokard. In der Spätphase der Entwicklung (Stadium 25-42) wird bislang hauptsächlich eine Hex-Expression in den entodermalen Organen Leber und Pankreas dargestellt.

Tabelle 1: Lokalisation von Hex in verschiedenen Stadien der Hühnchenentwicklung (Aus: Geisha- Hühner In-situ-Hybridisierungen, http://geisha.arizona.edu; 2009)

\begin{tabular}{|c|l|}
\hline Stadium & Lokalisation von Hex \\
\hline $1-3$ & Area pellucida \\
& Hypoblast \\
& Kollers Sichel \\
& Frühes Entoderm \\
& Primitivstreifen \\
\hline $4-6$ & Vordere Darmpforte \\
& Area opaca \\
& Area pellucida \\
& Blutinseln \\
\hline
\end{tabular}




\begin{tabular}{|l|l|}
\hline & Frühes Entoderm \\
& Kopffortsatz \\
& Primitivknoten \\
& Primitivstreifen \\
& Hypoblast \\
\hline $7-12$ & Vordere Darmpforte \\
& Blutinseln \\
& Blutgefäße \\
& Frühes Entoderm \\
& Leber \\
\hline $13-18$ & Vordere Darmpforte \\
& Blutinseln \\
& Blutgefäße \\
& Leber \\
& Schwanzknospe \\
& Schilddrüse \\
& Entoderm \\
& Ausflusstrakt des Herzens \\
& Endokard \\
& Darmrohr \\
\hline $31-42$ & Sinus venosus \\
\hline $19-24$ & Allantois \\
Blutgefäße \\
Endokard \\
Ausflusstrakt des Herzens \\
& Leber \\
& Sinus venosus \\
& Schilddrüse \\
\hline & Entoderm \\
& Leber \\
\hline & Entoderm \\
& Pankreas (intrahepatische Gallengänge) \\
\hline & \\
&
\end{tabular}




\subsection{Fragestellung und Zielsetzung der Arbeit}

Das Homeobox-Gen HEX ist bei Wirbeltieren und Menschen hoch konserviert und es gibt Hinweise darauf, dass das Gen bei der Entstehung humaner Pathologien beteiligt ist. Eine dezidierte Beschreibung der Genexpression kann also für das Verständnis humaner Pathologien hilfreich sein. In der Frühphase der Entwicklung ist die Hex-Expression intensiv untersucht worden. In der Spätphase konzentrieren sich die Arbeiten auf die Untersuchung der entodermalen Organe Leber und Pankreas. Ich habe daher das Expressionsmuster von Hex bei Vogelembryonen in der Frühphase und darüber hinaus in differenzierten Organen von Tag 10 Hühnerembryonen untersucht. Das vornehmliche Ziel war es, das Expressionsmuster im Gefäßsystem darzustellen, um der Frage nachzugehen, ob Hex in allen Abschnitten des Gefäßsystems und in allen Organsystemen exprimiert wird. Gibt es Unterschiede im arteriellen und venösen System? Wird Hex in lymphatischen Gefäßen exprimiert? Gibt es organspezifische Unterschiede?

Dabei habe ich auf die Lokalisation des Hex-Gens auf zellulärer Ebene und auf den zeitlichen Verlauf der Genexpression besonderen Wert gelegt. In der Diskussion vergleiche ich das Hex-Expressionsmuster des Vogels mit dem von Mammaliern. Anhand des Expressionsmusters soll auf Funktionen von Hex in verschiedenen Organsystemen eingegangen werden. Ich habe auch die Rolle von Hex bei der Tumorangiogenese untersucht. Auch hier stellte sich die Frage, ob Hex ein ubiquitärer Marker von Tumorgefäßen ist. Dabei habe ich das Modell experimenteller Gliome auf der Chorioallantoismembran (CAM) gewählt. Einen weiteren wichtigen Punkt der Diskussion stellt die Frage dar, welche Bedeutung das Gen und die Pathologien, die durch Missexpression von Hex hervorgerufen werden, für den Menschen hat. 


\section{Material und Methoden}

\subsection{Chemikalien und Lösungen}

\section{Chemikalien}

Anti-Digoxigenin-Antikörper konjugiert mit

Roche, Mannheim

Alkalischer Phosphatase (Anti-Dig-AP)

Bidestilliertes Wasser $\left(\mathrm{H}_{2} \mathrm{O}\right.$-bidest)

Fresenius Kabi, Bad Homburg

Blocking-Pulver

Roche, Mannheim

5-Brom-4-Chlor-3-Indolylphosphat /

Roche, Mannheim

Nitroblautetrazolium (NBT / BCIP)

Diethylenpyrocarbonat (DEPC)

Sigma-Aldrich, Deisenhofen

Digoxigenin-11-Uraciltriphosphat (Dig-11-

Roche, Mannheim

UTP)

Dimethylformamid

Sigma-Aldrich, Deisenhofen

Dinatriumhydrogenphosphat $\left(\mathrm{Na}_{2} \mathrm{HPO}_{4}\right)$

Merck, Darmstadt

DNAse I, RNAse-frei

Roche, Mannheim

Dulbecco`s Modified Eagle's Medium

Cambrex Bio Science Verviers, Belgien

(DMEM)

Entellan

Ethanol / Methanol

Merck, Darmstadt

Merck, Darmstadt

Ethylendiamintetraacetat (EDTA)

Paesel und Lorei, Duisburg

Fetales Kälberserum

Biochrome AG, Berlin

Fluoromount

Biozol, Eching

Formaldehyd (FA), 37\%

Merck, Darmstadt

Formamid

Merck, Darmstadt

Glutardialdehyd, 25\%

Merck, Darmstadt

Glycin

Sigma-Aldrich, Deisenhofen

Hefe-Transfer-Ribonukleinsäure (Hefe-

tRNA)

Heringssperma

Sigma-Aldrich, Deisenhofen

Pferde-Serum

Kaliumchlorid $(\mathrm{KCl})$

Kaliumdihydrogenphosphat $\left(\mathrm{KH}_{2} \mathrm{PO}_{4}\right)$

Kernechtrot

Invitrogen, Karlsruhe

Invitrogen, Karlsruhe

Merck, Darmstadt

Merck, Darmstadt

Waldeck, Münster

Loading Dye Solution für RNA-

Fermentas, St. Leon-Rot

Elektrophorese

Magnesiumchlorid $\left(\mathrm{MgCl}_{2}\right)$

Sigma-Aldrich, Deisenhofen 
Matrigel

Mononatriumphosphat-1-hydrat $\left(\mathrm{NaH}_{2} \mathrm{PO}_{4}\right)$

Natriumchlorid $(\mathrm{NaCl})$

Natriumcitrat

Natriumdodecylsulfat (SDS)

Natronlauge $(\mathrm{NaOH})$

Nukleoidtriphosphate

Paraffin

4\% Paraformaldehyd (PFA)

PCR Purification Kit zum Aufreinigen des linearisierten Plasmids

Pen-Strep $(5000 \mathrm{U} / \mathrm{ml} / 5000 \mu \mathrm{l} / \mathrm{ml})$

Plasmid Midi Kit zum Herstellen

von Plasmid-DNA

Polyoxyethylensorbitanmonolaurat (Tween

20)

Proteinase $\mathrm{K}$

RNA-Polymerase

RNAse A

RNAse-freies Wasser

RNeasy Mini Kit zum Aufreinigen

von Digoxigenin-gelabelten RNA-Sonden

Rotihistol

Saccharose

Salzsäure $(\mathrm{HCl})$

Tissue-Tek Einbettungsmedium

Tris (Hydroxymethyl) Aminomethan (Tris)

Trypsin

Wasserstoffperoxid $\left(\mathrm{H}_{2} \mathrm{O}_{2}\right), 30 \%$

Xylol

Zitronensäure

\section{Geräte:}

Brutschrank

Thermomixer

Digital pH Meter

Feinwaage
BD Biosciences

Merck, Darmstadt

Roth, Kralsruhe

Sigma-Aldrich, Deisenhofen

Sigma-Aldrich, Deisenhofen

Merck, Darmstadt

Fermentas, St. Leon-Rot

Merck, Darmstadt

Sigma-Aldrich, Deisenhofen

Sigma-Aldrich, Deisenhofen

Cambrex Bio Science Verviers, Belgien

Qiagen, Hilden

Roth, Karlsruhe

Merck, Darmstadt

Fermentas, St. Leon-Rot

Roche, Mannheim

Fermentas, St. Leon-Rot

Qiagen, Hilden

Roth, Karlsruhe

Merck, Darmstadt

Merck, Darmstadt

Sakura, Finetek, Niederlande

AppliChem, Darmstadt

Cambrex Bio Science Verviers, Belgien

Merck, Darmstadt

Merck, Darmstadt

Merck, Darmstadt

Brutschrank BSS 300, Ehret, Emmendingen

Thermomixer MR 3001,Heidolph Schwabach

Digital pH Meter 646, Knick, Berlin

Feinwaage BP 3100, Sartorius, Göttingen 
Paraffin-Mikrotom

Rollwippe

Gefrier- und Kühlschränke

Mikroskop

Kamera

Kryomikrotom

Physio Care Pipetten

Zentrifuge

\section{Versuchstiere:}

Befruchtete Hühnereier: gewerblicher Züchter (Firma Bronner, 79112 Freiburg)

\section{CNS-1 Zelllinie:}

Überlassen von Herrn Dr. M. Platten, Labor für Molekulare Neuro-Onkologie und Neurodegeneration, Abteilung Neurologie der Universität Tübingen, Deutschland

\section{Lösungen und Puffer für die ISH an Paraffinschnitten}

Lösung 1: PBS (20x); Stammlösung; $\mathrm{pH} 7,4$

$-2,74 \mathrm{M} \mathrm{NaCl}$

$-0,05 \mathrm{M} \mathrm{KCl}$

- $0,20 \mathrm{M} \mathrm{Na}_{2} \mathrm{HPO}_{4}$

$-0,04 \mathrm{M} \mathrm{KH}_{2} \mathrm{PO}_{4}$

Lösung 2: SSC (20x); Stammlösung; $\mathrm{pH}$ 7,0 mit $\mathrm{NaOH}$ einstellen

$-3 \mathrm{M} \mathrm{NaCl}$

- 0,3M Na-Citrat

Lösung 3: Tris-Glycin-Puffer

$-0,5 \mathrm{M}$ Tris

- 0,5M Glycin

Lösung 4: Hybridisierungspuffer

- 40\% Formamid

$-25 \% \mathrm{SSC}$

- $35 \%$ DEPC- $\mathrm{H}_{2} \mathrm{O}$ bidest
Paraffin-Mikrotom RM 2155, Leica Micro-

systems, Wetzlar

Liebherr, Ochsenhausen

Fluoreszenzmikroskop DM 4000 B, Leica

Microsystems, Wetzlar

Digitalkamera DFC 340 FX, Leica Microsys-

tems, Wetzlar

Kryomikrotom CM 3050 S, Leica Microsys-

Eppendorf, Hamburg

Zentrifuge 5412, Eppendorf, Hamburg tems, Wetzlar 
Lösung 5: Hybridisierungslösung

- $40 \%$ Formamid

$-25 \% \mathrm{SSC}$

- 1\% Denhardt's (100x)

$-1 \%$ tRNA $(10 \mu \mathrm{g} / \mu \mathrm{l})$

- $1 \%$ Heringssperma $(100 \mu \mathrm{g} / \mu \mathrm{l})$

- 1\% markierte RNA-Sonde

- $31 \%$ DEPC- $\mathrm{H}_{2} \mathrm{O}$ bidest

Die Lösung 4 min bei $95^{\circ} \mathrm{C}$ denaturieren und anschließend 5 min auf Eis legen.

Lösung 6: Posthybridisierungspuffer

- $20 \%$ Formamid

$-2,5 \% \mathrm{SSC}$

- $77,5 \% \mathrm{H}_{2} \mathrm{O}$ bidest

Lösung 7: Denhardt's (100x)

- 20g Ficoll ( Type 400, Pharmacia)

- 20g Polyvinylpyrrolidin

- 20g BSA

Alle Komponenten in 11 DEPC- $\mathrm{H}_{2} \mathrm{O}$ lösen und steril filtrieren.

Lösung 8: NTMT-Alkalische Phosphatase-Puffer

$-100 \mathrm{mM} \mathrm{NaCl}$

- $50 \mathrm{mM} \mathrm{MgCl}$

- 100mM Tris, pH 9,5

$-0,1 \%$ Tween 20

Lösung 9: Färbelösung

$-4,5 \mu 1$ Nitroblautetrazolium

- 3,5 $\mu 1$ 5-Bromo-4-chloro-3-indolylphosphat

- 1ml NTMT-Alkalische Phosphatase Puffer

Lösung 10: TBS (10x); Stammlösung

$-1,37 \mathrm{M} \mathrm{NaCl}$

$-0,03 \mathrm{M} \mathrm{KCl}$

- 25\% Tris- $\mathrm{HCl}(1 \mathrm{M}) ; \mathrm{pH} 7,5$ 


\section{Lösungen und Puffer für die WMISH}

Lösung 1: PBS (10x); pH 7,4

Ansatz für 1000ml: $\quad \mathrm{Na}_{2} \mathrm{HPO}_{4} \quad 14,2 \mathrm{~g}$

$\mathrm{KH}_{2} \mathrm{PO}_{4} \quad 2,4 \mathrm{~g}$

$\mathrm{KCl} \quad 2,0 \mathrm{~g}$

$\mathrm{NaCl} \quad 80,0 \mathrm{~g}$

DEPC-H2O ad $1000 \mathrm{ml}$

Die Lösung autoklavieren und bei RT lagern.

Lösung 2: DEPC- $\mathrm{H}_{2} \underline{\mathrm{O}}$

Ansatz für $1000 \mathrm{ml}: \quad$ DEPC $1000 \mu \mathrm{l}$

$\mathrm{H}_{2} \mathrm{O} \quad 999 \mathrm{ml}$

Die Lösung wird über Nacht bei $37^{\circ} \mathrm{C}$ in einem Schüttler autoklaviert und bei RT gelagert.

Lösung 3: Tween $(20 \%)$

Ansatz für 100ml: $\quad$ Tween $20 \quad 20 \mathrm{ml}$

DEPC- $\mathrm{H}_{2} \mathrm{O} \quad 80 \mathrm{ml}$

Die Lösung wird in zwei Falcon Tubs zu je $50 \mathrm{ml}$ angesetzt und bei $4^{\circ} \mathrm{C}$ im Dunkeln gelagert.

Lösung 4: PBT (1x) (PBST)

Ansatz für 1000ml: $\quad$ PBS (10x) $\quad 100 \mathrm{ml}$

Tween $20(20 \%) 5 \mathrm{ml}$

DEPC- $\mathrm{H}_{2} \mathrm{O} \quad 895 \mathrm{ml}$

Die Lösung wird bei $4^{\circ} \mathrm{C}$ im Dunkeln gelagert.

Lösung 5: 5M NaCl

Ansatz für 1000ml: $\quad 5 \mathrm{M} \mathrm{NaCl} \quad 292,9 \mathrm{~g}$

DEPC- $\mathrm{H}_{2} \mathrm{O} \quad$ ad $1000 \mathrm{ml}$

Die Lösung autoklavieren und bei RT lagern.

Lösung 6: 0,5M EDTA; $\mathrm{pH} 8$

Ansatz für 1000ml: $\quad 0,5 \mathrm{M}$ EDTA $\quad 186,1 \mathrm{~g}$

DEPC $-\mathrm{H}_{2} \mathrm{O} \quad$ ad $1000 \mathrm{ml}$

Die Lösung wird mit $\mathrm{NaOH}$ auf $\mathrm{pH} 8$ eingestellt, autoklaviert und bei RT gelagert.

Lösung 7: $1 \mathrm{M}$ Tris-HCl; pH 7,5

Ansatz für $1000 \mathrm{ml}: \quad 1 \mathrm{M}$ Tris $\quad 121,14 \mathrm{~g}$

DEPC- $\mathrm{H}_{2} \mathrm{O} \quad$ ad $1000 \mathrm{ml}$

Der pH-Wert wird mit $\mathrm{HCl}$ eingestellt. Anschließend wird die Lösung autoklaviert und bei RT gelagert.

Ebenso wird 1M Tris- $\mathrm{HCl}$ mit $\mathrm{pH} 9,5$ und $\mathrm{pH} 8,2$ angesetzt. 
Lösung 8: SDS (10\%)

Ansatz für 50ml: SDS

$5 \mathrm{~g}$

DEPC- $\mathrm{H}_{2} \mathrm{O}$ ad $50 \mathrm{ml}$

Die Lösung wird bei RT gelagert.

Lösung 9: SSC (20x); pH 5,0

Ansatz für 1000ml: $\quad 3 \mathrm{M} \mathrm{NaCl} \quad 175,3 \mathrm{~g}$

$0,3 \mathrm{M} \mathrm{Na}$-Citrat $\quad 88,2 \mathrm{~g}$

DEPC- $\mathrm{H}_{2} \mathrm{O} \quad$ ad $1000 \mathrm{ml}$

Die Lösung autoklavieren und bei RT lagern.

Lösung 10: 1M Zitronensäure

Ansatz für 1000ml: $\quad$ 1M Zitronensäure $\quad 210,14 \mathrm{~g}$

$\mathrm{H}_{2} \mathrm{O}$-bidest $\quad$ ad $1000 \mathrm{ml}$

Die Lösung autoklavieren und bei RT lagern.

Lösung 11: Hybridisierungsstammlösung (bei $-20^{\circ} \mathrm{C}$ lagern)

Ansatz für $500 \mathrm{ml}$ :

$\operatorname{SSC}(20 \mathrm{x}) \quad 125 \mathrm{ml}$

Tween $20(20 \%) \quad 2,5 \mathrm{ml}$

$1 \mathrm{M}$ Zitronensäure $\quad 3 \mathrm{ml}$

DEPC $-\mathrm{H}_{2} \mathrm{O} \quad$ ad $500 \mathrm{ml}$

Lösung 12: Hybridisierungspuffer

Ansatz in einem 50-ml-Falcon-Tube: Der Puffer besteht aus der Hybridisierungsstammlösung, Heringssperma $(10 \mathrm{mg} / \mathrm{ml})$ und tRNA $(9,4 \mathrm{mg} / \mathrm{ml})$. Die tRNA und das Heringssperma werden getrennt für $5 \mathrm{~min}$ bei $94^{\circ} \mathrm{C}$ denaturiert und zur Stammlösung hinzugefügt (pro 1ml Hybridisierungsstammlösung je $10 \mu 1$ Heringssperma und $10 \mu \mathrm{l}$ tRNA). Diese Lösung sollte immer frisch angesetzt werden.

Lösung 13: Posthybridisierungspuffer 1

\begin{tabular}{lll} 
Ansatz für 500ml: & Formamid (100\%) & $250 \mathrm{ml}$ \\
& SSC (20x); pH 5 & $125 \mathrm{ml}$ \\
& SDS (10\%) & $50 \mathrm{ml}$ \\
& DEPC- $\mathrm{H}_{2} \mathrm{O}$ & $75 \mathrm{ml}$ \\
\hline
\end{tabular}

Lösung 14: Posthybridisierungspuffer 2

$\begin{array}{lll}\text { Ansatz für 1000ml: } & \text { Formamid (100\%) } & 250 \mathrm{ml} \\ & \text { SSC (20x); pH 5 } & 125 \mathrm{ml} \\ & \text { Tween 20 (20\%) } & 2,5 \mathrm{ml} \\ & \text { DEPC- } \mathrm{H}_{2} \mathrm{O} & 122,5 \mathrm{ml}\end{array}$


Lösung 15: TBS (10x)-Stammlösung

$\begin{array}{lll}\text { Ansatz für 1000ml: } & 1,37 \mathrm{M} \mathrm{NaCl} & 80,06 \mathrm{~g} \\ & 0,03 \mathrm{M} \mathrm{KCl} & 2,23 \mathrm{~g} \\ & 25 \% \text { Tris-HCl } 1 \mathrm{M} ; \mathrm{pH} 7,5 & 250 \mathrm{ml} \\ & \mathrm{H}_{2} \mathrm{O} \text {-bidest } & \text { ad } 1000 \mathrm{ml}\end{array}$

Die Lösung autoklavieren und bei RT lagern.

Lösung 16: TBST (1x)

Ansatz für $1000 \mathrm{ml}$ :

TBS (10x) 100ml

Tween $20(20 \%) 5 \mathrm{~m}$

$\mathrm{H}_{2} \mathrm{O}$-bidest $\quad 895 \mathrm{ml}$

Lösung 17: $1 \mathrm{M} \mathrm{MgCl}_{2}$

Ansatz für 1000ml:

$\begin{array}{ll}1 \mathrm{M} \mathrm{MgCl}_{2} & 203,3 \mathrm{~g} \\ \mathrm{H}_{2} \mathrm{O} \text {-bidest } & \text { ad } 1000 \mathrm{ml}\end{array}$

Die Lösung autoklavieren und bei RT lagern.

Lösung 18: Alkalische Phosphatase Puffer

Ansatz für $250 \mathrm{~m}$

$\begin{array}{ll}5 \mathrm{M} \mathrm{NaCl} & 5 \mathrm{ml} \\ 1 \mathrm{M} \mathrm{MgCl}_{2} & 12,5 \mathrm{ml} \\ 1 \mathrm{M} \text { Tris-HCl; } \mathrm{pH} 9,5 & 25 \mathrm{ml} \\ \text { Tween } 20(20 \%) & 1,25 \mathrm{ml} \\ \mathrm{H}_{2} \mathrm{O} \text {-bidest } & \text { ad } 1000 \mathrm{ml}\end{array}$

Die Lösung sollte immer frisch angesetzt und auf den pH-Wert 9 kontrolliert werden. Bei der Färbung fügt

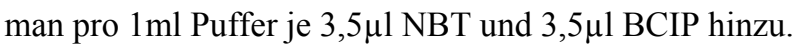

Lösung 19: Stopplösung zum Beenden der Farbreaktion

$\begin{array}{lll}\text { Ansatz für 50ml: } & \text { PBST (1x) } & 23 \mathrm{ml} \\ & 0,5 \mathrm{M} \text { EDTA; pH } 8 & 2 \mathrm{ml} \\ & \text { Formamid } & 5 \mathrm{ml}\end{array}$

\section{Puffer für die experimentellen Gliome auf der CAM}

Lösung 1: Sörensen-Puffer (0,3M),

Lösung A:

- 41,37g $\mathrm{Na}_{2} \mathrm{HPO}_{4} \times \mathrm{H}_{2} \mathrm{O}$ auf 11 aq. tridest., bei $4^{\circ} \mathrm{C}$ lagern

Lösung B:

$42,58 \mathrm{~g} \mathrm{KH}_{2} \mathrm{PO}_{4}$ in 11 aq. tridest., bei RT lagern;

Vor Gebrauch werden 18,2ml Lösung A mit 81,8ml Lösung B gemischt. 


\subsection{Verfahren der In-situ-Hybridisierung}

Die In-situ-Hybridisierung (ISH) ist ein Verfahren, mit dem sowohl DNA- als auch RNASequenzen direkt im biologischen Präparat (in situ), das heißt in einer Zelle, in Geweben oder in intrazellulären Strukturen dargestellt werden können (Leitch et al.,1994). Die Methode wurde erstmals von John et al. (1969) und Gall \& Pardue (1969) publiziert, die hiermit ribosomale RNA-Sequenzen in Zellpräparaten lokalisierten. Das Prinzip beruht auf der molekularen Hybridisierung von einzelsträngigen Nukleinsäuren. Eine markierte Nukleinsäuresonde hybridisiert somit in situ mit einem Nukleinsäurestrang, wie z.B. einer Protein-kodierenden mRNA (John et al., 1969; Gall \& Pardue, 1969). Seit der Etablierung nicht-radioaktiver Markierungssysteme stellt die ISH in vielen Laboratorien ein Routineverfahren dar (Langer et al., 1981).

Das Verfahren findet mittlerweile in vielen verschiedenen Bereichen Einsatz (Leitch et al., 1994):

a) Analyse von Chromosomenstrukturen und deren Abweichungen

b) Untersuchung der Struktur, Funktion und Evolution von Chromosomen und Genom

c) Bestimmung der räumlichen und zeitlichen Expression von Genen

d) Identifikation und Charakterisierung von Viren, viralen Sequenzen und Bakterien in Geweben

e) Geschlechtsbestimmung

f) Lokalisation von transformierenden Sequenzen und Onkogenen

g) Analyse der Expression von Neurotransmittern.

Bei dieser Arbeit liegt der Schwerpunkt in der Bestimmung der räumlichen und zeitlichen Expression des Homeobox-Gens Hex in verschiedenen Stadien der Hühnchenentwicklung. Mit der Methode der ISH können zusätzlich grobe Abschätzungen über die quantitative mRNA-Menge vorgenommen werden (Luttmann et al., 2004). Angefärbt (hybridisiert) werden dabei nur diejenigen Zellen, in denen das zu untersuchende Gen aktiv ist und daher die mRNA im Zytoplasma vorliegt. Als Präparat, in dem man die mRNA darstellen möchte, wählt man entweder Zellen einer Zellkultur oder Gewebeschnitte. Vor der Hybridisierung muss das Gewebe fixiert werden. Die Färbung stellt daher nur eine Momentanaufnahme des Zustands dar, in dem sich das Gewebe befand, als es fixiert wurde. Hybridisierung beschreibt dabei den Vorgang, bei dem sich eine Desoxyribonukleinsäure bzw. eine Ribonukleinsäure der komplementären Nukleinsäurebase anlagert und sich zwischen diesen Wasserstoffbrücken ausbilden (Leitch et al., 1994). 
Es gibt verschiedene Varianten der ISH. Zum einen die RNA-In-situ-Hybridisierung, bei der als Sonde eine markierte antisense-RNA eingesetzt wird und zum anderen die DNAISH, bei der man eine zur mRNA komplementäre DNA als Sonde verwendet. Die RNAISH kommt auf Grund der höheren Sensitivität häufiger zum Einsatz. Als weitere Form ist die Fluoreszenz-ISH (FISH) ein weit verbreitetes Verfahren. Hierbei wird die Sonde mittels eines fluoreszierenden Farbstoffes nachgewiesen, mit dem Ziel, eine bestimmte DNASequenz auf einem Chromosom zu lokalisieren (Luttmann et al., 2004).

\subsection{In-situ-Hybridisierung an Paraffinschnitten}

Bei der Untersuchung von Geweben mit der ISH findet ein Verfahren Anwendung, das sich in mehrere Schritte gliedern lässt (Luttmann et al., 2004):

1. Vorbereitung

2. Fixierung und Paraffineinbettung

3. Schnitt

4. Nachbehandlung

5. Hybridisierung

6. Immundetektion

7. Gegenfärbung

8. Eindeckung.

\subsubsection{Vorbereitung}

Die Vorbereitung der ISH besteht im Wesentlichen aus zwei wichtigen Komponenten. Zum einen werden die RNA-Sonden hergestellt und zum anderen werden die Hühnerembryonen präpariert.

\section{Herstellung der RNA-Sonden (Ribosonden) für die Hybridisierung}

Die RNA-Sonden für die ISH habe ich mit Hilfe der in vitro-Transkription hergestellt. Dabei wurde die gewünschte DNA Sequenz in einen Vektor kloniert, welcher Promotorsequenzen von Bakteriophagen-RNA-Polymerasen enthält. Die entsprechende $5^{\prime} \rightarrow 3^{\prime}$-RNAPolymerase synthetisiert unter Anwesenheit von Digoxigenin-markierten Nukleotiden die gewünschten einzelsträngigen markierten RNA-Sonden mit definierter Länge und Sequenz. Digoxigenin (DIG) ist ein pflanzliches Steroid aus Digitalis purpura und Digitalis lanata (Leitch et al., 1994). Digoxigenin wird anschließend mit einem Anti-Digoxigenin- 
Antikörper, an dem ein Enzym gekoppelt ist, gebunden. Das Enzym, bei dem es sich um Alkalische Phosphatase handelt, setzt durch Zusatz von bestimmten Reagenzien einen Farbstoff um, der kovalent im Gewebe gebunden wird und sich somit nicht durch Diffusion verteilt.

Den Erfolg der in-vitro-Transkription habe ich mittels der Agarose-Gelelektrophorese überprüft (Abbildung 3). Bei dieser werden im elektrischen Feld die negativ geladenen Nukleinsäuremoleküle durch die Gelmatrix gezogen, wobei die kleineren Moleküle schneller wandern und somit eine Auftrennung der Nukleinsäurestränge (DNA oder RNA) nach ihrer Größe möglich ist. Durch Zugabe von Ethidiumbromid, das mit den Basen der RNA bzw. DNA interkaliert, können die Nukleinsäurebanden unter ultraviolettem Licht sichtbar gemacht werden.

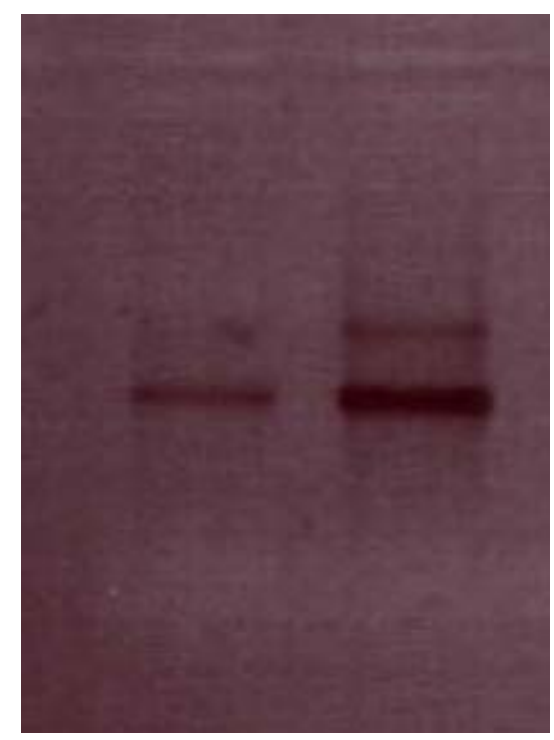

\section{Abbildung 3: Agarose-Gelelektrophorese}

Die Abbildung zeigt das Ergebnis der Agarose-Gelelektrophorese, mit der ich den Erfolg der in-vitroTranskription zur Herstellung der Ribosonden überprüft habe. In der ersten Spur sind zwei Banden RNA (2Varianten der RNA Anlagerung) nach der Behandlung mit DNAse zu sehen. Eine DNA-Bande ist demzufolge nicht mehr sichtbar. Die zweite Spur zeigt die dieselben zwei RNA Banden nach der Aufreinigung.

Um die Verdauung der mRNA-Sonden durch freie RNasen zu vermeiden, wird bis zum Schritt der Hybridisierung mit sterilen bzw. autoklavierten Geräten und Latexhandschuhen gearbeitet. Außerdem werden alle wässrigen Lösungen bis zur Hybridisierung mit RNasefreiem Wasser angesetzt. Dieses gewinnt man durch die Behandlung mit Diethylpyrocarbonat (DEPC), einem starken RNase-Inhibitor. Zusätzlich wird das Wasser autoklaviert, um DEPC zu entfernen. Für die Markierung der RNA-Sonden wurde das Digoxigenin La- 
beling-Kit von Boehringer Mannheim verwendet. Die Detektion erfolgte mit dem Digoxigenin Nucleic Acid Detection Kit von Boehringer Mannheim.

\section{Präparation der Hühnerembryonen}

In einem weiteren Schritt müssen die Hühnerembryonen präpariert werden. Die Inkubation der Hühnereier erfolgt im Brutschrank bei einer Temperatur von $37,8^{\circ} \mathrm{C}$ und einer relativen Luftfeuchtigkeit von $80 \%$. Nach der Bebrütung werden die Hühnereier mit einer Pinzette am stumpfen Ei-Pol eröffnet. Dabei wird die Eierschale durchbrochen und anschließend die Schalenmembran entfernt, um den Hühnchenembryo entnehmen zu können.

\subsubsection{Fixierung und Paraffineinbettung}

Die chemische Fixierung hat das Ziel, die ursprüngliche Zell- bzw. Gewebemorphologie als Momentaufnahme zu erhalten. Das Präparat wird dabei gehärtet und konserviert, indem Proteine denaturiert (quervernetzt und/oder koaguliert) werden. Bei fehlender Fixierung wird die Gewebeprobe durch autolytische Vorgänge und mikrobielle Degradation schnell unbrauchbar. Außerdem sind manche Antigene in wässriger Lösung löslich, so dass es zur Diffusion in andere Lokalisationen kommt und somit Färbeartefakte auftreten. Besonders wichtig ist es, bei der Fixierung darauf zu achten, dass die Epitope der Proteine, die antigenen Determinanten, in ausreichendem Maße erhalten bleiben, so dass die Immundetektion möglich bleibt. Es muss also ein Kompromiss zwischen Artefaktbildung und Strukturerhaltung der Epitope gefunden werden (Luttmann et al., 2004). Paraformaldehyd, ein Formaldehydpolymer, bildet mit basischen Aminosäuren Hydroxymethylenbrücken aus - es kommt zur Quervernetzung von Proteinen. Ethanol wirkt koagulatorisch und wird besonders dann verwendet, wenn die Epitoperhaltung im Vordergrund steht. Nachteil beim Ethanol ist jedoch, dass es Gewebe schlechter durchdringt als die Aldehyde (Luttmann et al., 2004).

Zunächst habe ich die Hühnerembryonen über Nacht in Paraformaldehyd fixiert. Bevor es danach in einer aufsteigenden Ethanolreihe zur Entwässerung kommt, habe ich das Fixativ gründlich in PBS ausgewaschen. Nächster Schritt ist die Entfettung und Entalkoholisierung durch Rotihistol, ein nichttoxischer Lösungsmittelersatz für Xylol. Als letztes habe ich die Präparate in $58^{\circ} \mathrm{C}$ warmen Paraffin eingebettet.

- Fixierung in PFA (4\%) über Nacht

- 3 x 15 min. in PBS waschen

- 45 min. mit 50\% Ethanol waschen 
- 45 min. mit 70\% Ethanol waschen

- 45 min. mit 80\% Ethanol waschen

- 45 min. mit 90\% Ethanol waschen

- 45 min. mit 100\% Ethanol waschen

- 45 min. mit 100\% Ethanol waschen

- 30 min. Rotihistol

- 45 min. Rotihistol

- 2-3 Std. in Paraffin im Wärmeschrank,

- Einbetten in Paraffin

- 1-2 Std. bei Raumtemperatur, dann bei $4^{\circ} \mathrm{C}$ über Nacht aushärten lassen.

\subsubsection{Schneiden}

Vor dem Schneiden werden die Paraffinblöcke auf $-20^{\circ} \mathrm{C}$ abgekühlt und anschließend in ein Mikrotom eingespannt. Die Dünnschnitte erreichen so eine Dicke von 4-8 $\mu \mathrm{m}$. Je dünner der Schnitt ist, desto detaillierter lassen sich Strukturen darstellen (Luttmann et al., 2004).

\subsubsection{Nachbehandlung}

Die Nachbehandlung besteht aus mehreren Teilschritten. Zum einen ist die Entparaffinierung und Rehydrierung wichtig. Des Weiteren muss eine Permeabilisierung und eine Epitopdemaskierung vorgenommen werden. Es folgt eine Blockierung der endogenen Enzyme, falls eine Enzymmarkierung zum Antigennachweis verwendet wurde. Als Letztes werden freie Aldehydgruppen blockiert (Luttmann et al., 2004).

Bei der Entparaffinierung mittels Xylol wird darauf geachtet, dass die Lösung häufig gewechselt wird, da sich in dieser das Paraffin schnell anreichert. Die Rehydrierung erfolgt in einer absteigenden Alkoholreihe. Zuletzt erfolgt eine Spülung mit PBS (phosphatgepufferte Kochsalzlösung).

Entparaffinieren (RNase frei):

- 2x 10 min in Xylol (100\%)

- 2x 5 min in Ethanol (100\%)

- 1 min in Ethanol (95\%)

- 1 min in Ethanol (90\%)

- 1 min in Ethanol (80\%)

- 1 min in Ethanol (70\%)

-1 min in Ethanol (50\%) 
- 1 min in Ethanol (30\%)

- 5 min in PBS waschen

- 30 min in 4\% Paraformaldehyd in PBS nachfixieren

- 2x 5 min PBS waschen.

Für die Permeabilisierung des Gewebes habe ich das proteinabbauende Enzym Proteinase K genutzt. Das Gewebe wird dadurch für die Sonden und Nachweisreagenzien zugänglicher (Leitch et al., 1994). Um eine ausreichende Zugänglichkeit der RNA zu erzielen, sollte besonders nach einer chemischen Fixierung ein Proteinverdau stattfinden. Hier werden Quervernetzungen von Proteinen, die durch die Fixation bedingt sind, wieder aufgebrochen. Dieses habe ich ebenfalls mit der Proteolyse durch Proteinase K erzielt. Die Enzymwirkung besteht darin, dass die Nukleinsäuren von assoziierten Proteinen befreit werden. Zuletzt müssen freie Aldehydgruppen, die zu Artefakten führen können, durch Inkubation mit Glycin in PBS neutralisiert werden (Luttmann et al., 2004).

Proteolyse mit Proteinase K $(0,025 \mathrm{mg} / \mathrm{ml} \mathrm{PBS})$; RT:

- 7 min Proteolyse in Proteinase K

- 2x 5 min in PBS waschen

- 15 min in 4\% Paraformaldehyd in PBS nachfixieren

- 2x 5 min in PBS waschen

- 2x 5 min in $\operatorname{SSC}(2 x)$ waschen; RT

- 30 min in Tris-Glycin-Puffer inkubieren; RT.

\subsubsection{Hybridisierung}

Wichtig für das Ergebnis der ISH ist die Wahl der richtigen Sonde. RNA-Sonden eignen sich besonders gut für die ISH, da die Stabilität zwischen RNA-RNA-Hybriden am höchsten ist. Außerdem kann man durch Zugabe von RNase unspezifisch gebundene Sonden zerlegen und anschließend abwaschen, um somit die Hintergrundfärbung bestmöglich zu reduzieren. Nachteile der RNA-Sonden ist ihre schwierige Herstellung mittels der in-vitroTranskription und die hohe Empfindlichkeit gegen RNase-Kontamination (Leitch et al., 1994). Bei dem Hybridisierungsverfahren nutzt man die Reassoziationskinetik doppelsträngiger Nukleinsäuremoleküle. Es paaren sich zwei komplementäre Einzelstränge, wobei sich zwischen den Basen Cytosin und Guanin drei Wasserstoffbrücken ausbilden und die Basen Adenin und Thymin durch zwei Wasserstoffbrücken zusammengehalten werden. Die H-Brücken bilden sich dabei jeweils zwischen den Aminogruppen $\left(\mathrm{NH}_{2}\right)$ und den Ketogruppen $(\mathrm{C}=\mathrm{O})$ (Leitch et al., 1994). Für die Hybridisierung müssen sowohl Sonde als auch Zielsequenz als Einzelstrang vorliegen. Daher sollten die RNA-Sonden, die leicht 
durch intramolekulare Basenpaarung Doppelstränge bilden, vor der Hybridisierung denaturiert werden (Leitch et al., 1994).

Die Hybridisierungslösung enthält neben den Nukleinsäuresonden noch weitere Komponenten. Formamid macht es möglich, den Hybridisierungsvorgang bei Temperaturen stattfinden zu lassen, die die Gewebestrukturen nicht schädigen. Der Einsatz von gelösten Salzen wirkt sich stabilisierend auf die Nukleinsäuredoppelstränge aus. Durch einen Überschuss an unmarkierter DNA (Heringssperma) bzw. RNA (Hefe-tRNA) wird die Wirkung unspezifischer, sondenbindender Moleküle abgeschwächt. BSA (Rinderserumalbumin) wird eingesetzt, um unspezifische Hybridisierungen zu verhindern (Leitch et al., 1994). Nach dem Hybridisierungsvorgang habe ich einige Waschritte durchgeführt, um ungebundene und locker gebundene Sonden abzuspülen. Mit der abschließenden RNase Behandlung werden einzelsträngige, nichthybridisierte Sonden entfernt und somit das Hintergrundsignal reduziert. Doppelsträngige Nukleinsäuren werden durch die RNase nicht angegriffen (Leitch et al., 1994).

Hybridisierung

Die Hybridisierung erfolgt durch Inkubation mit Hybridisierungspuffer bei $65^{\circ} \mathrm{C}$ über Nacht in einer angefeuchteten Kammer. Pro Objektträger habe ich etwa $60 \mu 1$ Hybridisierungslösung aufgetragen.

RNase A Behandlung:

- 3x 15 min in SSC (5x) waschen; RT

- $40 \mathrm{~min}$ bei $60^{\circ} \mathrm{C}$ in Posthybridisierungspuffer inkubieren

- 15 min in SSC (2x) waschen; RT

- 15 min mit RNase A $(1,25 \mathrm{mg} / 100 \mathrm{ml} \mathrm{SSC}(2 \mathrm{x}))$ bei $37^{\circ} \mathrm{C}$ inkubieren

- 15 min in SSC (2x) waschen; RT

- 20 min bei $60^{\circ} \mathrm{C}$ in Posthybridisierungspuffer inkubieren

- 2x 15 min in SSC (2x) waschen; RT.

\subsubsection{Immundetektion - der Nachweis der Hybridisierungsstellen}

Für die Immundetektion und die anschließende Visualisierung der Antigen-AntikörperKomplexe gibt es viele verschiedene Möglichkeiten. Das die Ribosonde markierende Digoxigenin wird in diesem Schritt von einem Anti-Digoxigenin-Antikörper gebunden. Durch den Einsatz von Fab-Fragmenten findet man eine schwächere Hintergrundfärbung, da der Fc-Teil hier fehlt und daher keine Bindung an Fc-Rezeptoren am Präparat stattfindet. Zudem penetrieren Fab-Fragmente auf Grund ihrer geringeren Größe das Gewebe und die Zellen besser (Luttmann et al., 2004). Die Antikörper (bzw. die Fab-Fragmente) sind 
mit einem Enzym, der Alkalischen Phosphatase gekoppelt. Dieses wird durch den Umsatz des chromogenen Substrats BCIP/NBT (Bromchlorindolylphosphat/Nitrotetrazoliumblau) sichtbar. Das lösliche Chromogen wird bei der Reaktion an relevanten Strukturen immobilisiert, kann sich somit nicht durch Diffusion verteilen und kann unter dem Mikroskop als Blaufärbung nachgewiesen werden. Um bessere Ergebnisse in der mikroskopischen Ansicht zu erzielen, färbt man das Gewebe mit einem zweiten Farbstoff gegen.

Antikörperinkubation

Ich habe pro Objektträger ca. $500 \mu 1$ des Antikörpers anti-DIG-AP-Fab (Verdünnung von 1:4000) in Blockierungslösung (1\%) aufgetragen und über Nacht bei $4^{\circ} \mathrm{C}$ in einer mit SSC (2x) angefeuchteten Kammer inkubiert. Potentielle unspezifische Bindungen werden durch die BSA-Lösung (Rinderserum-Albumin) blockiert.

Waschen

Es folgt eine gründliche Spülung mit TBS. Wählt man die Alkalische Phosphatase als Detektionstool, sollte bei sämtlichen Schritten TBS anstelle von PBS als Puffer genommen werden, da das anorganische Phosphat der PBS-Lösung die Alkalische Phosphatase kompetitiv hemmen kann (Luttmann et al., 2004).

- 3x 10 min in TBS; RT

- 3x 30 min in TBS; RT

- 2x 60 min in TBS; RT.

Farbreaktion

Zuerst wurden die Schnitte 3x 10 min in NTMT-Alkalische Phosphatase Puffer gewaschen. Anschließend habe ich pro Objektträger $2 \mathrm{ml}$ Färbelösung aufgetragen und im Dunkeln bis zum Eintritt der Farbreaktion inkubiert. Der Färbevorgang wird mittels EDTA (Ethylendiamintetraessigsäure) abgestoppt, indem EDTA, ein Komplexbildner, sehr stabile Chelatkomplexe mit Kationen eingeht. EDTA fängt somit $\mathrm{MgCl}_{2} \mathrm{ab}$, welches als Kofaktor für die Alkalische Phosphatase benötigt wird (Luttmann et al., 2004).

- 3x 10 min in NTMT-Alkalische-Phosphatase-Puffer waschen

- 2 - 3x 10 min mit 1mM EDTA in PBS die Farbreaktion stoppen

\subsubsection{Gegenfärbung}

Bei einer Gegenfärbung färbt man die nicht spezifisch gefärbten Gewebeanteile des Präparats, so dass morphologische Strukturen besser zur Geltung kommen. Wichtig ist darauf zu achten, dass sich die zur Immunfärbung und die zur Gegenfärbung eingesetzten Reagenzien vertragen. Ich habe zur Gegenfärbung Kernechtrot verwendet. 


\subsubsection{Eindecken}

Vor dem Eindecken wird das Präparat in einer aufsteigenden Alkoholreihe dehydriert.

Dehydrierung:

- 1 min in Ethanol (70\%)

- 1 min in Ethanol (80\%)

- 1 min in Ethanol (90\%)

- 1 min in Ethanol (95\%)

- 2x 5 min in Ethanol (100\%)

- Rotihistol.

Anschließend erfolgt die Eindeckung mit einem Deckglas Entellan (Eindeckmedium).

\subsection{In-situ-Hybridisierung an whole-mount-Embryonen}

Der große Vorteil von In-situ-Hybridisierungen an whole-mount-Embryonen (WMISH) liegt darin, dass die Topographie erhalten bleibt und dass somit dreidimensionale Informationen über das Präparat gewonnen werden können. Die ISH an ganzen Organismen läuft prinzipiell genauso ab wie die ISH an Paraffinschnitten, jedoch kann das Eindringen der Sonde Schwierigkeiten bereiten (Leitch et al., 1994).

\subsubsection{Rehydrierung und Bleichen der Embryonen}

Vor Beginn der ISH befinden sich die Embryonen in Methanol (100\%). Zur ISH sollte jeder Embryo in ein 5-ml-Glasröhrchen mit Schraubverschluss überführt werden. Während der Waschschritte werden die Glasröhrchen auf eine Rollwippe gelegt und jeweils mit $3 \mathrm{ml}$ Lösung befüllt.

\section{$\underline{\text { Rehydrierung }}$}

Die Rehydrierung der Embryonen erfolgt in einer absteigenden Methanolreihe:

- 10 min in Methanol (90\%) mit DEPC-PBS, RT

- 10 min in Methanol (75\%) mit DEPC-PBS, RT

- 10 min in Methanol (50\%) mit DEPC-PBS, RT

- 10 min in Methanol (25\%) mit DEPC-PBST, RT.

Bleichen

Das Bleichen ist wichtig, da die Pigmentierung von Embryonen zum Teil sehr störend sein kann und schwache WMISH-Signale dadurch überdeckt werden können. Ich habe die Embryonen 60 min mit $\mathrm{H}_{2} \mathrm{O}_{2}(6 \%)$ in DEPC- $\mathrm{H}_{2} \mathrm{O}$ auf Eis gebleicht.

Anschließend folgen drei Waschschritte von je $10 \mathrm{~min}$ in DEPC-PBST bei RT. 


\subsubsection{Proteolyse und Postfixierung}

Die Inkubationszeiten der Embryonen sollten bei diesem Schritt streng eingehalten. Sie richten sich nach dem Alter bzw. der Größe der Embryonen. Die Proteolysebehandlung mit Proteinase $\mathrm{K}$ hat dabei denselben Effekt wie bei der ISH an Paraffinschnitten.

- Embryonen 3. Tag $30 \mathrm{~min}$; RT

- Embryonen 4. Tag $35 \mathrm{~min}$; RT

- Embryonen 5. Tag $40 \mathrm{~min}$; RT.

Nach der Proteinase-K-Behandlung habe ich die Embryonen für 10 min bei RT in eine Lösung aus DEPC-PBST/Glycin überführt. Es folgen zwei Waschschritte von jeweils 10 min in DEPC-PBST bei RT.

Zur Konservierung werden die Embryonen $30 \mathrm{~min}$ im Postfixans (Formaldehyd) bei RT inkubiert. Wieder folgen zwei Waschschritte von jeweils $10 \mathrm{~min}$ in DEPC-PBST bei RT.

\subsubsection{Prähybridisierung}

Die Prähybridisierung wird zur Absättigung von unspezifischen Bindungen durchgeführt. Zum Äquilibrieren der Embryonen werden diese für 15 min bei RT in der Hybridisierungsstammlösung (ohne Heringssperma und ohne tRNA) inkubiert. Währenddessen habe ich das Heringssperma und die tRNA bei $94^{\circ} \mathrm{C}$ im Thermomixer denaturiert und danach für 5 min auf Eis gestellt. Anschließend wird beides in den Hybridisierungspuffer, welcher dann denaturiertes Heringssperma und tRNA, jedoch noch nicht die denaturierte RNA-Sonde enthält, überführt. Die Glasröhrchen werden über Nacht in die Dampfphase eines Wasserbades gestellt. Das Heringssperma und die tRNA dienen wie bei der ISH an Paraffinschnitten dazu, unmarkierte DNA bzw. RNA im Überschuss zu haben, um die Wirkung unspezifischer, sondenbindender Moleküle abzuschwächen.

\subsubsection{Hybridisierung}

Zuerst habe ich die Digoxigenin-markierten RNA-Sonden, welche bei $-20^{\circ} \mathrm{C}$ eingefroren sind, aufgetaut und dann bei $80^{\circ} \mathrm{C}$ für $5 \mathrm{~min}$ im Thermomixer denaturiert. Heringssperma und tRNA werden ebenfalls aufgetaut und bei $94^{\circ} \mathrm{C}$ getrennt voneinander denaturiert. Anschließend werden alle Aliquots auf Eis gestellt. Der Hybridisierungspuffer, bestehend aus der Hybridisierungsstammlösung, Heringssperma, tRNA und denaturierter RNA-Sonde wird angesetzt. Die Embryonen werden nun in diesen überführt und über Nacht ins Wasserbad gestellt. 


\section{Posthybridisierungswaschen}

Es werden jeweils 50ml vom Posthybridisierungspuffer 1 und 2 für 15 min ins Wasserbad gestellt. Die Embryonen werden dann zuerst im Posthybridisierungspuffer 1 und anschließend im Posthybridisierungspuffer 2 jeweils $2 x$ für 30 min bei $65^{\circ} \mathrm{C}$ im Wasserbad gewaschen.

\subsubsection{Immundetektion - der Nachweis der Hybridisierungsstellen}

Antikörperbehandlung

Zuerst habe ich die Embryonen 3x 10 min in TBST (1x) bei RT gewaschen. Anschließend werden sie zum Blockieren unspezifischer Bindungen für 120 min in TBST (1x) mit 10\% Pferdeserum überführt. Während der Inkubation wird die Antikörperlösung vorbereitet. Dazu habe $25 \mathrm{mg}$ Blockierungspulver in $25 \mathrm{ml}$ TBST (1x) gegeben, bei $70^{\circ} \mathrm{C}$ im Wasserbad für 30 min erhitzt und dann auf Eis wieder abgekühlt. Danach wird $250 \mu 1$ Pferdeserum hinzugefügt und zuletzt der Anti-Digoxigenin-Antikörper im Verhältnis 1:3000 hinzupipettiert. Die Lösung wird für eine Stunde in Eis auf die Rollwippe gelegt und bei 4000rpm 5 min abzentrifugiert. Die Embryonen werden nun in die angefertigte Lösung gegeben und inkubieren über Nacht bei $4^{\circ} \mathrm{C}$ auf der Rollwippe.

Waschen

Überschüssiger Antiköper wird durch mehrere Waschschritte entfernt:

- 2x 10 min in TBST; RT

- 2x 30 min in TBST; RT.

Farbreaktion

Die Embryonen werden 3x 10 min im Alkalische-Phosphatase-Puffer (pH 9,5) bei RT gewaschen. Es folgt anschließend die Zugabe des Chromogens NBT/BCIP (pro 1ml Alkali-

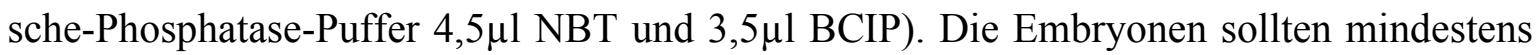
6 Stunden auf Eis und Rollwippe färben.

Stoppen der Farbreaktion

Zuerst wird wie bei der ISH an Paraffinschnitten die Alkalische Phosphatase mittels des Chelators EDTA, der Kofaktoren wie $\mathrm{Mg}^{2+}$, die das Enzym für seine Aktivität benötigt, gestoppt. Dazu inkubieren die Embryonen 3x 10 min bei RT in der EDTA-Lösung. Anschließend habe ich die überschüssige Hintergrundfärbung mit Dimethylformamid herausgewaschen. Es folgen zwei Waschschritte in einer Stopplösung bestehend aus PBST, EDTA und Formamid, die zur erneuten Fixierung und Stoppen der Farbreaktion dienen:

- 2 min in Stopplösung; RT

- 1 min in Stopplösung; RT. 
Die Stopplösung habe ich in drei Schritten (je 10 min) mit PBS (1x) herausgewaschen. Zuletzt werden die Embryonen 3x 5 min in Formaldehyd/PBS Lösung konserviert. In dieser Lösung können die Embryonen danach langfristig bei $4^{\circ} \mathrm{C}$ gelagert werden.

\subsubsection{Kryoschnitte}

Die bereits hybridisierten whole-mount-Embryonen habe ich nach der Analyse des HexExpressionsmusters zur Anfertigung von Kryoschnitten verwendet. Dadurch ist es möglich, auch die Embryonen der Entwicklungstage 3, 4 und 5 an Schnitten zu analysieren. Die Embryonen habe ich dazu in flüssigem Stickstoff kryokonserviert, anschließend in Tissue-Tek eingebettet und mit dem Kryotom geschnitten.

\subsection{Experimentelle Gliome auf der CAM}

Ich habe die Versuche zu den experimentellen Gliomen auf der Chorioallantoismembran (CAM) nach dem Prinzip von Papoutsi et al. (2000) durchgeführt.

\subsubsection{Zellkultur}

Als Zellkultur habe ich die CNS-1-Ratten-Gliomzelllinie verwendet. In der Zellkultur wurden die Zellen bei $37^{\circ} \mathrm{C}$ und $5 \% \mathrm{CO}_{2}$ in Mediumkulturflaschen mit $10 \%$ fetalem Kälberserum und 1\% Penicillin/Streptomycin in DMEM gehalten. Das fetale Kälberserum enthält verschiedene Proteine zur Ernährung der Zellen sowie Wachstumsfaktoren. DMEM ist ein herkömmliches Zellkulturmedium, welches ebenfalls bestimmte Wachstumsfaktoren beinhaltet. Die Antibiotika Penicillin und Streptomycin beugen einer bakteriellen Verunreinigung des Mediums vor.

\section{Ernten von Zellen}

Um die Zellen zu ernten, habe ich zuerst das Medium abgesaugt und die Zellen mit $5 \mathrm{ml}$ PBS gespült. Dann habe ich 2ml Trypsin zum Ablösen der Zellen vom Schalenboden hinzu gegeben. Die Zellen wurden anschließend mit 3ml Medium in ein Falcon Röhrchen transferiert. Zur Bestimmung der Zellzahl in der Suspension habe ich von dieser $100 \mu 1$ in $10 \mathrm{ml}$ isotonen Puffer pipettiert und danach die Konzentration an Zellen mithilfe eines automatischen Zellzählers gemessen. Die Zellsuspension habe ich zentrifugiert und den Überstand verworfen. Das Zellpellet wurde dann mit etwas Medium und 50\% Matrigel versetzt, so dass pro Ei ungefähr $5 \times 10^{6}$ Zellen in $20 \mu 1$ aufgegeben werden konnten. Bei Matrigel handelt es sich um ein Proteingemisch, welches von Maustumorzellen sezeniert wird und der komplexen Extrazellulärmatrix ähnelt. Bei Temperaturen um $4^{\circ} \mathrm{C}$ ist das Gemisch flüssig und bei ca. $37^{\circ} \mathrm{C}$ gallertartig. Auf diese Weise wird gewährleistet, dass die Zellen auf der 
CAM sich während der Inkubation im Brutschrank nicht über die gesamte Fläche verteilen, sondern an einem begrenzten Ort bleiben und dort proliferieren.

\subsubsection{Auftragung von Zellen auf die CAM}

Das Zell-Matrigel-Gemisch habe ich auf die Chorioallantoismembran von zuvor zehn Tage inkubierten Hühnerembryonen aufgetragen. In diesem Entwicklungsstadium bedeckt die CAM fast die gesamte Innenfläche der Eischale. Die CAM ist eine stark vaskularisierte Membran, die sich außerhalb des sich entwickelnden Hühnerembryos befindet und durch Fusion aus Chorion und Allantois entstanden ist. Am 3. Entwicklungstag habe ich in die Eischale ein Fenster gesägt und dieses mit einem Klebestreifen wieder verschlossen. Die Eier wurden danach weiter bis zum 10. Entwicklungstag im Brutschrank inkubiert. Zum Aufbringen der Zellen wurde der Klebestreifen über dem Fenster in der Eischale aufgeschnitten. Unter dem Binokular konnte ich dann mithilfe einer Plastikpipette das Zellgemisch auf die CAM transferieren. Das Ei wurde abschließend wieder verschlossen und bei $37^{\circ} \mathrm{C}$ im Brutschrank 7 Tage inkubiert.

\subsubsection{Präparation der Tumoren und Herstellung von Paraffinschnitten}

Nach einer Woche Inkubation im Brutschrank wurde das Ei am Fenster wieder eröffnet und der Tumor auf der CAM mittels 4\% PFA über Nacht fixiert. Die Eier wurden zum Abtöten der Embryonen in den Kühlschrank gelegt. Die Tumorpräparate habe ich in Paraffin eingebettet und mit diesen die ISH durchgeführt, wie bereits oben beschrieben. 


\section{Ergebnisse}

Mittels der In-situ-Hybridisierung habe ich das Expressionsmuster des Homeobox-Gens Hex an den Entwicklungstagen 3, 4 und 5 an whole-mount-Embryonen untersucht. Anschließend habe ich die hybridisierten Embryonen mit einem Gefriermikrotom geschnitten, um das Hex-Expressionsmuster in diesen frühen Entwicklungsstadien noch detaillierter darzustellen und Einblicke über die Lokalisation auf zellulärer Ebene zu gewinnen. An Tag 10 der Hühnchenentwicklung habe ich das Expressionsmuster an Paraffinschnitten untersucht.

\subsection{Entwicklungstag 2}

Der 2. Entwicklungstag entspricht den Stadien 7 bis 12 nach Hamburger und Hamilton. In diesen Stadien sieht man das Neuralrohr mit bis zu 16 benachbart angeordneten Somitenpaaren mesodermalen Ursprungs (Abbildung 4). Es zeigen sich die drei primären Gehirnbläschen, Prosenzephalon, Mesenzephalon und Rhombenzephalon, aus denen sich die zentralen Sinnesorgane Riechen, Hören und Sehen bilden (Abbildung 4). Das Herz stellt sich in diesem Stadium als S-förmige, blutgefüllte Struktur dar.

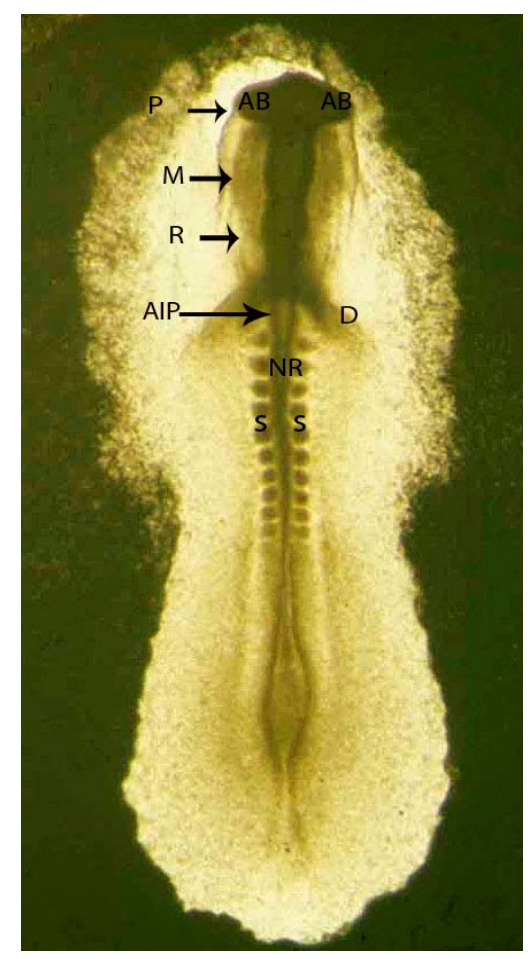

Abbildung 4: Hühnerembryo im HH-Stadium 10

Die Abbildung zeigt einen Hühnerembryo mit 10 Somitenpaaren. (AB: Augenbläschen; AIP: anteriorer Darmmund; D: Dottervene; M: Mesenzephalon; NR: Neuralrohr; P: Prosenzephalon; R: Rhombenzephalon; S: Somiten) 


\section{$3.2 \quad$ Entwicklungstag 3}

Der 3. Entwicklungstag entspricht den Stadien 13-20 nach Hamburger und Hamilton (1951). Das Gehirn besteht zu diesem Zeitpunkt aus 5 Segmenten, dem Telenzephalon, dem Dienzephalon, dem Mesenzephalon, dem Metenzephalon und dem Myelenzephalon. Es existieren in diesen Stadien 37- 49 Somitenpaare. Das Herz entwickelt sich weiter und die Leberanlage wird größer. Die Flügel- und Beinknospen stülpen sich aus der Somatopleura hervor.

Am 3. Entwicklungstag ist das auffälligste Hex-Signal in der Leber zu finden (Abbildung 5, Abbildung 6, Abbildung 7, Abbildung 8). Die Leber bildet sich aus entodermalen und mesodermalen Strukturen im Bereich der Leberbucht, dem Leberdivertikel (Abbildung 9). Im Ventrikelendokard sind deutliche Hex-Signale zu erkennen (Abbildung 5, Abbildung 6, Abbildung 7, Abbildung 10). Des Weiteren ist in der Ausflussbahn des Herzens, wo Zellen, die zur Septierung der Ausflussbahn in Aorta und Truncus pulmonalis führen, aus der Neuralleiste einwandern, eine Hex-Expression zu beobachten (Abbildung 5, Abbildung 7, Abbildung 10, Abbildung 11). Die Anlage der paarigen Aorta zeigt im Endothel eine Hex-Expression (Abbildung 12, Abbildung 13) und entlang der Aorta sieht man im Bereich des Aortenbodens Hex-positive Signale (Abbildung 5, Abbildung 6, Abbildung 10). Hex-Expression ist am 3. Entwicklungstag außerdem im Endothel verschiedener Gefäße sichtbar: Im Endothel der Viszeralbogenarterien (Abbildung 5, Abbildung 6, Abbildung 11) und der intersomitischen Gefäße (Abbildung 5, Abbildung 11, Abbildung 14, Abbildung 15) ist eine Hex-Expression zu erkennen. Des Weiteren zeigen perineurale Gefäße (Abbildung 12, Abbildung 16) und Gefäße im Bereich des Wolff-Ganges (Abbildung 12) Hex-positive Signale. In den Blutinseln der Allantois, dem Ort der extraembryonalen Blutbildung ist am 3. Entwicklungstag eine starke Hex-Expression zu finden (Abbildung 5, Abbildung 6, Abbildung 17). 


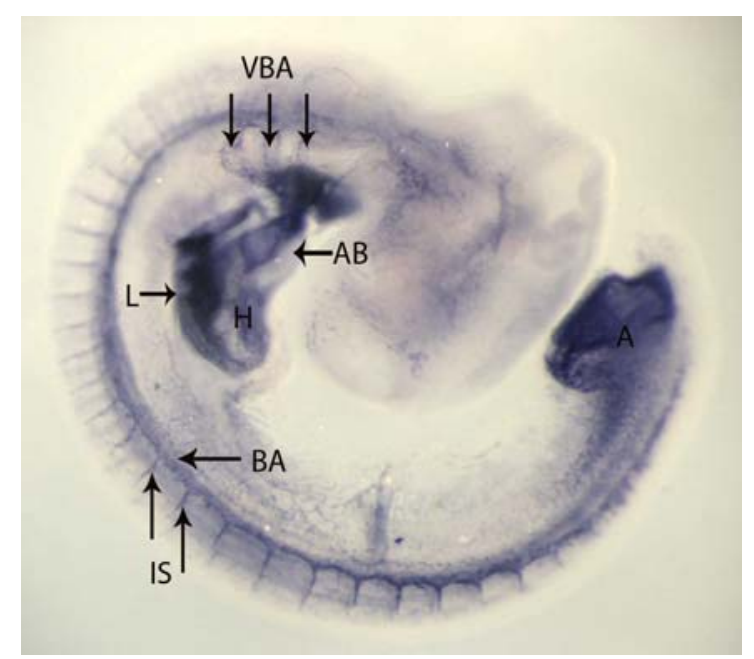

Abbildung 5: Hühnerembryo Tag 3; Übersicht im HH-Stadium 17

In der Abbildung sieht man die Hex-Expression im Hühnerembryo am 3. Entwicklungstag im $\mathrm{HH}-$ Stadium 17. (A: Allantois; AB: Ausflussbahn des Herzens; BA: Boden der Aorta; H: Herzanlage; IS: intersomitische Gefäße; L: Leberanlage; VBA: Viszeralbogenarterien)

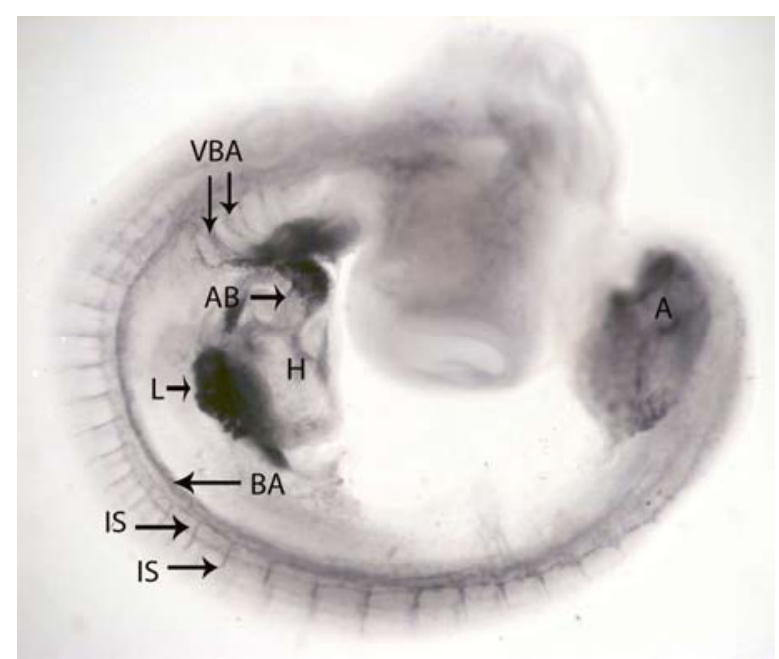

Abbildung 6: Hühnerembryo Tag 3; Übersicht im HH- Stadium 18

In der Abbildung sieht man die Hex-Expression im Hühnerembryo am 3. Entwicklungstag im HHStadium 18. (A: Allantois; AB: Ausflussbahn des Herzens; BA: Boden der Aorta; H: Herzanlage; IS: intersomitische Gefäße; L: Leberanlage; VBA: Viszeralbogenarterien)

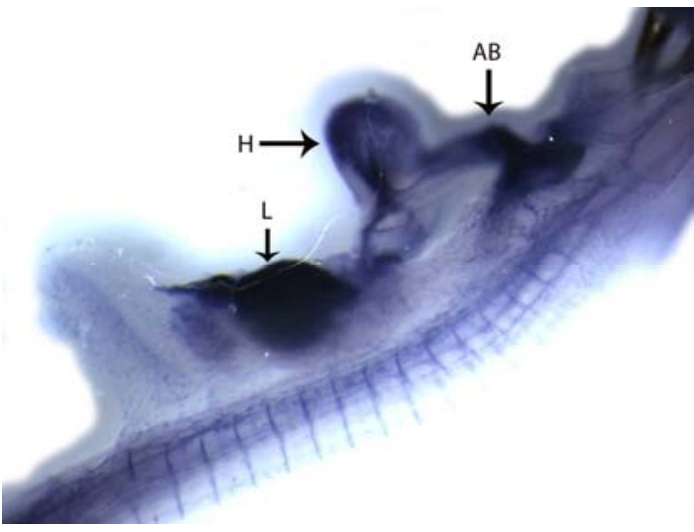

Abbildung 7: Hühnerembryo Tag 3; Leber und Herzanlage

Man sieht im Hühnerembryo am Tag 3 eine HexExpression in der Leberanlage. Außerdem erkennt man in der Abbildung eine Hex-Expression in der Ausflussbahn des Herzens. (AB: Ausflussbahn des Herzens; H: Herzanlage; L: Leber) 


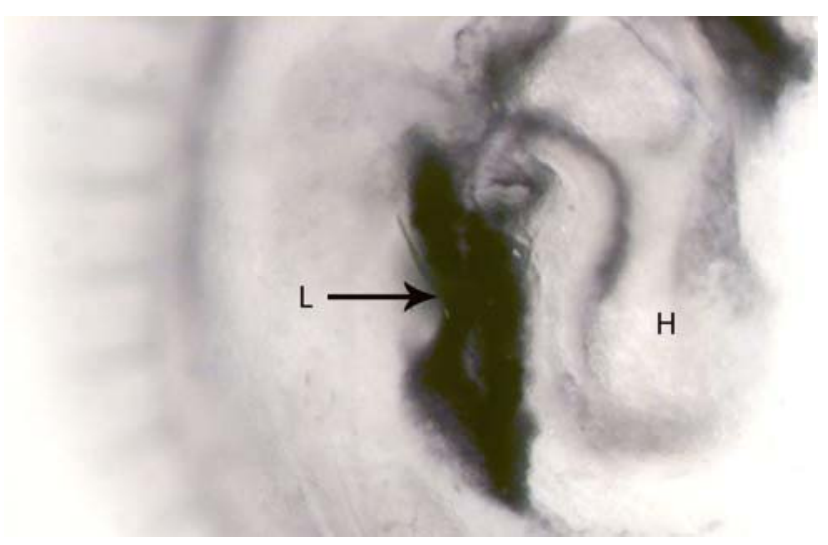

Abbildung 8: Hühnerembryo Tag 3; Leber

Man sieht eine Anfärbung im Bereich der Leberanlage. (H: Herz; L: Leber)

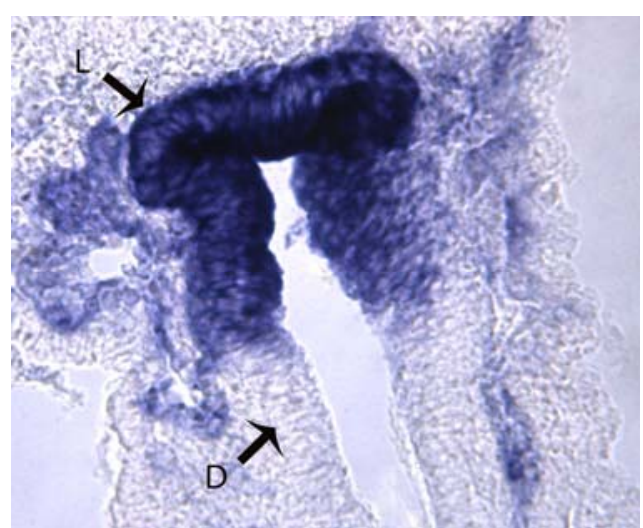

Abbildung 9: Hühnerembryo Tag 3; Leberknospe am Übergang zum Darm Die Abbildung zeigt die Anfärbung des Entoderms am Übergang des Vorderdarms zur Leberanlage. Hier wird das entodermale Material für die Leber abgeschnürt. (D: Darm; L: Leberknospe)

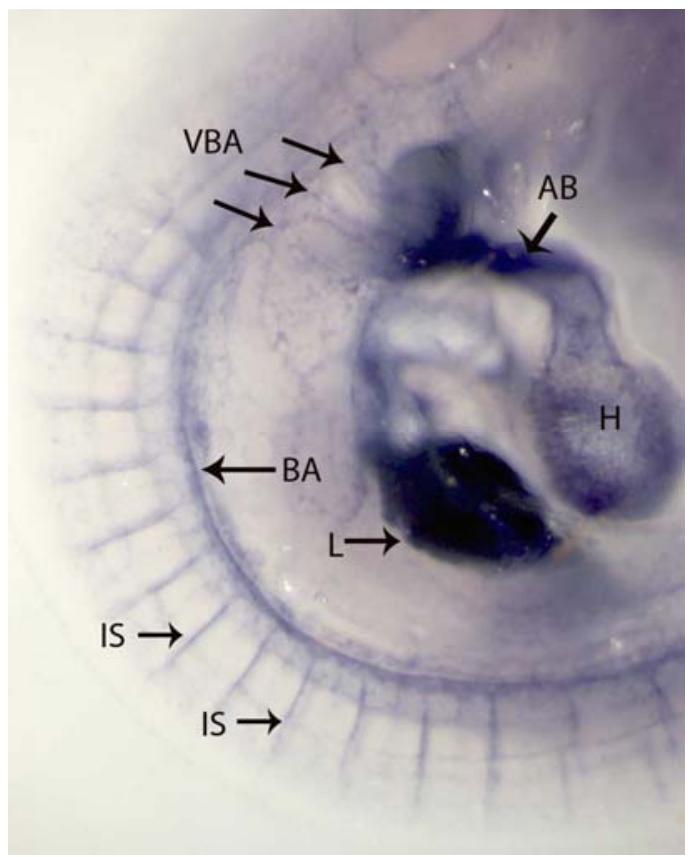

Abbildung 10: Hühnerembryo Tag 3; Darstellung des Herzens, der Ausflussbahn und des Aortenbodens

Man sieht ein Hex-Signal im Ventrikelendokard, in der Ausflussbahn des Herzens, die sich später in Aorta und Truncus pulmonalis teilt und in den Viszeralbogenarterien (AB: Ausflussbahn des Herzen; BA: Boden der Aorta; H: Herz, L: Leber, VAB: Viszeralbogenarterien; IS: intersomitische Gefäße) 


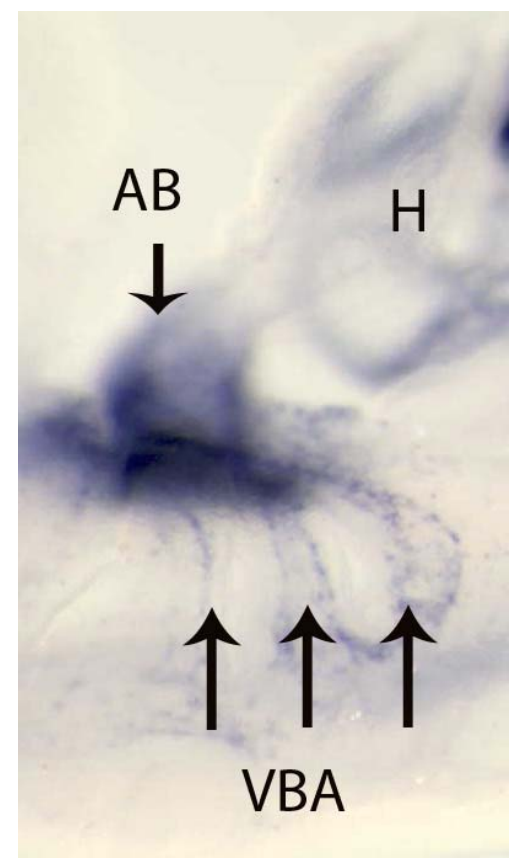

Abbildung 11: Embryo Tag 3; Darstellung der Viszeralbogenarterien

In dieser Abbildung sieht man die Anfärbung des Endothels der Viszeralbogenarterien. (AB: Ausflussbahn des Herzens; H: Herz; VAB: Viszeralbogenarterien)

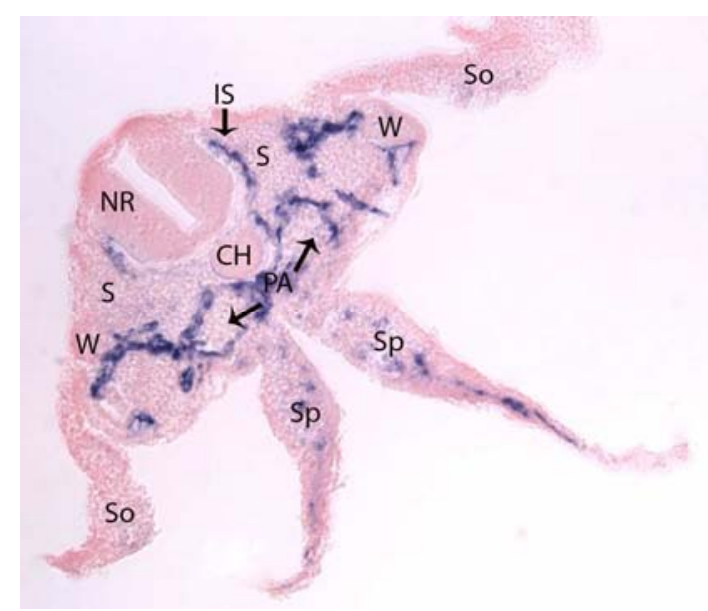

Abbildung 12: Hühnerembryo Tag 3;

\section{Querschnitt}

Die Abbildung zeigt eine Anfärbung des Endothels der paarigen Aortenanlage, des Gefäßplexus um das Neuralrohr und des Endothels der intersomitischen Gefäße. Außerdem ist ein Hex-Signal in Gefäßen im Bereich des Wolff-Ganges erkennbar. (CH: Chorda; IS: intersomitische Gefäße; NR: Neuralrohr; PA: paarige Aorta; S: Somit; Sp: Splanchnopleura; So: Somatopleura; W: WolffGang)

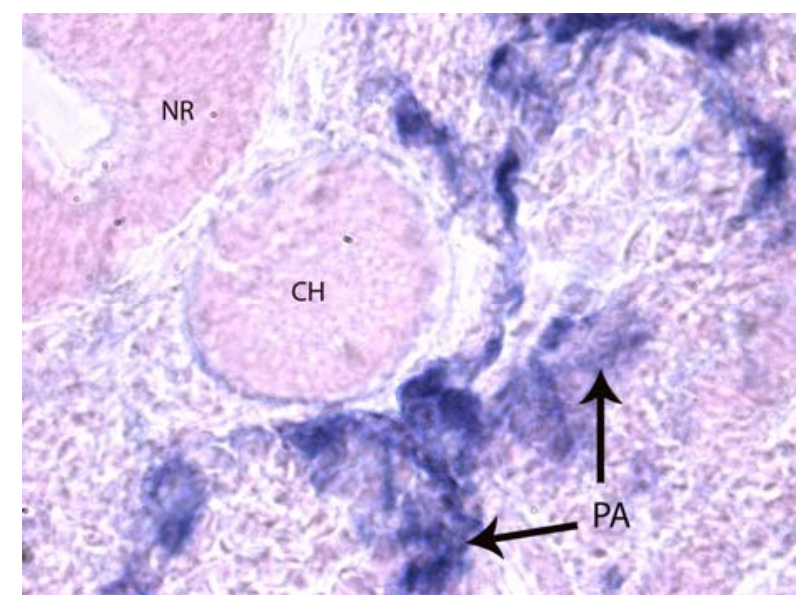

Abbildung 13: Hühnerembryo Tag 3; Vergrößerung der paarigen Aortenanlage aus

\section{Abbildung 12}

Die Abbildung zeigt ein Hex-Signal im Endothel der paarigen Aortenanlage. (CH: Chorda; NR: Neuralrohr; PA: paarige Aorta) 


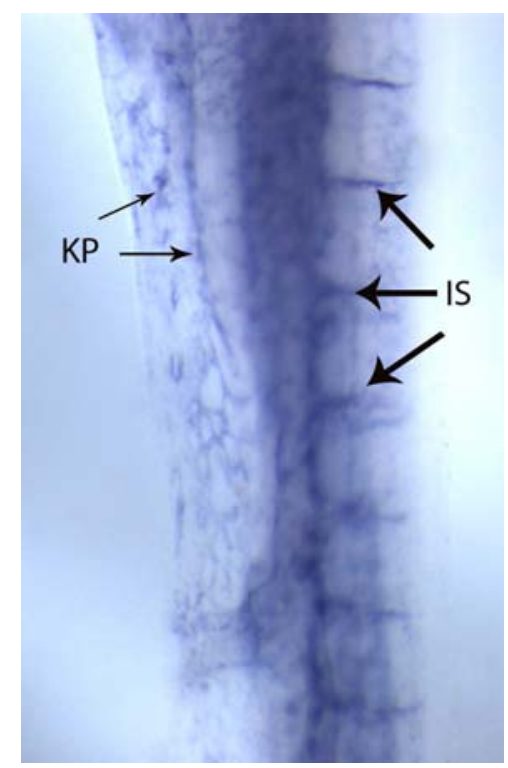

Abbildung 14: Embryo Tag 3; Intersomitische Gefäße In der Abbildung sieht man eine Hex-Expression im Endothel der intersomitischen Gefäße. Des Weiteren ist ein Hex-Signal im Kapillarplexus der Körperwand zu erkennen. (IS: intersomitische Gefäße; KP: Kapillarplexus in der Körperwand)

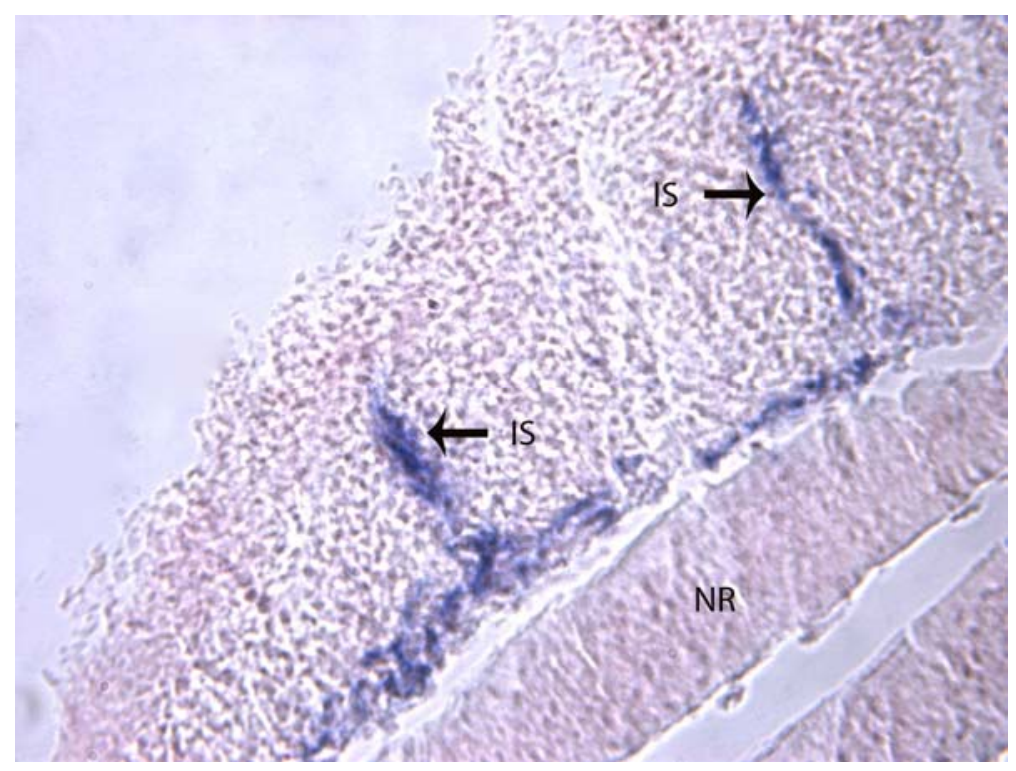

Abbildung 15: Hühnerembryo Tag 3; Intersomitische Gefäße

Die Abbildung zeigt das angefärbte Endothel der intersomitischen Gefäße. (IS: intersomitische Gefäße; NR: Neuralrohr)

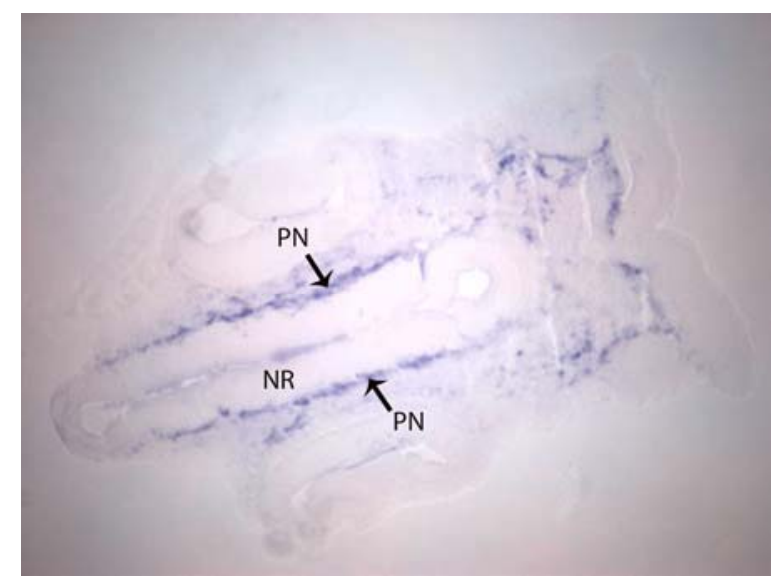

Abbildung 16: Hühnerembryo Tag 3; Perineuraler Gefäßplexus

Die Abbildung zeigt die Hex-Expression im Endothel des perineuralen Gefäßplexus. (NR: Neuralrohr; PN: perineuraler Gefäßplexus) 


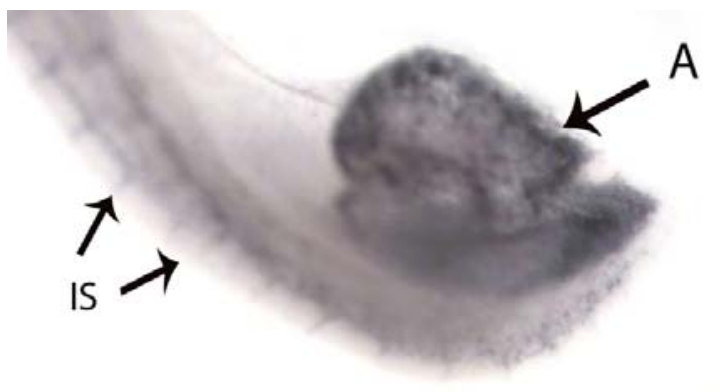

\begin{abstract}
Abbildung 17: Hühnerembryo Tag 3; Allantois

In der Abbildung ist ein starkes Hex-Signal im Bereich der Allantois zu erkennen. (A: Allantois; IS: intersomitische Gefäße)
\end{abstract}

\title{
3.3 Entwicklungstag 4
}

Am 4. Entwicklungstag ist wie am 3. Entwicklungstag unverändert eine starke HexExpression in der Leberanlage (Abbildung 18, Abbildung 20, Abbildung 23) in den Hepatoblasten (Abbildung 23) zu sehen. In der Herzanlage ist weiterhin Hex-Expression im Ventrikelendokard (Abbildung 19, Abbildung 21) und in der Herzausflussbahn (Abbildung 19, Abbildung 20, Abbildung 25) zu erkennen. Des Weiteren zeigt der AVKanal, wo die Teilung zwischen Vorhof und Ventrikel stattfindet, Hex-positive Signale (Abbildung 19, Abbildung 20). Auch entlang der dorsalen Aorta im Bereich der AGMRegion (Aorta-Gonaden-Mesonephros-Region), wo an den Entwicklungstagen 4 und 5 die Blutbildung stattfindet, ist weiterhin ein Hex-Signal vorhanden (Abbildung 22). Wie am 3. Entwicklungstag ist Hex-Expression im Endothel von verschiedenen Gefäßen zu finden: Die Viszeralbogenarterien (Abbildung 18, Abbildung 19, Abbildung 25) und die intersomitischen Gefäße (Abbildung 18, Abbildung 19) sowie Gefäße im Bereich des Mesonephros (Abbildung 24) zeigen eine Hex-Expression im Endothel. Das Hex-Signal in den Blutinseln der Allantois nimmt hingegen im Vergleich zum Vortag leicht ab (Abbildung 27). Am 4. Entwicklungstag ist erstmals eine deutliche Hex-Expression in der Schilddrüse zu beobachten (Abbildung 25, Abbildung 26). Außerdem ist in diesem Entwicklungsstadium eine erstmalige Hex-Expression in den Gefäßen der Bein- und Flügelanlagen zu beobachten (Abbildung 28, Abbildung 29). 

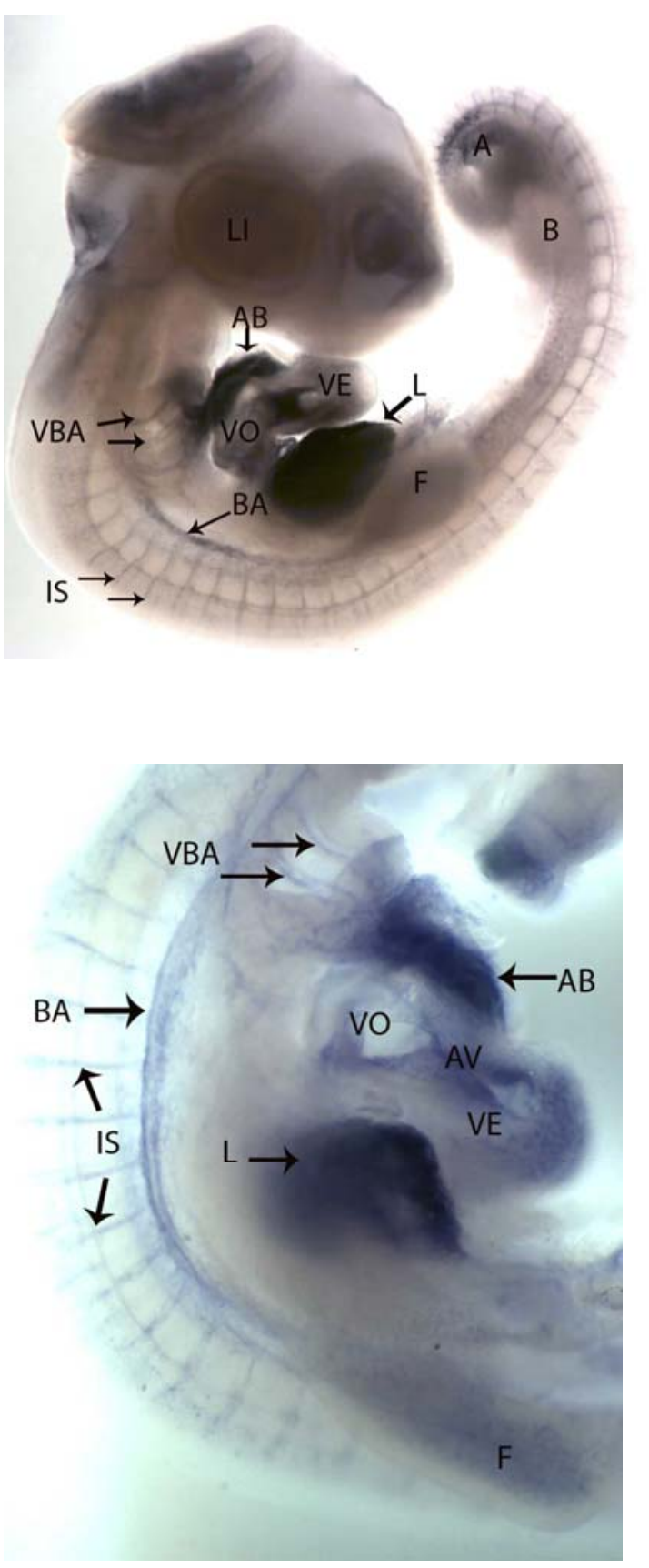

Abbildung 18: Hühnerembryo Tag 4; Übersicht Die Abbildung zeigt einen Hühnerembryo am 4. Entwicklungstag. (A: Allantois; AB: Ausflussbahn des Herzen; B: Beinknospe; BA: Boden der Aorta; F: Flügelknospe; IS: intersomitische Gefäße; L: Leber; Li: Linsenplakode; VBA: Viszeralbogenarterien; VE: Ventrikel; VO: Vorhof)

Abbildung 19: Hühnerembryo Tag 4; Darstellung der Organanlagen und des Aortenbodens

Die Abbildung zeigt eine Hex-Expression im Bereich des AV-Kanals, im Ventrikelendokard und in der Herzausflussbahn. Außerdem ist in der Abbildung die HexExpression im Endothel des Aortenbodens und im Endothel der Viszeralbogenarterien zu sehen. (AB: Ausflussbahn; AV: AV-Kanal; BA: Boden der Aorta; F: Flügelknospe; IS: intersomitische Gefäße; L: Leber; VB: Bogenarterien, VE: Ventrikel; VO: Vorhof) 


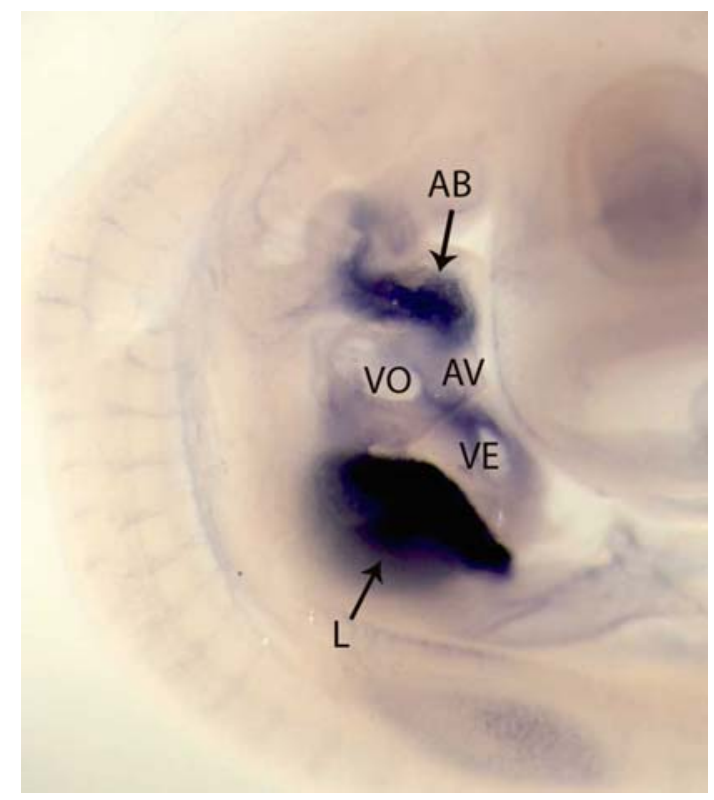

Abbildung 20: Embryo Tag 4; Darstellung des Herzens und der Ausflussbahn

In der Abbildung sieht man eine Anfärbung der Ausflussbahn des Herzens. Außerdem erkennt man ein Hex-Signal im Bereich des AV-Kanals zwischen Vorhof und Ventrikel. (AB: Ausflussbahn des Herzens; AV: AV-Kanal; L: Leber VE: Ventrikel; VO: Vorhof)

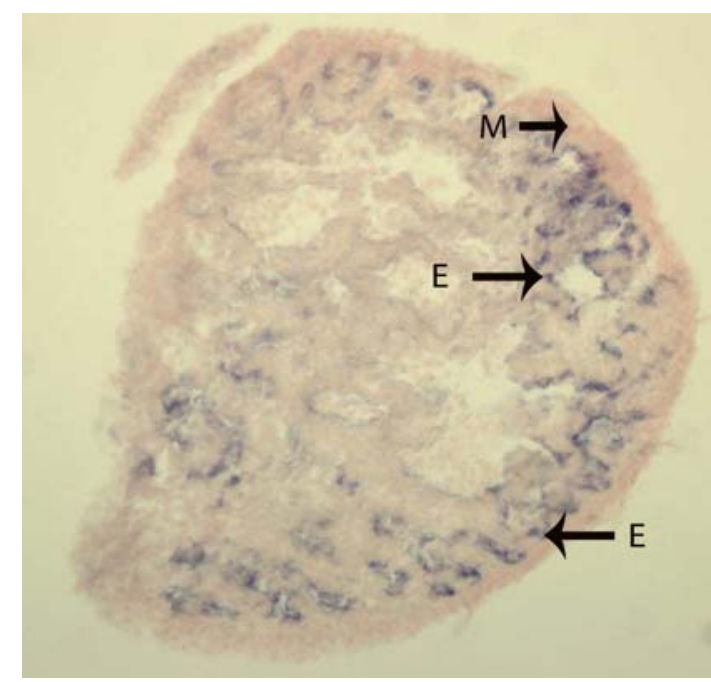

Abbildung 21: Hühnerembryo Tag 4; Darstellung des Ventrikels

In der Abbildung sieht man die Hex-Expression im Endokard des Herzventrikels. Das Trabekelsystem des Myokards ist hingegen Hex-negativ. (E: Endokard; M; Myokard) 


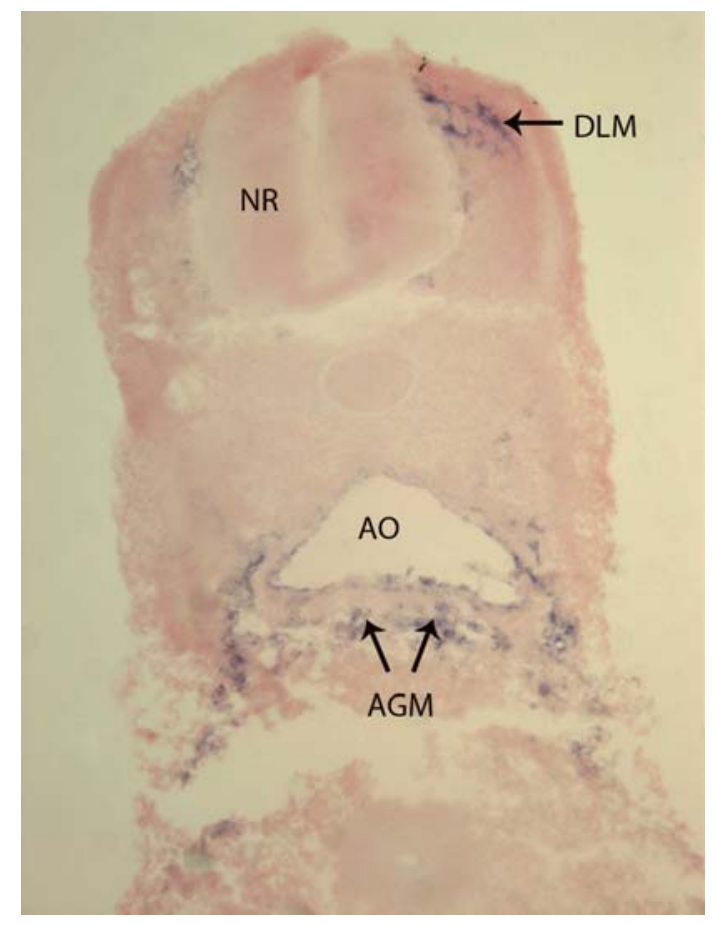

Abbildung 22: Hühnerembryo Tag 4; Darstellung der AGM-Zellen

In der Abbildung sieht man die Hex-Expression in den AGM-Zellen. Im dorsolateralen Mesenchym ist ebenfalls ein Hex-Signal zu erkennen. (A: Aorta; AGM: AGMZellen; DLM: dorsolaterales Mesenchym; NR: Neuralrohr)

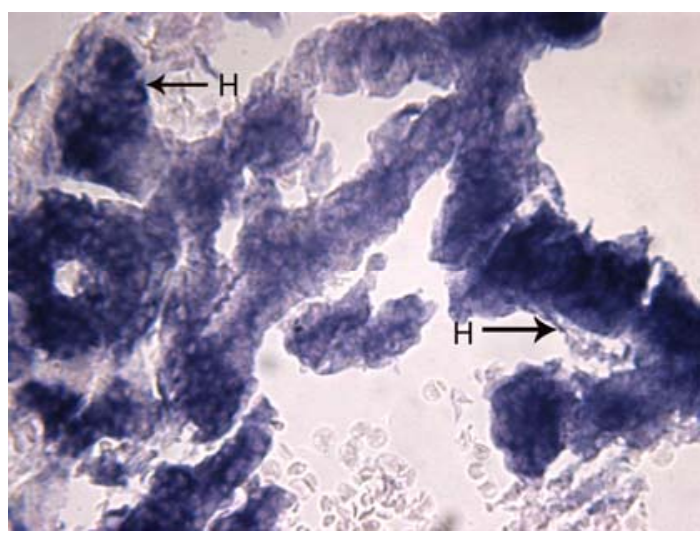

Abbildung 23: Hühnerembryo Tag 4; Darstellung der Leberanlage

In der Abbildung sieht man die Hex-Expression in den Hepatoblasten. (H: Hepatoblasten)

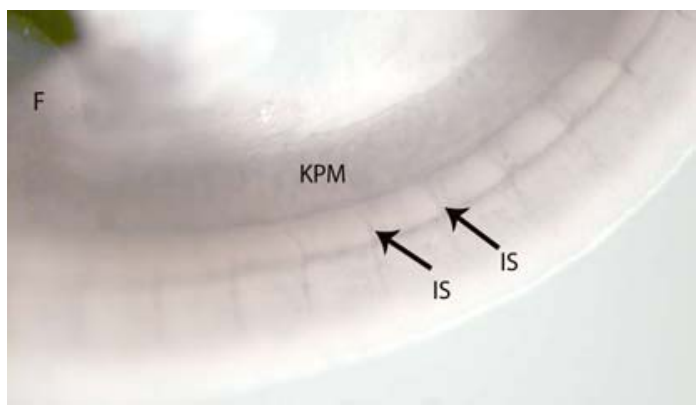

Abbildung 24: Embryo Tag 4; Mesonephros mit Gefäßzeichnung

Die Abbildung zeigt den Hex-positiven Kapillarplexus im Bereich des Mesonephros. (F: Flügelknospe; IS: intersomitische Gefäße; KPM: Kapillarplexus im Bereich des Mesonephros) 


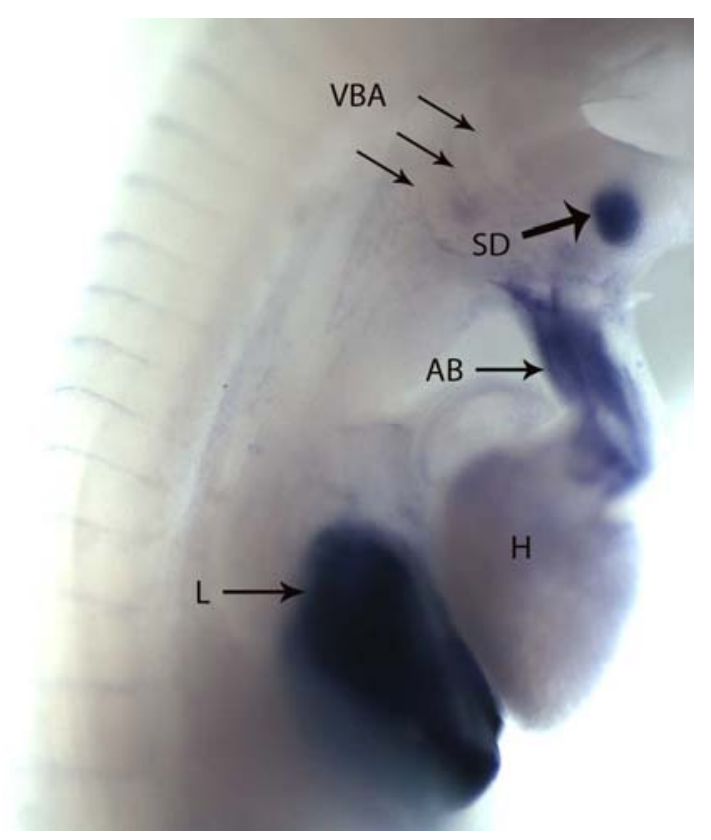

Abbildung 25: Hühnerembryo Tag 4; Darstellung der ventralen Organe und der Schilddrüse

In der Abbildung ist das deutliche Hex-Signal im Bereich der Schilddrüsenanlage zu sehen. (AB: Ausflussbahn des Herzens; H: Herzanlage; L: Leberanlage; SD: Schilddrüsenanlage; VBA: Viszeralbogenarterien)

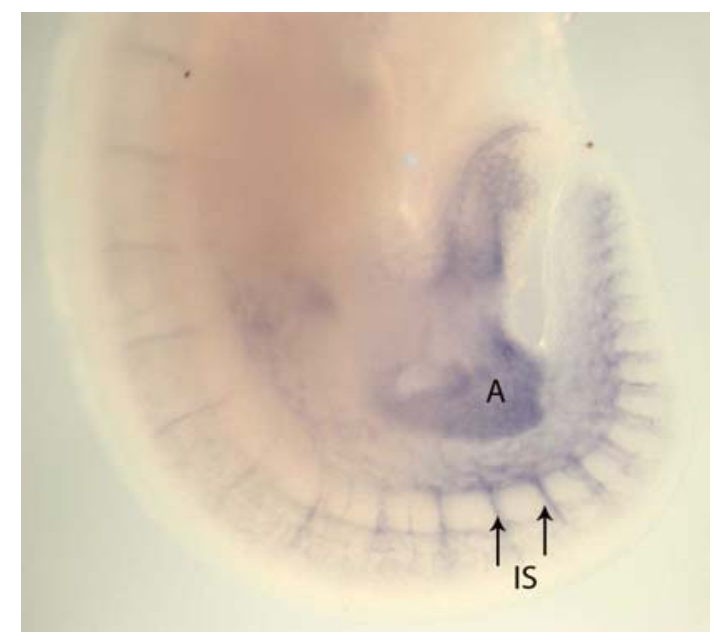

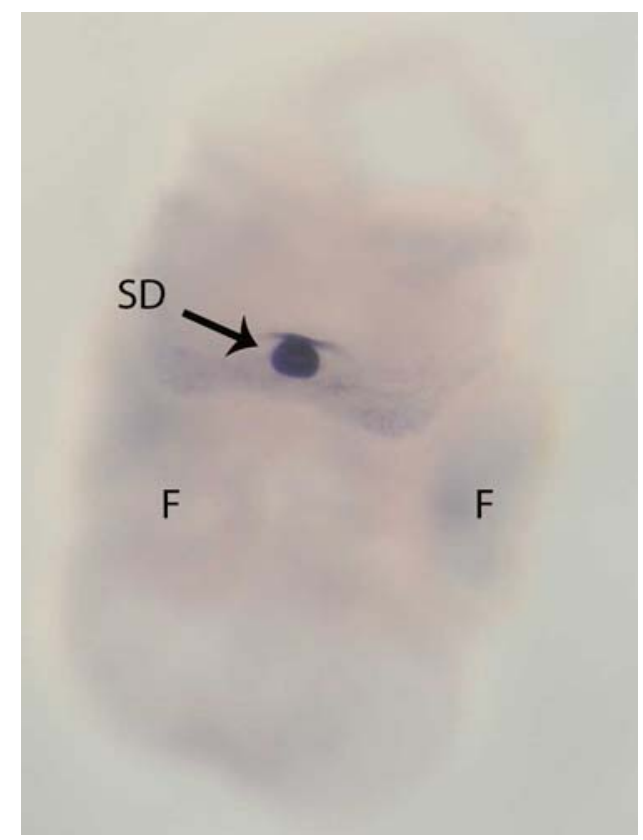

Abbildung 26: Embryo Tag 4; Schilddrüse

In der Abbildung sieht man die Expression von Hex in der Schilddrüsenanlage. (F: Flügelknospen; SD: Schilddrüse)

Abbildung 27: Hühnerembryo Tag 4; Darstellung der Allantois

Die Abbildung zeigt, dass die Hex-Expression in der Allantois am Tag 4 im Vergleich zu den Entwicklungstagen 2 und 3 abnimmt. (AL: Allantois; I: intersomitische Gefäße) 


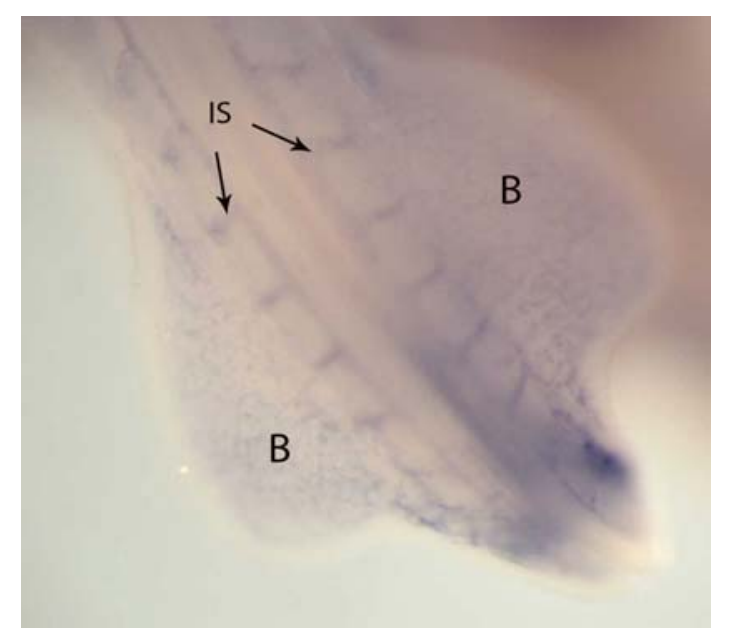

Abbildung 28: Hühnerembryo Tag 4; Darstellung der Gefäßzeichnung in den Beinknospen

Die Abbildung zeigt die Hex-Expression in Gefäßen der Beinanlagen. (B: Beinanlage; IS: intersomitische Gefäße)

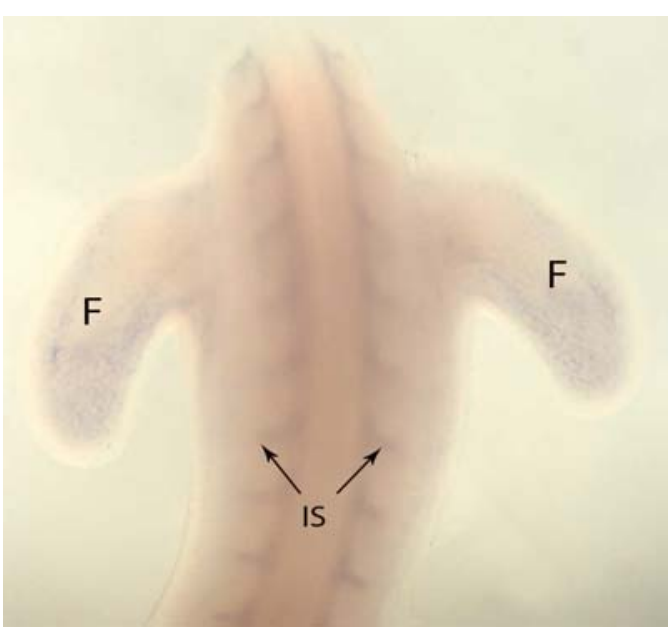

Abbildung 29: Hühnerembryo Tag 4; Darstellung der Gefäßzeichnung in den Flügelknospen

In der Abbildung ist ein Hex-Signal in den Gefäßen der Flügelknospen zu erkennen. (F: Flügelknospen; IS: intersomitische Gefäße)

\subsection{Entwicklungstag 5}

Am 5. Entwicklungstag ist unverändert eine Hex-Expression in den Hepatoblasten der Leberanlage zu beobachten (Abbildung 31, Abbildung 32, Abbildung 33, Abbildung 34). In der Herzanlage wird weiterhin Hex im Ventrikelendokard (Abbildung 32), in der Ausflussbahn (Abbildung 30, Abbildung 31, Abbildung 32) und im AV-Kanal (Abbildung 30) exprimiert. Ebenso ist im Bereich der AGM-Region weiterhin eine Hex-Expression zu erkennen (Abbildung 34). Auch in der Schilddrüsenanlage zeigt sich wie am 4. Entwicklungstag ein Hex-Signal (Abbildung 30, Abbildung 31). In den Gefäßen des Mesonephros (Abbildung 34), im Gefäßplexus, der das Neuralrohr umgibt (Abbildung 33) sowie im Endothel der intersomitischen Gefäße und der Viszeralbogenarterien (Abbildung 30) ist am 5. Entwicklungstag Hex-Expression zu finden. In Abbildung 35 und in Abbildung 36 ist das Hex-Expressionsmuster in den Extremitätenanlagen dargestellt. Dieses unterscheidet sich vom Expressionsmuster am 4. Entwicklungstag, denn nun ist eine Expression im interdigitalen Mesenchym und in mesenchymalen Anteilen des Zeugopodiums, aber nicht mehr in den Blutgefäßen der Extremitäten zu beobachten. In der vorderen Extremitätenanlage (Abbildung 35) ist in diesem Stadium ein anderes Expressionsmuster als in der hinteren Extremitätenanlagen (Abbildung 36) zu erkennen. Dieses kann vermutlich auf Unterschiede im Skelettsystem von Vorder- und Hinterextremität zurückgeführt werden. 


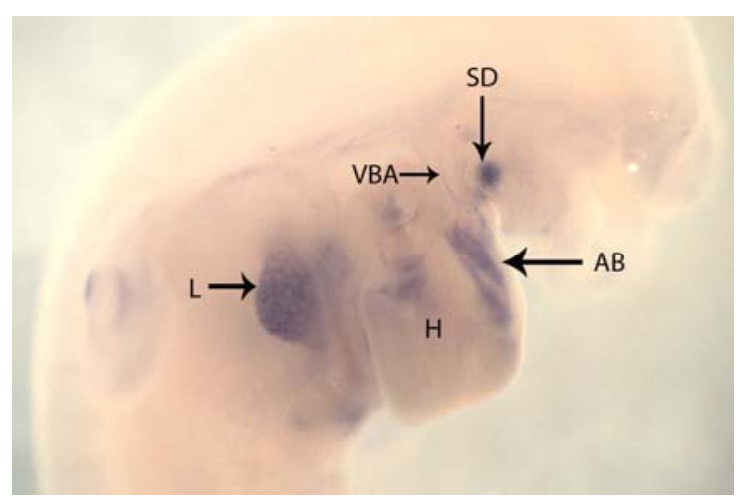

Abbildung 30: Hühnerembryo Tag 5; ventrale Organanlagen in seitlicher Sicht

Die Abbildung zeigt die Hex-Expression in den ventralen Organanlagen, dem Herzventrikelendokard, der Herzausflussbahn, der Leber und der Schilddrüse. Außerdem ist ein Hex-Signal in den Viszeralbogenarterien zu erkennen. (AB: Ausflussbahn; H: Herz; L: Leber; SD: Schilddrüse; VBA: Viszeralbogenarterien)

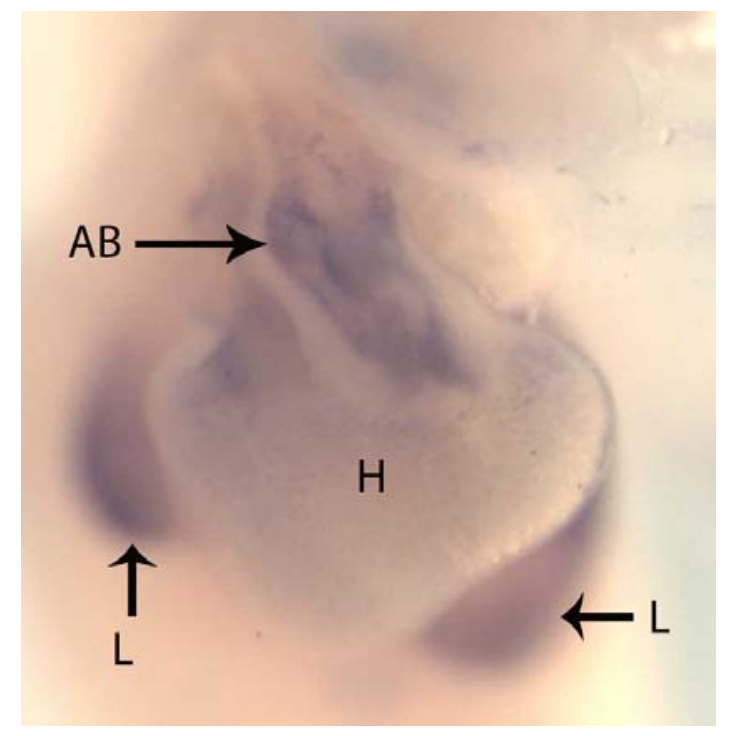

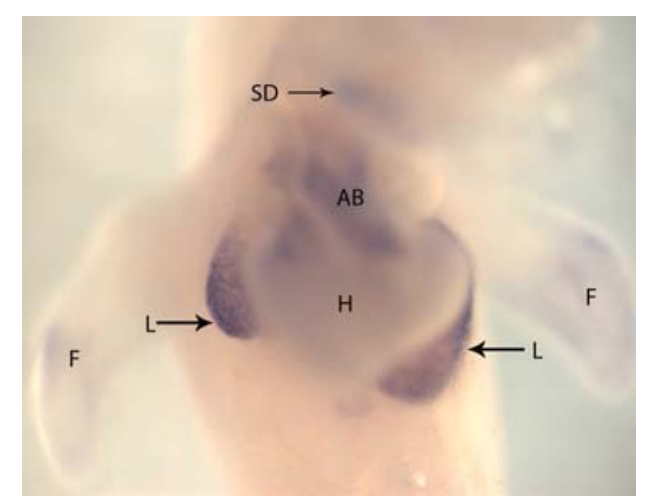

Abbildung 31: Hühnerembryo Tag 5; ventrale Organanlagen

Die Abbildung zeigt die Hex-Expression in der Leber, welche hinter dem Herzen durchscheint. Außerdem ist die Hex-Expression in der Ausflussbahn des Herzens und in der Schilddrüse zu erkennen. (AB: Ausflussbahn des Herzens; F: Flügelknospen; H: Herz; L: Leber; SD: Schilddrüse)
Abbildung 32: Hühnerembryo Tag 5; Herz und Leber

In der Abbildung ist die Hex-Expression Ventrikelendokard und in der Ausflussbahn des Herzens dargestellt. Die Hex-positive Leber ist hinter dem Herzen zu sehen. (AB: Ausflussbahn des Herzens; H: Herz; L: Leber) 


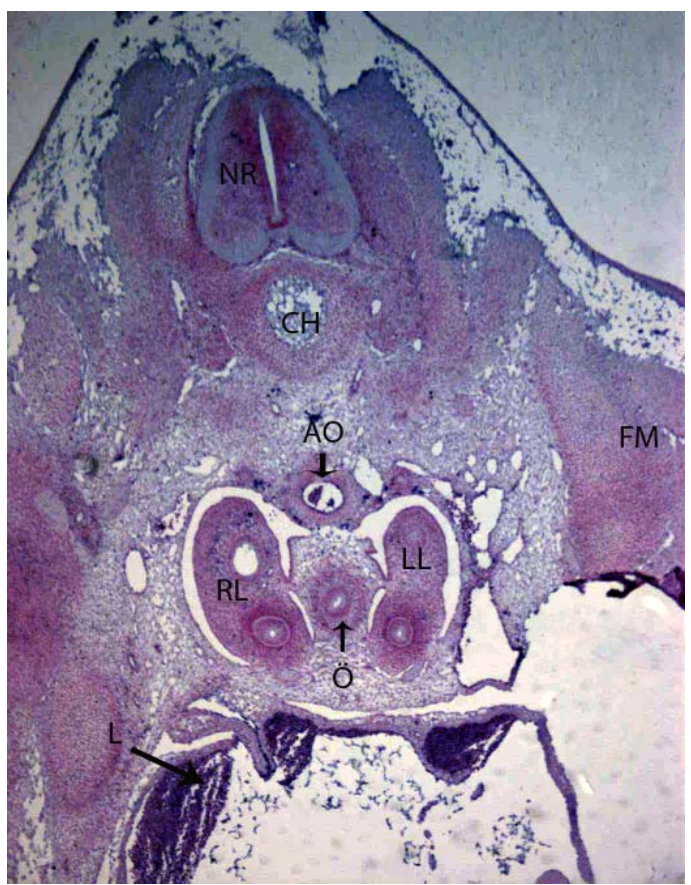

Abbildung 33: Hühnerembryo Tag 5; Querschnitt auf Höhe der Lungenknospen

Die Abbildung zeigt den Querschnitt eines Hühnerembryos am 5. Entwicklungstag auf Höhe der Lungenknospen. Man erkennt ein Hex-Signal in der Leberanlage. (AO: dorsale Aorta; $\mathrm{CH}$ : Chorda dorsalis; FM: Flügelmuskulatur; L: Leberanlage; LL: linke Lungenknospe; NR: Neuralrohr; RL: rechte Lungenknospe; Ö: Ösophagus)

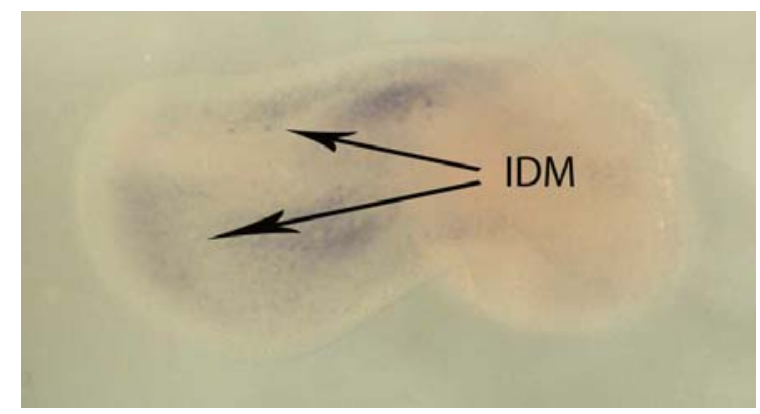

Abbildung 35: Embryo Tag 5; Vordere Extremität

Die Abbildung zeigt die Hex-Expression im Mesenchym des Interdigitalbereiches in der Anlage der rechten vorderen Extremität. (IDM: Interdigitalmesenchym)

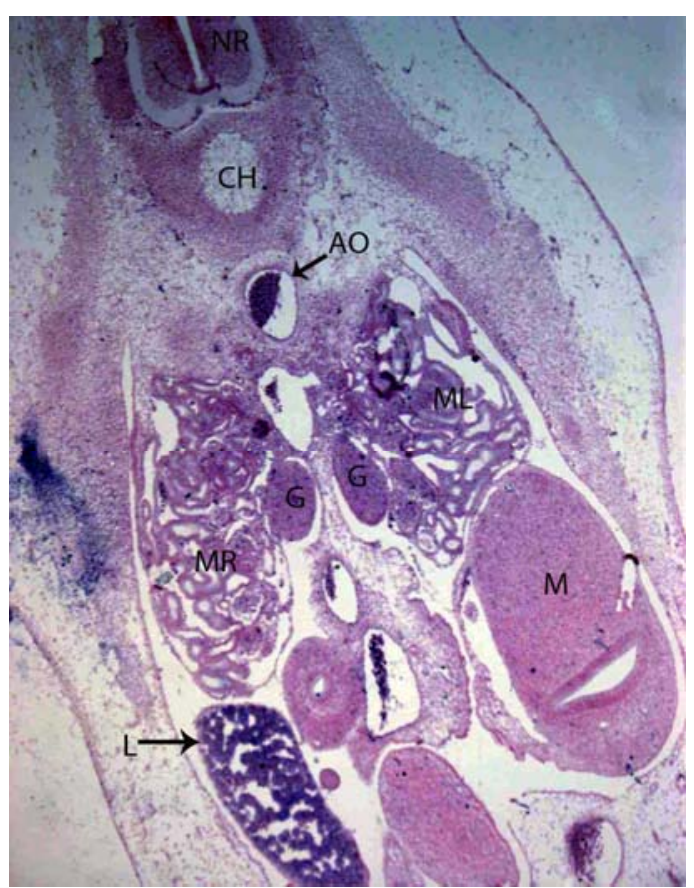

Abbildung 34: Hühnerembryo Tag 5; Querschnitt auf Höhe des Mesonephros und des Magens

In der Abbildung erkennt man die HexExpression in der Leber, in Gefäßen des Mesonephros und in der AGM-Region. In der dorsalen Aorta zeigen hämatopoetische Zellen ein HexSignal. (AO: dorsale Aorta; $\mathrm{CH}$ : Chorda dorsalis; G: Gonade; L: Leber; M: Magen; ML: Mesonephros links; MR: Mesonephros rechts; NR: Neuralrohr)

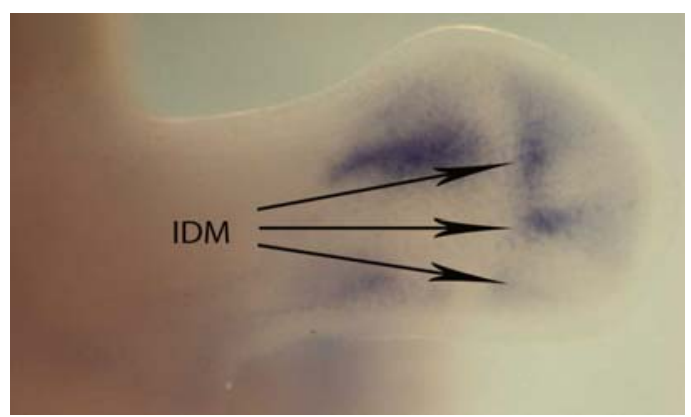

Abbildung 36: Embryo Tag 5; Hintere Extremität

In der Abbildung ist die Hex-Expression in der hinteren Extremität im Interdigitalmesenchym dargestellt. (IDM: Interdigitalmesenchym) 


\subsection{Entwicklungstag 10}

Am 10. Entwicklungstag zeigen die Hepatozyten der Leberanlage ein starkes Hex-Signal (Abbildung 37, Abbildung 38, Abbildung 39, Abbildung 40). Im Endothel der Lebersinusoide ist ebenfalls Hex-Expression zu finden (Abbildung 39). In der Herzanlage sieht man eine Hex-Expression im Ventrikelendokard (Abbildung 48, Abbildung 49) und im koronaren Gefäßsystem (Abbildung 49). Das Ventrikelmyokard hingegen weist keine Hex-Expression auf (Abbildung 49). An Tag 10 ist in venösen und in arteriellen Gefäßen annähernd gleich starke Hex-Expression zu finden. Im Endothel der Vena hepatica (Abbildung 40, Abbildung 41) und der Vena mesenterica (Abbildung 42) sowie im Endothel der Arteria mesenterica (Abbildung 42, Abbildung 43) ist eine starke HexExpression zu beobachten, während die Media in beiden Gefäßtypen kein Hex-Signal aufweist. Die Lymphgefäße, welche die Arteria mesenterica begleiten, zeigen in ihrer Wand in Abbildung 43 eine leichte Hex-Expression, jedoch ist dieses Hex-Signal in Lymphgefäßen der Abbildung 42 nicht eindeutig zu erkennen. Im Drüsenmagen ist Hex-Expression im mikrovaskulären Gefäßsystem nachweisbar (Abbildung 46, Abbildung 47), nicht jedoch in den Drüsenepithelien. Sowohl im Mesonephros als auch im Metanephros, der Nachniere, die sich dorsal des Mesonephros entwickelt, ist eine Hex-Expression im Endothel der peritubulären Kapillaren zu sehen (Abbildung 50, Abbildung 51). Die Nierentubuli selber hingegen zeigen keine Hex-Expression. Abbildung 52 zeigt, dass auch im Gefäßsystem der Gonaden Hex-Signale zu finden sind. Am 10. Entwicklungstag haben sich im Hühnerembryo die Wirbelkörper mit Wirbelbögen und das Rückenmark gebildet. Hier sieht man Hex-Expression im Gefäßplexus, der das Rückenmark umgibt (Abbildung 53). Auch in Gefäßen im Rückenmark, vor allem in der grauen Substanz, sind Hex-positive Signale zu beobachten (Abbildung 53). In Abbildung 44 und in Abbildung 45 sind einige hämatopoetische Zellen im Mesenchym, die eine starke Hex-Expression aufweisen, dargestellt. In den kernhaltigen Erythrozyten des Hühnerembryos, die beispielsweise in den Lebersinusoiden und in der Vena hepatica zu sehen sind, findet man hingegen keine HexSignale (Abbildung 38, Abbildung 41). 


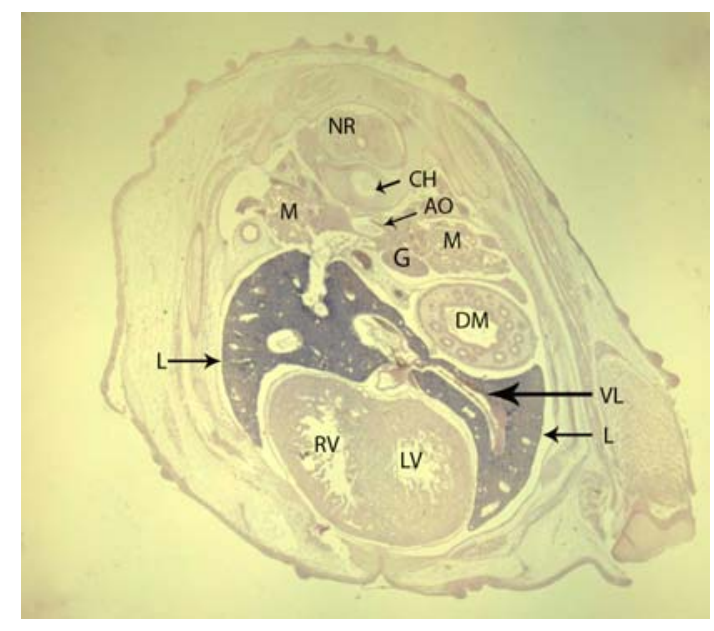

Abbildung 37: Hühnerembryo Tag 10; Übersicht

Die Abbildung zeigt einen Übersichtsquerschnitt eines Hühnerembryos am 10. Entwicklungstag. (AO: Aorta; CH: Chorda dorsalis; DM: Drüsenmagen, G: Gonade; L: Leber; LV: linker Ventrikel; M: Mesonephros; NR: Neuralrohr; RV: rechter Ventrikel; VL: Vene der Leber)

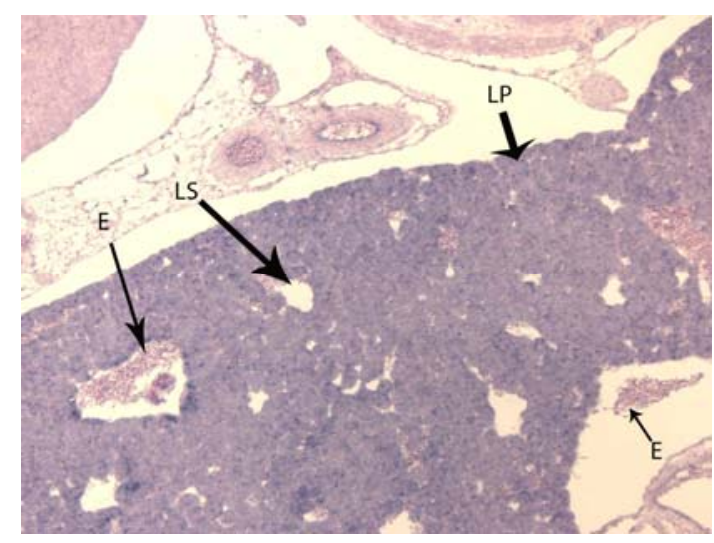

Abbildung 38: Hühnerembryo Tag 10;

Leber

In der Abbildung sieht man die Hex-Expression im Leberparenchym. In den Lebersinusoiden befinden sich Erythrozyten. (E: Erythrozyten; LP: Leberparenchym; LS: Lebersinus)

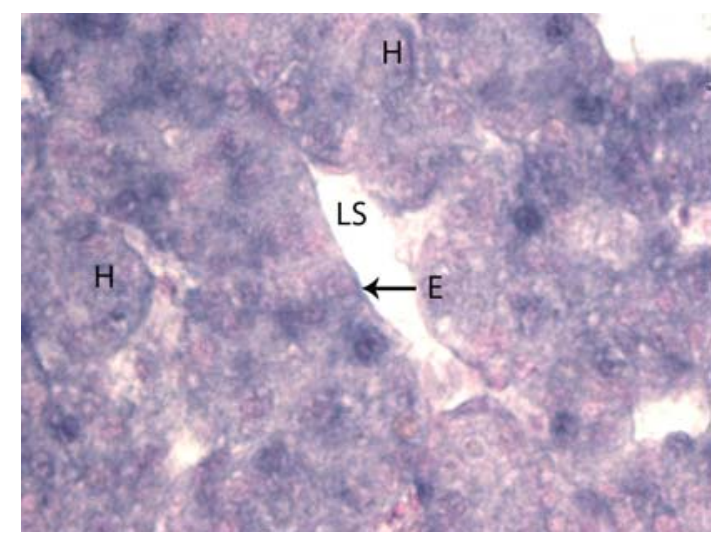

Abbildung 39: Hühnerembryo Tag 10;

\section{Lebersinus und Hepatozyten}

Die Abbildung zeigt die starke Hex-Expression in den Hepatozyten und ein Hex-Signal im Sinusendothel. Im Lebersinus sind einige nicht angefärbte Erythrozyten zu erkennen. (E: Erythrozyten; H: Hepatozyten; LS: Lebersinus) 


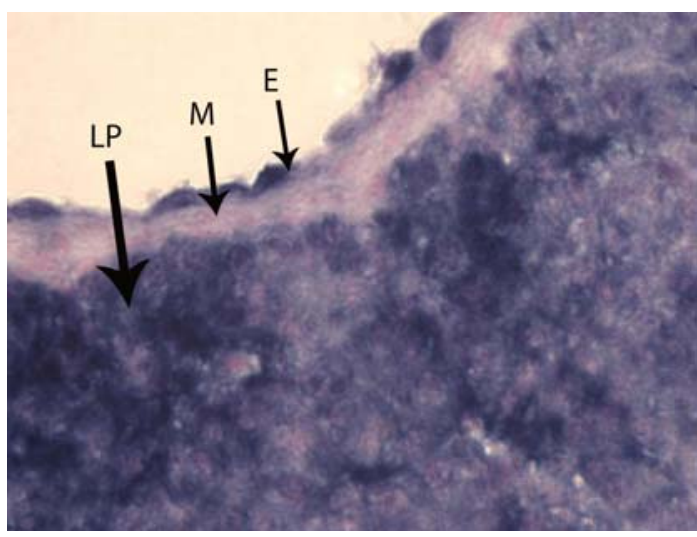

Abbildung 40: Hühnerembryo Tag 10;

Leber und Ast der V. hepatica

Die Abbildung zeigt die Hex-Expression im Leberparenchym. Des Weiteren sieht man die Expression von Hex im venösen Endothel. In der Media findet man keine Hex-Expression. (E: venöses Endothel; LP: Leberparenchym; M: Media)

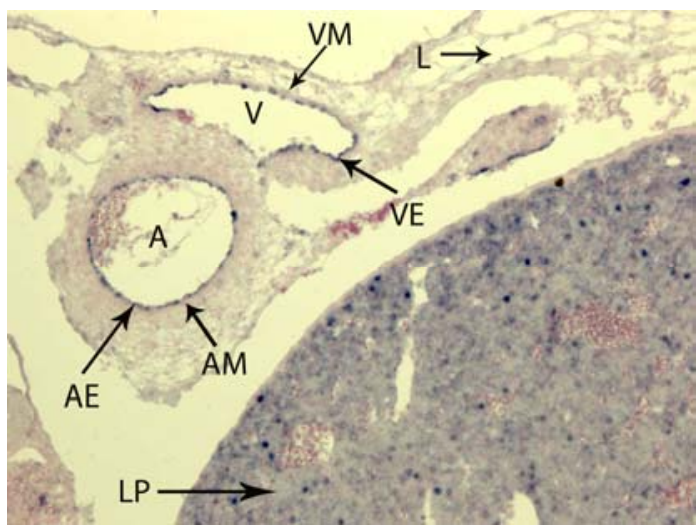

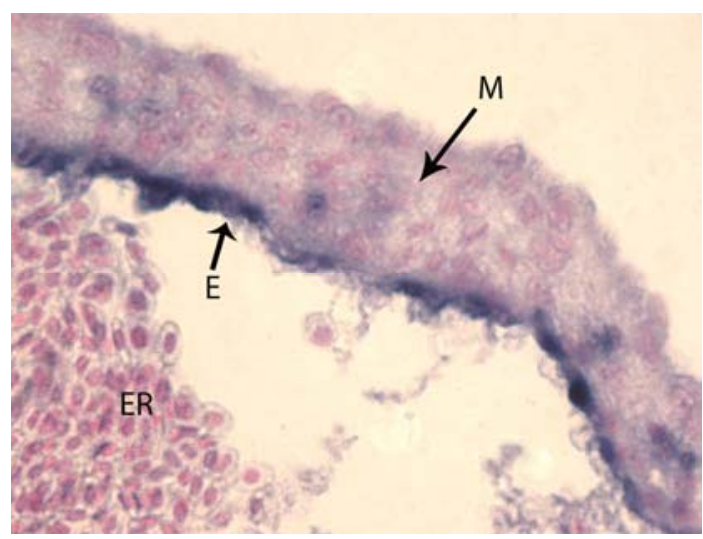

Abbildung 41: Hühnerembryo Tag 10;

\section{Lebervene}

In der Abbildung sieht man wieder die HexExpression im venösen Endothel und die fehlende Expression in der Media. In den kernhaltigen Erythrozyten ist ebenfalls kein Hex-Signal zu erkennen. (E: venöses Endothel; ER: Erythrozyten; M: Media)

Abbildung 42: Hühnerembryo Tag 10; Leber und Mesenterialgefäße

Die Abbildung zeigt die Hex-Expression sowohl im venösen als auch im arteriellen Endothel der Mesenterialgefäße. In der Media ist in Venen und in Arterien kein Hex-Signal zu erkennen. Auch in den Lymphgefäßen scheint Hex nicht exprimiert zu werden. (A: Arteria mesenterica; AE: arterielles Endothel; AM: arterielle Media; L: Lymphgefäße; LP: Leberparenchym; V: Vena mesenterica; VE: venöses Endothel; VM: venöse Media) 


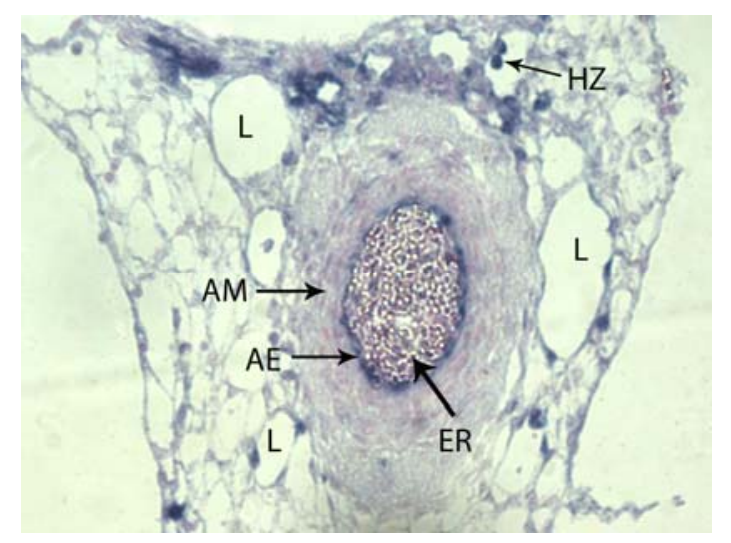

Abbildung 43: Hühnerembryo Tag 10; Lymphgefäße entlang der A. mesenterica

In der Abbildung sieht man die Arteria mesenterica mit ihren begleitenden Lymphgefäßen. In den Lymphgefäßen ist in dieser Abbildung ein schwaches Hex-Signal zu beobachten. Außerdem sind Hex-positive hämatopoetische Zellen zu sehen. Weiterhin erkennt man die Hex-Expression im Endothel der A. mesenterica bei negativem Signal in der Media. (AE: arterielles Endothel; AM: arterielle Media; ER: Erythrozyten; HZ: hämatopoetische Zellen (Leukozyten); L: Lymphgefäße)

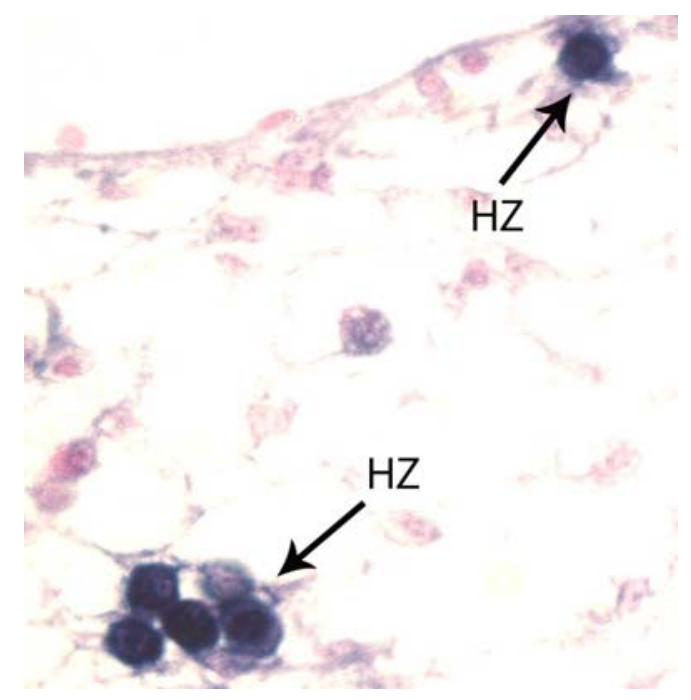

Abbildung 44: Hühnerembryo Tag 10;

Hämatopoetische Zellen

In der Abbildung sieht man eine starke Hex-

Expression in hämatopoetischen Rundzellen. (HZ: hämatopoetische Rundzellen)

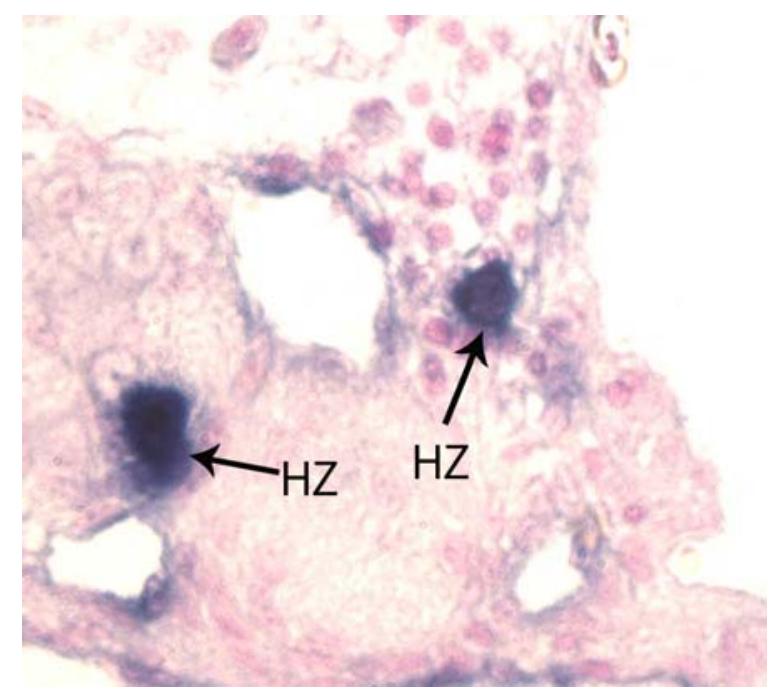

Abbildung 45: Hühnerembryo Tag 10; Hämatopoetische Zellen im Mesenchym

Diese Abbildung zeigt sich eine Hex-Expression Zellen des hämatopoetischen Systems im Mesenchym. (HZ: hämatopoetische Zellen) 


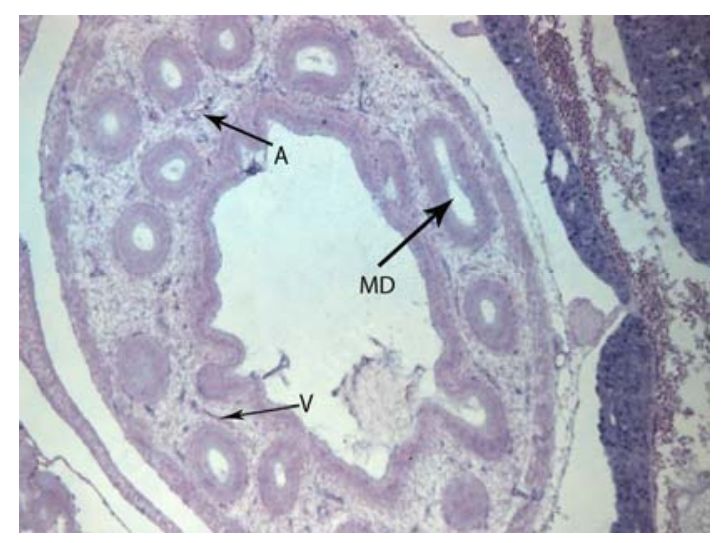

Abbildung 46: Hühnerembryo Tag 10;

Drüsenmagen

In der Abbildung sieht man den Drüsenmagen eines Hühnerembryos am 10. Entwicklungstag. In diesem erkennt man eine Hex-Expression im Gefäßnetz. Die Gefäße ohne Lumen stellen vermutlich Arteriolen dar, diejenigen mit Lumen Venolen. (A: Arteriolen; MD: Magendrüsen; V: Venolen)

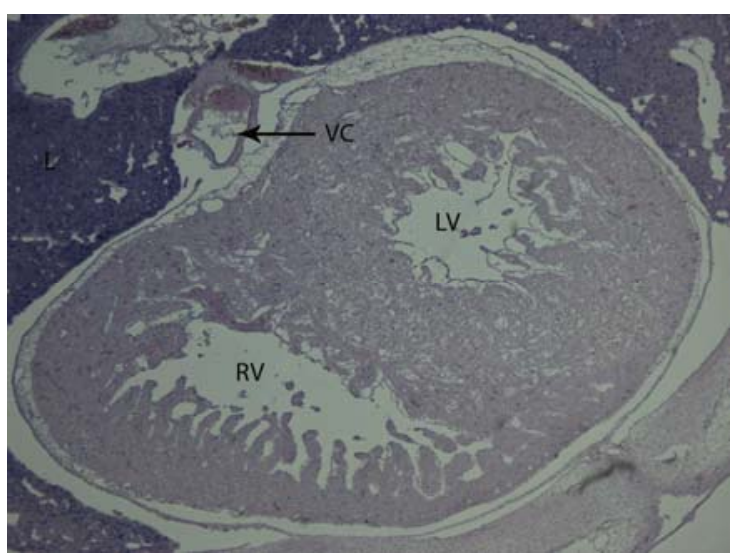

Abbildung 48: Hühnerembryo Tag 10;

Schnitt durch die Ventrikel

Die Abbildung zeigt einen Schnitt durch den linken und rechten Ventrikel. Angrenzend ist die Hexpositive Leber zu sehen. (L: Leberanlage; LV: linker Ventrikel; RV: rechter Ventrikel; VC: Vena cava)

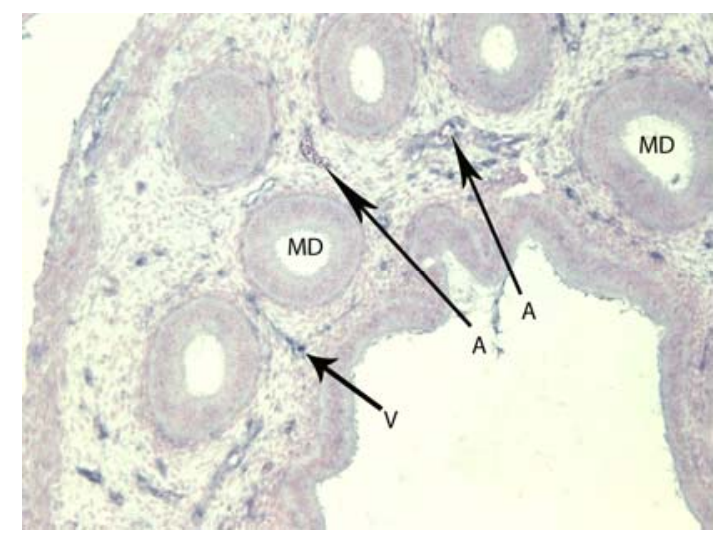

Abbildung 47: Hühnerembryo Tag 10;

Gefäßsystem des Drüsenmagens

Die Vergrößerung aus Abbildung 46 zeigt die HexExpression im mikrovaskulären Gefäßsystem des Drüsenmagens. (A: Arteriolen; MD; Magendrüsen; $\mathrm{V}$ : Venolen)

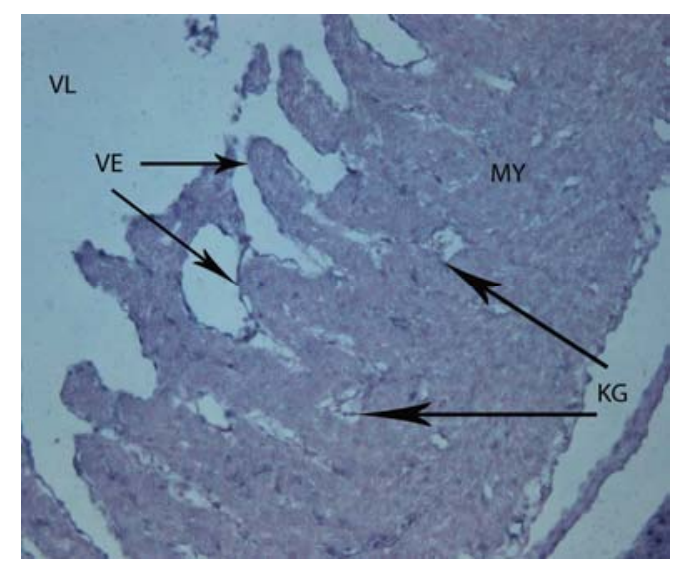

Abbildung 49: Hühnerembryo Tag 10; Übersicht der Herzwand

Die Vergrößerung aus Abbildung 48 zeigt die HexExpression im Ventrikelendokard und im koronaren Gefäßsystem. Das Myokard ist nicht angefärbt. (E: Endokard; KG: koronares Gefäßsystem; MY: Myokard) 


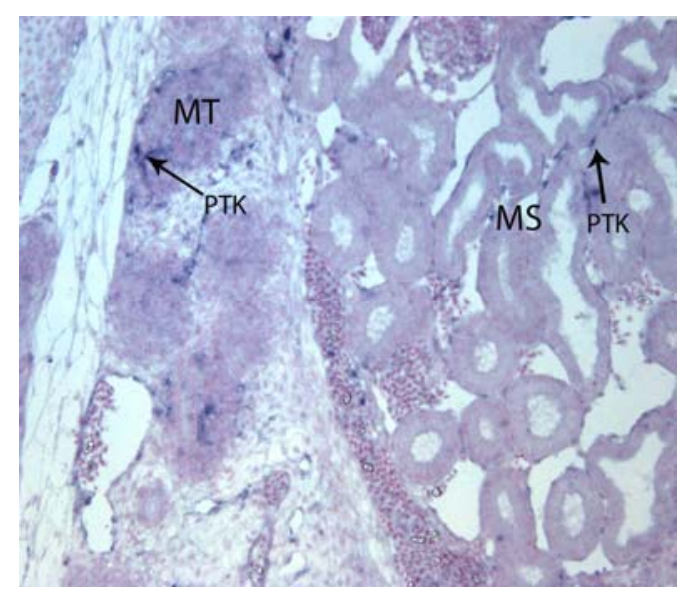

Abbildung 50: Hühnerembryo Tag 10;

Darstellung des Mesonephros und des Metanephros

In der Abbildung erkennt man sowohl im Mesonephros als auch im Metanephros, der Nachniere, die sich dorsal des Mesonephros entwickelt, eine HexExpression im Endothel der peritubulären Gefäße. (MS: Mesonephros; MT: Metanephros; PTK: peritubulären Kapillaren)

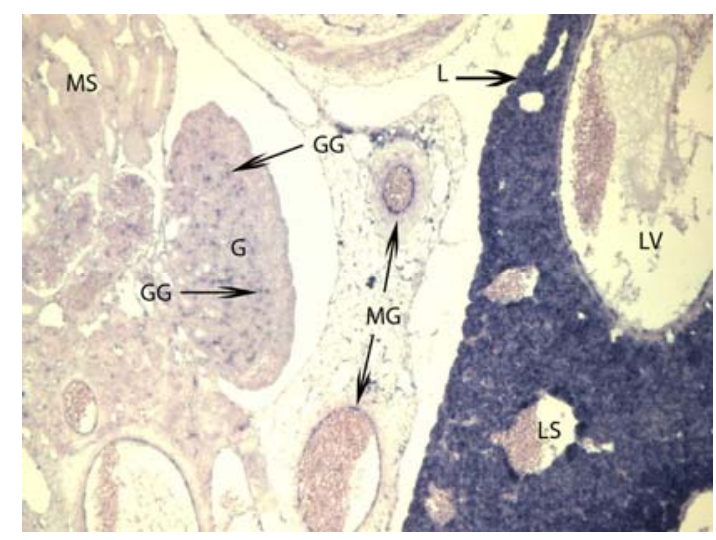

Abbildung 52: Hühnerembryo Tag 10; Gonade

Die Abbildung zeigt eine Hex-Expression im Gefäßsystem der Gonade. Des Weiteren ist die Hex-Expression in den peritubulären Kapillaren des Mesonephros, im Endothel der Mesenterialgefäße und der Lebervene sowie in den Hepatozyten zu erkennen. (G: Gonade; GG: Gefäße in der Gonade; L: Leber; LS: Lebersinus; LV: Lebervene; MG: Mesenterialgefäße; MS: Mesonephros)
Abbildung 51: Hühnerembryo Tag 10;

Nierentubuli mit peritubulären Kapillaren

Die Vergrößerung des Mesonephros aus Abbildung 50 zeigt die Hex-Expression in den peritubulären Kapillaren. (NT: Nierentubulus; PTK: peritubuläre Kapillare) 


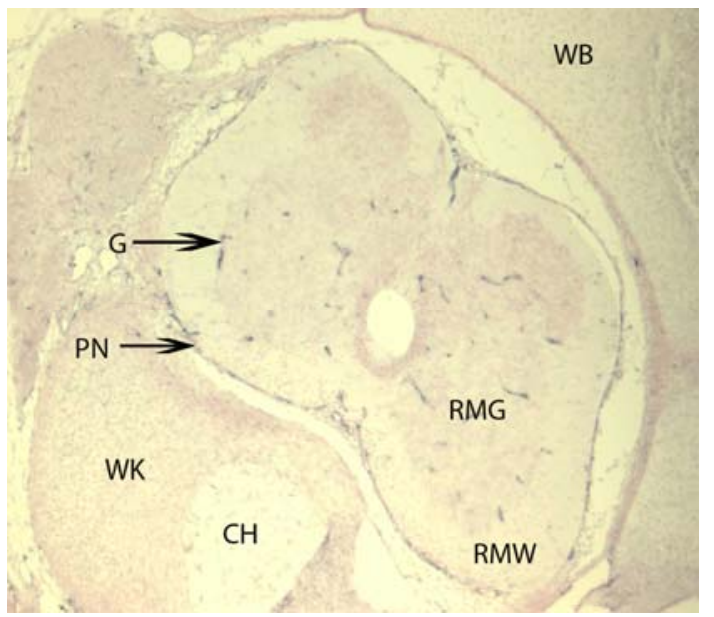

Abbildung 53: Hühnerembryo Tag 10; Perineurales Gefäßsystem und Rückenmark

In dieser Abbildung sieht man die Hex-Expression im perineuralen Gefäßnetz und in Gefäßen des Rückenmarkes, vor allem in der grauen Substanz. (CH: Chorda dorsalis; G: Gefäße im RM; PN: perineurales Gefäßnetz; RMG: Rückenmark, graue Substanz; RMW: Rückenmark, weiße Substanz; WB: Wirbelbogen; WK: Wirbelkörper)

\subsection{Hex im Tumor}

Am 7. Tag nach Tumorwachstum auf der Chorioallantoismembran (Abbildung 54) erkennt man eine vom Embryo ausgehende Vaskularisierung des Tumors. Im Endothel dieses neu gebildeten Gefäßnetzes ist in manchen Bereichen eine Hex-Expression zu finden (Abbildung 55, Abbildung 56, Abbildung 57).

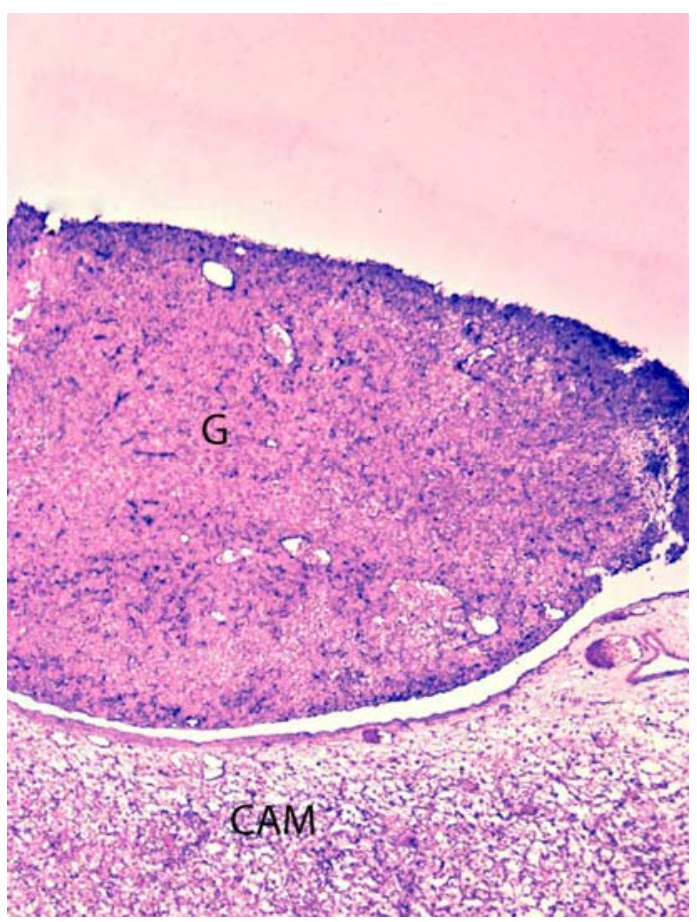

Abbildung 54: Experimentelles Gliom auf der Chorioallantoismembran

Die Abbildung zeigt ein Gliom auf der Chorioallantoismembran eines Hühnchens. (CAM: Chorioallantoismembran; G: Gliom)

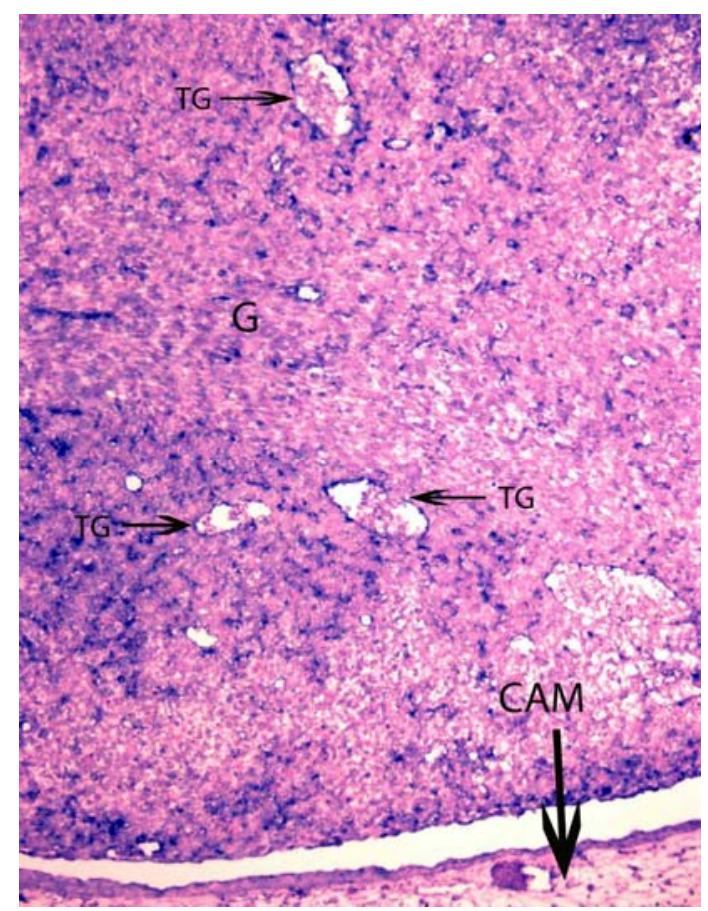

Abbildung 55: Gliom; Vergrößerung aus Abbildung 54

In der Abbildung ist das Gefäßsystem des Gliomtumors dargestellt. In diesem erkennt man eine HexExpression in einigen der Gefäße. (CAM: Chorioallantoismembran; G: Gliom; TG: Tumorgefäße) 


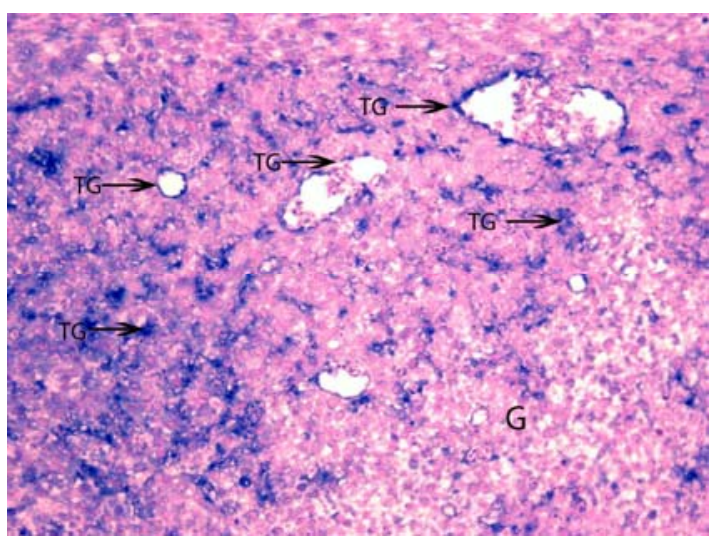

Abbildung 56: Gliom; Vergrößerung aus

Abbildung 55

Die Abbildung zeigt das Gliom mit Gefäßnetz. Man erkennt, dass im Endothel einiger Tumorgefäße Hex exprimiert wird. (G: Gliom; TG: Tumorgefäße)

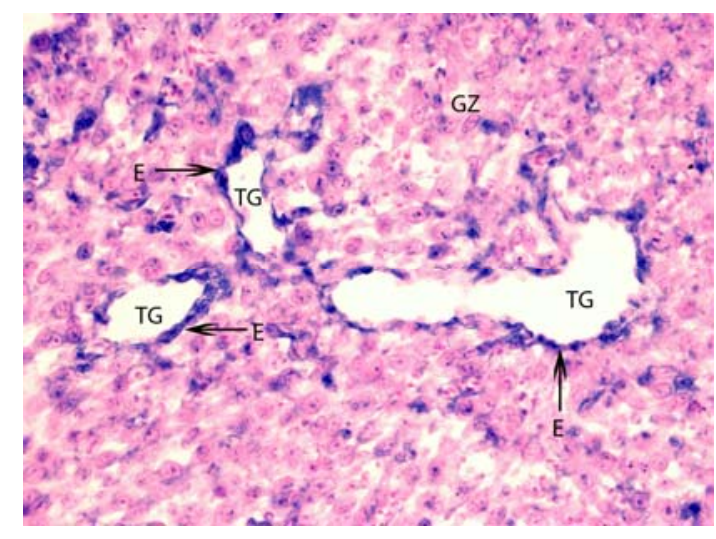

Abbildung 57: Gliom mit Tumorgefäßen; Vergrößerung aus Abbildung 55

Die Abbildung zeigt die Hex-Expression im Endothel der Tumorgefäße. Die Gliomzellen selber sind nicht angefärbt. (E: Endothel der Tumorgefäße; GZ: Gliomzellen; TG: Tumorgefäße)

\section{Diskussion}

Das Gen Hex kodiert für das Prolin-Rich Homeodomain Protein (PRH). Während der Embryogenese wird die Hex-mRNA zuerst in extraembryonalen Geweben detektiert, die an der Bildung der anterior-posterioren Achse und des primitiven Gefäß- und Blutsystems involviert sind. Nach der Gastrulation wird Hex im Embryo selber exprimiert. Zum einen beobachtet man eine Expression in mesodermalen Geweben, aus denen hämatopoetische und vaskuläre Vorläuferzellen sowie das Herzendokard hervorgehen. Zum anderen ist eine Hex-Expression in entodermalen Geweben zu sehen, aus denen sich die Organe Leber, Schilddrüse, Gallenblase und Pankreas bilden (Soufi und Jayaraman, 2008). Die Funktion des Gens ist dabei essentiell für die Entwicklung des definitiven Entoderm, der Leber, der Gl. Thyroidea und des Vorderhirns (Martinez Barbera et al., 2000). Des Weiteren spielt Hex eine Rolle bei der Differenzierung der Hämangioblasten zu definitiven hämatopoetischen Vorläuferzellen (Chan et al., 2006). Fehlexpression des Homeobox-Gens oder veränderte subzelluläre Verteilung ist mit einer Reihe von Krankheiten einschließlich Leukämie und Krebs assoziiert (Soufi und Jayaraman, 2008). Aufgrund seiner klinischen Relevanz habe ich die Expression des Gens bei der Vogelentwicklung und in experimentellen Tumoren untersucht. 


\subsection{Genbeschreibung}

Das Hex-Gen ist beim Haushuhn (Gallus gallus domesticus) auf dem Chromosom 6: 21.873.453-21.876.726 lokalisiert (Ensembl Gen-Datenbank, http://www.ensembl.org, 2009) (Abbildung 58). Das Chromosom 6 ist ein akrozentrisches Chromosom (Smith und Burt, 1998), was bedeutet, dass das Zentromer am Ende liegt und der p-Arm somit sehr klein ist.

\footnotetext{
1 gcggcggcgg tggcagcagc cggcggccgc gctcggggcc gctctccgag gggcagccgg 61 gccgcggggg gccggggagc cgcgccatgc agtatcaggc gccgggcgcg gctccggcgg 121 cggccetggg cgtcggcgtc cctctgtacg cgcccacgcc gctgctgcag cccgcgcacc 181 ccacgccett ctacatcgag gacatcctgg gccgcggecc cgccgccgeg ccggcccccc 241 actccetgcc cgccccgccg ccgccgacgc tgccgtcgcc caactcctcc ttcaccagcc 301 tggtggcccc gtaccggacc cccgtctacg agccgacccc catccaccog gccttctctc 361 accacctcgc cgccacctac ggcaccggcg cttacgccgg gcccetctac tcctttcccc 421 gcgccgtcgg cgactacacg cacgcactga tccgccagga ccccctggga aagccgctgc 481 tgtggagccc cttcatccag cggccgctgc ataagaggaa gggtgggcag gtgcgcttct 541 ccaacgagca gaccatcgag ctggagaaga agttcgagac gcagaaatac ctctccccgc 601 ccgagaggaa gcgcctggcc aagctgctgc agctcagcga gcgccaggtc aaaacgtggt 661 tccagaaccg cagagccaaa tggaggcgac tgaagcagga gaacccccag gccaccaaaa 721 aggaggaggc ggaaggcacc ggcgatcacg gcgaccctcg gtcggagggc agcccagcc 781 ccgcgggggg gggcgaggcc gagccgcagg acagccettc ggccgcctcg caggaggacc 841 ccgagtccga cgtctccgac gactccgacc aggaggtgga catcgagggc gacaaaggct 901 tctacagcgc cacacgctga cggccogcgg gcacggagcc gagctcggct tgcgctgtcc 961 cgggactgcg ggaaggagga ttttatgacg ggagaggacc ttcaccattc cgccgaaaga 1021 caaagaagca cgaacggact cgttctgtaa taatctgaga aagaaaagat attcgttctg 1081 caaacggtcc gtttttttt ggcagatctc tgatttgatt gtagggactg atcggtggtt 1141 tgtatttact gtgtaagatc tgtgtgtatg ttgattggtg ctctgaccgg gacacagcgc 1201 tgtgcccatc tccggctgct ggaaccccc tcttccccag ctcgtgtagt gggggagcac 1261 tgagggcacc accgtgcctt tgtgtgtgcg aacgaatctg ctttaaatgg agtaatttaa 1321 gtgtccttcg caggcagaga aatgtattct gtgccataga gagggattgg agcatccoga 1381 gagtgcctta ccccacccag gacctgcagc tgcatccccc ggaaggatcc cccctcaccg 1441 ggcagaggct gtgggcacgt tccgttttgc tcttgatgga gtgaaatgtc cctcatcgca 1501 ttttggagga ttttgcccca caatctgtgt ggttccattt gcagggaaaa aaaaaaacaa 1561 aacaaaaaca aaaaccaaac acagcaacaa accaacccag gctattttt tccttgacaa 1621 atctgtcgtg ctgtccccca gatttcccat ttcagaagga aatgaggggc tgatagggca 1681 ctgcgaggcg cagtgtgaca gcgggcaccc gtgcctggcg tgtccctctc tgctcgtgta 1741 catagcagtt tgccttaaaa gtctttgcgg ttttatacct cacattgttc atatttgta 1801 catattggtt taaaagaaaa aaaaaaaag gaatcaaaaa ctggt
}

Abbildung 58: Gensequenz des Homeobox-Gens Hex beim Huhn (aus: NCBI Gendatenbank, http://www.ncbi.nlm.nih.gov, 2009)

Die Abbildung zeigt die Basensequenz des Hex-Gens im Huhn. (a: Adenin; c: Cytosin; g: Guanin; t: Thymin) 


\section{Das Protein Hex (PRH)}

Das Protein Hex besteht beim Huhn aus 277 Aminosäuren und ist ein entscheidender Regulator der Embryonalentwicklung. Hex reguliert dabei die Zellproliferation und Differenzierung und ist mitverantwortlich für die Bildung der anterior-posterioren Körperachse, des hämatopoetischen und vaskulären Systems sowie für die Bildung vieler lebenswichtiger Organe (Soufi und Jayaraman, 2008). Hex ist ein Regulator der Transkription und fungiert hierbei über multiple Mechanismen sowohl als Repressor als auch als Aktivator. Außerdem reguliert Hex den nukleären Transport von spezifischen mRNAs und gehört somit zu den Proteinen, die die Genexpression sowohl auf der Ebene der Transkription als auch auf der Ebene der Translation kontrollieren (Soufi und Jayaraman, 2008). Das lösliche Protein Hex enthält ein amino-terminales Ende, eine zentrale Homeodomäne und ein carboxyterminales Ende (Soufi et al., 2006). Es ist gezeigt worden, dass PRH in Zellen Oligomere formt. Anhand der molekularen Masse wird vermutet, dass es sich dabei um Oktamere handelt und dass nur eine bestimmte Oligomerform an die DNA binden kann (Soufi und Jayaraman, 2008). Über die Lokalisation auf subzellulärer Ebene ist bekannt, dass das Hex-Protein sowohl im Zytoplasma als auch im Nukleus zu finden ist, wobei es von Bedeutung ist, in welchem der beiden Kompartimente PRH vorkommt (Ghosh et al., 2000).

\section{Die amino-terminale Domäne}

Die amino-terminale Domäne des PRH-Proteins ist reich an Prolin (20\%), Alanin (15\%) und Glycin (10\%). Das N-terminale Ende bildet in Lösung Dimere, die ihm einige typische Eigenschaften verleihen (Soufi und Jayaraman, 2008). Das amino-terminale Ende führt nach Bindung an die DNA unabhängig von der Homeodomäne zur Repression der Transkription (Soufi et al., 2006). Dabei ist gezeigt worden, dass das amino-terminale Ende mehrere Regionen enthält, die eine Hemmung der Transkription bewirken und dass diese Domäne des PRH-Proteins als Schnittstelle für eine Vielzahl von Protein-Protein Interaktionen dient (Soufi und Jayaraman, 2008). Des Weiteren konnte beobachtet werden, dass das gekürzte PRH-Protein bestehend aus carboxy-terminalem Ende und Homeodomäne eine wesentlich höhere Bindungsaffinität zur DNA aufweist, als das PRH-Protein in seiner vollen Länge. Dies lässt darauf schließen, dass das amino-terminale Ende die HomeodomänDNA Interaktion hemmt (Soufi et al., 2006) 


\section{Die PRH-Homeodomäne}

Die PRH-Homeodomäne umfasst 60 Aminosäuren und besteht aus einem N-terminalem Arm und drei Helices. Der N-terminale Arm und die dritte Helix sind an der Bindung an spezifische DNA Sequenzen beteiligt. Die Homeodomäne ist sehr ähnlich zu der von HOX11, einem Protein, welches in T-Zell Leukämien fehlexprimiert wird. PRH enthält beim Beginn der zweiten Helix in der Homeodomäne zwei aufeinander folgende Prolinreste, was einzigartig für dieses Protein ist (Soufi und Jayaraman, 2008). PRH gehört zur NK (nuclear body-associated kinase) - Subgruppe der Homeodomän Proteine. Diese tragen ein TN (tinman) Motiv am N-terminalen Arm, eine konservierte Dekapeptid-Sequenz, die Homeoproteine besitzen, welche in die Herzentwicklung involviert sind. Die PRHBindungsseite beinhaltet die Sequenz 5'-C/TA/TAAA/G-3'. Die isolierte PRHHomeodomäne bindet an DNA Sequenzen, die 5'-TAAT-3', 5'-CAAG-3' oder 5'ATTAA-3' enthalten. Die PRH-Homeodomäne scheint demnach eine weniger stringente DNA-Bindungsspezifität aufzuweisen als andere Homeodomänen. Wegen der Oligomerisation des PRH-Proteins findet es jedoch seine Zielgene trotz der wenig definierten, kurzen DNA-Erkennungsseite (Soufi und Jayaraman, 2008).

\section{Die carboxy-terminale Domäne}

Die carboxy-terminale Domäne des PRH-Proteins besteht aus fast viermal mehr sauren als basischen Resten und ist, wie bei den meisten Transkriptionsfaktoren, an der Transkriptionsaktivierung beteiligt. Dabei fungiert sie jedoch zusammen mit der PRH-Homeodomäne als Aktivator. Der genaue Aktivierungsmechanismus ist noch nicht bekannt. Dabei könnte die Interaktion der Homeodomäne und des carboxy-terminalem Endes mit anderen Transkriptionsfaktoren wie dem TBP (TATA-box-binding protein) von Bedeutung sein (Soufi und Jayaraman, 2008).

\section{Das Genom des Haushuhns}

Das Genom des Haushuhns besteht aus 38 Autosomenpaaren und den Geschlechtschromosomen, die mit Z und W bezeichnet werden. Im Gegensatz zu den Säugern ist das weibliche Huhn heterogamet und das männliche homogamet. Wie bei anderen Vögeln unterscheiden sich die Chromosomen beim Haushuhn erheblich in ihrer Größe und werden daher als Mikro- und Makrochromosomen beschrieben. Der Karyotyp des Huhns besteht wie bei den meisten Vogelarten aus 8 Makrosomen und 30 Mikrosomen (Smith und Burt, 1998). Die Sequenz deutet darauf hin, dass das kleinere Ausmaß des Vogelgenoms im 
Vergleich zu den Mammaliern hauptsächlich auf dem vergleichsweisen Mangel an repetitiven Elementen beruht (Smith und Burt, 1998). Untersuchungen ergaben, dass das Huhn in jedem diploiden Zellkern 2,5pg DNA besitzt, was einer Größe von 2,4x10 bp im diploiden bzw. 1,2 $\times 10^{9}$ bp im haploiden Chromosomensatz entspricht (Smith und Burt, 1998).

\subsection{Vergleich des Hex-Gens von Huhn und Maus}

Bei der Maus ist das Hex-Gen auf dem Chromosom 19; 19 D1; 1947.5 cM lokalisiert. Das Hex-Protein besteht bei der Maus aus 271 Aminosäuren und hat eine molekulare Masse von 35-37 kDa. Synonyme für das Hex-Gen bei der Maus sind (NCBI Gendatenbank, http//www.ncbi.nlm.nih.gov, 2009):

- Prh

- Prhx

- Hhex-rs2

- Hhex

Die Basensequenzen zeigen beim Haushuhn und bei der Maus eine Übereinstimung von 70\% (Abbildung 59).

\begin{tabular}{|c|c|c|}
\hline Query & 13 & 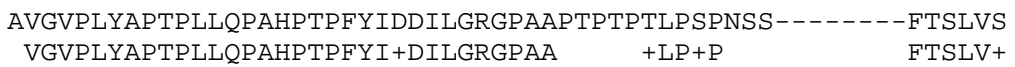 \\
\hline Sbjct & 15 & GVGVPLYAPTPLLQPAHPTPFYIEDILGRGPAAAPAPHSLPAPPPPTLPSPNSSFTSLVA \\
\hline Query & 65 & $\begin{array}{l}\text { SYRTPVYEPTPVHPAFSHHPAAALAAAYGPSGFGGPLYPFPRTVNDYTHALLRHDPLGKP } \\
\text { YRTPVYEPTP+HPAFSHH LAA YG + GPLY FPR V DYTHAL+R DPLGKP }\end{array}$ \\
\hline Sbjct & 75 & PYRTPVYEPTPIHPAFSHH - - - LAATYGTGAYAGPLYSFPRAVGDYTHALIRQDPLGKP \\
\hline Query & 125 & $\begin{array}{l}\text { LLWSPFLQRPLHKRKGGQVRFSNDQTVELEKKFETQKYLSPPERKRLAKMLQLSERQVKT } \\
\text { LLWSPF+QRPLHKRKGGQVRFSN+QT+ELEKKFETQKYLSPPERKRLAK+LQLSERQVKT }\end{array}$ \\
\hline Sbjct & 131 & LLWSPFIQRPLHKRKGGQVRFSNEQTIELEKKFETQKYLSPPERKRLAKLLQLSERQVKT \\
\hline Query & 185 & $\begin{array}{l}\text { WFQNRRAKWRRLKQENPQSNKK-DALDSLDTSCEQGQDLPSEQNKGASLDRSQCSPSPAS } \\
\text { WFQNRRAKWRRLKQENPQ+ KK }+\mathrm{A}+\mathrm{D}++\mathrm{PS} G+\mathrm{Q} \text { SPS AS }\end{array}$ \\
\hline Sbjet & 191 & WFQNRRAKWRRLKQENPQATKKEEAEGTGDHGDPRSEGSPSPAGGGEA - -EPQDSPSAAS \\
\hline Query & 244 & $\begin{array}{l}\text { QEDPDSEISEDSDQEVDIEGDKGYFNA } 270 \\
\text { QEDP+S++S+DSDQEVDIEGDKG+++A }\end{array}$ \\
\hline $\begin{array}{l}\text { Sbjet } \\
\text { Ident }\end{array}$ & $\begin{array}{l}249 \\
\text { itie }\end{array}$ & $\begin{array}{l}\text { QEDPESDVSDDSDQEVDIEGDKGFYSA } 275 \\
S=189 / 267(70 \%)\end{array}$ \\
\hline
\end{tabular}

Abbildung 59: Basensequenzvergleich des Hex-Gens von Maus und Huhn (aus: NCBI Gendatenbank, http//www.ncbi.nlm.nih.gov, BLAST (Basic Local Alignment Search Tool) - Programm, 2009)

Die Abbildung zeigt den Vergleich der Basensequenzen der Maus und des Huhns. Sie weisen eine Übereinstimmung von 70\% (189/267) auf. (Query: Basensequenz der Maus (Mus musculus), 271 Aminosäuren; Subject: Basensequenz des Huhns (Gallus gallus domesticus), 277 Aminosäuren; das + in der mittleren Zeile zeigt ähnliche Aminosäuren). 


\subsubsection{Expressionsmuster von Hex bei der Maus}

Bei der Maus fungiert Hex wie beim Huhn als Repressor und Aktivator der Transkription. Die Hex-Expression beginnt in der Maus bereits am Entwicklungstag 4,5 im primitiven Entoderm der Blastozyste mit einem Expressionsmuster, welches auf eine Funktion in der anterior-posterioren Gestaltbildung deutet. Diese Funktion wird dem Hex-Gen beim Huhn ebenfalls zugesprochen. Am Entwicklungstag 5,5 wird Hex asymmetrisch im Embryo in den Zellen des anterioren viszeralen Entoderms (AVE) exprimiert. Die Hex-Expression im AVE geht dabei der Formation des Primitivstreifens um mindestens 12 Stunden voraus. Die genaue Funktion von Hex im AVE ist dabei noch weitgehend unbekannt (Bogue et al., 2000). Bei der Maus hat das Hex-Gen wie beim Huhn eine Funktion in der Hämatopoese, Vaskulogenese und Herzentwicklung. Hex wird in verschiedenen hämatopoetischen und endothelialen Vorläuferzellen exprimiert und während der terminalen Differenzierung herabreguliert (Cong et al., 2006). Wichtig ist das Hex-Gen dabei für die Differenzierung der Hämangioblasten zu embryonalen hämatopoetischen Vorläuferzellen. Zellanalysen zeigen, dass Hex wie beim Menschen in multipotenten Vorläuferzellen, in B-Lymphozyten und Zellen der myeloischen Reihe, nicht jedoch in Erythrozyten und T-Lymphozyten exprimiert wird (Ghosh et al., 1999). Am Entwicklungstag 7 sind Hex-Transkripte im extraembryonalen Mesoderm in den Zellen der sich bildenden Blutinseln, den Hämangioblasten zu beobachten. Die Hex-Expression in diesen Zellen ist transient und wird bei der Differenzierung zu Endothelzellen herabreguliert. Hex-Expression im Endothel des sich entwickelnden Gefäßsystems lässt sich bereits an den Entwicklungstagen 7,5-8,5 beobachten (Cong et al., 2006). Die Hex-Expression wird dabei wie beim Huhn in Arealen beobachtet, wo sich Gefäße zum einen aus sich verschmelzenden endothelialen Progenitorzellen bilden, wie z.B. bei der dorsalen Aorta, und zum anderen, wo sich Gefäße durch Aussprossung formen, wie z.B. bei den intersomitischen Gefäßen. Man vermutet demnach, dass Hex eine Funktion in den initialen Phasen sowohl der Vaskulogenese als auch der Angiogenese hat. Das endotheliale Expressionsmuster von Hex wird in gleicher Weise beim Huhn beobachtet. (Hallaq et al., 2004). Am Entwicklungstag 8,0 findet man eine Hex-Expression in Endokardzellen der sich entwickelnden Herzschläuche, jedoch nicht in der myokardialen Zellschicht. Die Expression im Endokard persistiert bis zum Entwicklungstag 10,5 (Hallaq et al., 2004) und wird nicht wie in den Hämangioblasten bei der Differenzierung zu Endothelzellen wieder herunterreguliert, so dass man neben der Funktion in endothelialen Vorläuferzellen auch eine separate Funktion in der kardialen Entwicklung annimmt (Hallaq et al., 2004). Eine wichtige Aufgabe des Hex-Gens bei der Herzentwicklung und 
der Vaskulogenese ist, den VEGF-A (vascular endothelial growth factor-A) Spiegel zu senken (Hallaq et al., 2004). Versuche an Mäusen haben gezeigt, dass Hex ein transkriptioneller Repressor von ESM-1 (endothelial cell-specific molecule-1) ist. Das ESM-1 Protein wird in Endothelzellen von Lunge, Niere und Darm exprimiert und ist wichtig für die endotheliale Zellfunktion. ESM-1 wird durch VEGF-A induziert und in Endothelzellen von Tumor-Mikrogefäßen von Mäusen hochreguliert (Cong et al., 2006). Neben der Expression von Hex im kardiovaskulären System, wird wie beim Huhn auch eine Expression des Homeobox-Gens in Organen beobachtet, die sich vom Darmrohrentoderm ableiten. Hex wird im ventralen Darmrohrentoderm bei der frühen Leberentwicklung am Entwicklungstag 8,5 exprimiert (Hunter et al., 2007). Am 10. Entwicklungstag findet man eine Hex-Expression in den entodermalen Zellen der 3. Pharyngealtasche, aus der der Thymus entsteht und in den entodermalen Zellen der Leber, die in das Septum transversum einwandern. Des Weiteren wird in den Zellen der Schilddrüse, in der dorsalen Pankreasknospe und in der Gallenblasenanlage Hex exprimiert (Bogue et al., 2000). Am Entwicklungstag 13,5 ist die Hex-Expression in der Gl. thyroidea, der Leber, den epithelialen Zellen des Pankreas, in den Epithelzellen der extrahepatischen Gallengängen und in den epithelialen und mesenchymalen Zellen der Lunge hoch. Die Hex-Expression im Thymus ist in diesem Stadium deutlich geringer als in den übrigen, genannten Organen (Bogue et al., 2000). Hex-Expression nimmt am Entwicklungstag 16,5 im Vergleich zu den früheren Stadien in allen Organen ab. Sie bleibt jedoch gut nachweisbar im Follikelepithel der Gl. thyroidea, im Epithel der Pankreasgänge, im Gallengangsepithel, im Epithel und Mesenchym der Lunge und im Epithel und Mesenchym der Leber. Die Expression von Hex im Thymus ist kaum noch nachweisbar (Bogue et al., 2000). Am Entwicklungstag 18,5 ist die HexExpression im Epithel der Schilddrüsenfollikel und im Gallengangsepithel noch immer hoch, während die Hex-Expression in der Lunge und auch in der Leber im Vergleich zum Entwicklungstag 16,5 abnimmt. Im Pankreas und im Thymus findet man in diesem Stadium keine Hex-Transkripte mehr (Bogue et al., 2000). In adulten Mäusen ist weiterhin eine Hex-Expression im Follikelepithel der Gl. thyroidea, in epithelialen und mesenchymalen Zellen der Lunge und ubiquitär in der Leber zu beobachten. Man findet keine HexTranskripte in angrenzenden Muskel- oder Knorpelgewebe und keine Hex-Expression im adulten Pankreas und Thymus (Bogue et al., 2000).

In mehreren Studien wurden die Folgen des Fehlens des Hex-Gens bei Mäuseembryonen beschrieben. Am 13,5.-15,5. Entwicklungstag kommt es zum Tod der Embryonen. Es wer- 
den Defekte im Vorderhirn, in der Gl. thyroidea, bei der Monozyten- und Leberentwicklung sowie ein Block in der B-Zellentwicklung beschrieben. Des Weiteren kommt es zu signifikanten Abnormalitäten bei der Vaskulogenese und in der Herzbildung (Cong et al., 2006). $\mathrm{Hex}^{-/-}$Mausembryonen weisen eine fehlende Bildung der Leberknospe auf. Zwar wird in $\mathrm{Hex}^{-/-}$Mäusen die Bildung des hepatischen Divertikulums beschrieben, jedoch ist die Zellproliferation in diesem stark reduziert und somit findet nur eine ungenügende Zellmigration der frühen Hepatoblasten in das umgebende Mesenchym statt. Folglich kommt es zu einem Fehlen der Leberknospe und einer fehlenden Gallenblasenanlage (Hunter et al., 2007). Daraus konnten Hunter et al. (2007) schließen, dass Hex mitverantwortlich für die Delamination und Migration von frühen Hepatoblasten im hepatischen Divertikulum ist. Zur Beurteilung der Frage, ob Hex in den späteren Stadien der Leberentwicklung Funktionen besitzt, wurden genetisch modifizierte $\mathrm{Hex}^{-/-}$Mäuseembryonen untersucht. Hex-Deletion im hepatischen Divertikulum führt zu einer hypoplastischen, zystischen Leber und zum Verlust von HNF4 $\alpha$ und HNF6 (hepatocyte nuclear factor) Expression in den frühen Hepatoblasten. Die Gallenblase fehlte und die extrahepatischen Gallengänge konnten nicht identifiziert werden (Hunter et al., 2007). Hex-Deletion in der embryonalen Leber führt zu einer irregulären Entwicklung der intrahepatischen Gallengänge und zu einem Fehlen von HNF1 $\beta$ in vielen Gallenepithelzellen. Dieses resultierte in einer langsamen Form der polyzystischen Lebererkrankung in adulten Mäusen. Somit konnte gezeigt werden, dass Hex bei Mäusen in verschiedenen Stadien der hepatobiliären Entwicklung erforderlich ist. Die veränderte Expression von HNF4 $\alpha$, HNF6 und HNF1 $\beta$ zeigt, dass Hex eine wichtige Komponente in der genetischen Regulation der Hepatoblastendifferenzierung und der Bildung der intra- und extrahepatischen Gallengänge darstellt (Hunter et al., 2007). Des Weiteren kommt es in Hex ${ }^{-/-}$Mäuseembryonen zu Missbildungen in der Herz- und Gefäßentwicklung. Im Herzen beobachtet man eine Hypoplasie des rechten Ventrikels, übermäßig stark ausgebildete Endokardkissen, Ventrikelseptumdefekte, Anomalien des Ausflusstraktes, eine Dysplasie der AV-Klappe sowie eine aberrante Entwicklung des Myokards (Hallaq et al., 2004). Die übermäßig ausgebildeten Endokardkissen in diesen Mausembryonen sind Folge einer herabgesetzten Apoptose und einer Dysregulation der epithelio-mesenchymalen Transformation (Hallaq et al., 2004). Die Schilddrüse ist in $\mathrm{Hex}^{-/-}$ Mäusen in den frühen Entwicklungsstadien hypoplastisch oder aplastisch und kann bereits am 13. Entwicklungstag nicht mehr beobachtet werden. Am 7. Entwicklungstag sind in $\mathrm{Hex}^{-/-}$Mäusen Defekte im Vorderhirn zu finden (Martinez Barbera et al., 2000). 


\subsection{Vergleich des Hex-Gens von Huhn und Mensch}

Das HHEX-Gen ist beim Menschen (Homo sapiens) auf Chromosom: 10q23.33 lokalisiert. Das HHEX-Protein besteht aus 270 Aminosäuren und hat eine molekulare Masse von $30 \mathrm{kDa}$ (Soufi und Jayaraman, 2008). Synonyme für das HHEX-Gen beim Menschen sind (NCBI Gendatenbank, http//www.ncbi.nlm.nih.gov, 2009):

\section{$-P R H$ \\ - $\mathrm{HMPH}$ \\ - PRHX \\ - HOX11L-PEN}

Die Basensequenz des ganzen Proteins des Haushuhns und die des Menschen zeigen eine Übereinstimung von 73\% (Abbildung 60). Im Bereich der Homeodomäne zeigen sie 97\% Identität. Das Protein ist auch beim Menschen aus drei Domänen aufgebaut: Ein Nterminales, prolin-reiches Ende (Aminosäure 1-136 im menschlichen HHEX-Protein), eine Homeodomäne (Aminosäure 137-196 im menschlichen HHEX-Protein) und ein säurereiches C-terminales Ende (Aminosäure 197-270 im menschlichen HHEX-Protein) (Soufi und Jayaraman, 2008).

\begin{tabular}{|c|c|c|}
\hline Query & 12 & 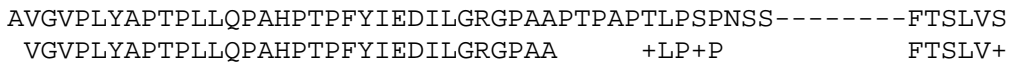 \\
\hline Sbjct & 15 & GVGVPLYAPTPLLQPAHPTPFYIEDILGRGPAAAPAPHSLPAPPPPTLPSPNSSFTSLVA \\
\hline Query & 64 & PYRTPVYEPTPIHPAFSHHSAAALAAAYGPGGFGGPLYPFPRTVNDYTHALLRHDPLGKP \\
\hline Sbjct & 75 & $\begin{array}{l}\text { PYRTPVYEPTPIHPAFSHH } \quad \text { LAA YG G + GPLY FPR V DYTHAL+R DPLGKP } \\
\text { PYRTPVYEPTPIHPAFSHH--- - LAATYGTGAYAGPLYSFPRAVGDYTHALIRQDPLGKP }\end{array}$ \\
\hline Query & 124 & $\begin{array}{l}\text { LLWSPFLQRPLHKRKGGQVRFSNDQTIELEKKFETQKYLSPPERKRLAKMLQLSERQVKT } \\
\text { LLWSPF+QRPLHKRKGGQVRFSN+QTIELEKKFETQKYLSPPERKRLAK+LQLSERQVKT }\end{array}$ \\
\hline Sbjct & 131 & LLWSPFIQRPLHKRKGGQVRFSNEQTIELEKKFETQKYLSPPERKRLAKLLQLSERQVKT \\
\hline Query & 184 & $\begin{array}{l}\text { WFQNRRAKWRRLKQENPQSNKKEELESLDSSCDQRQDLPSEQNKGASLDSSQCSPSPASQ } \\
\begin{array}{llll}\text { WFQNRRAKWRRLKQENPQ+ KKEE E } & \text { D R }+S & G & \text { Q SPS ASQ }\end{array}\end{array}$ \\
\hline Sbjct & 191 & WFQNRRAKWRRLKQENPQATKKEEAEGTGDHGDPRSE - GSPSPAGGGEAEPQDSPSAASQ \\
\hline Query & 244 & $\begin{array}{l}\text { EDLESEISEDSDQEVDIEGDKSYFNA } 269 \\
\text { ED ES++S+DSDQEVDIEGDK }+++A\end{array}$ \\
\hline Sbjct & 250 & EDPESDVSDDSDQEVDIEGDKGFYSA \\
\hline
\end{tabular}

Abbildung 60: Basensequenzvergleich des HHEX-Gens von Mensch und Huhn (aus: NCBI Gendatenbank, http//www.ncbi.nlm.nih.gov, BLAST (Basic Local Alignment Search Tool)- Programm, 2009)

Die Abbildung zeigt den Vergleich der Aminosäuresequenzen beim Menschen und beim Huhn. Sie weisen eine Übereinstimmung von $73 \%$ auf.

(Query: Sequenz des Menschen (Homo sapiens), 270 Aminosäuren; Subject: Sequenz des Huhns (Gallus gallus domesticus), 277 Aminosäuren; das + in der mittleren Zeile zeigt ähnliche Aminosäuren. 


\subsubsection{Expressionsmuster von Hex beim Menschen}

Das Expressionsmuster des Homeobox-Gens HHEX beim Menschen wird in der Literatur weniger detailliert beschrieben, als das Hex-Expressionsmuster bei der Maus und beim Huhn. HHEX-Expression wird in unbefruchteten menschlichen Oozyten und in 2-8 ZellStadien detektiert (Soufi und Jayaraman, 2008). Das Homeobox-Gen wird beim Menschen wie bei allen Vertebraten in der embryonalen Entwicklung benötigt und die HHEXExpression ist essentiell für die Entwicklung des embryonalen Vorderhirns, der Schilddrüse, der Lunge, der Leber und des Herzens. Des Weiteren beobachtet man eine HHEXExpression in der frühen Entwicklung von vaskulärem Gewebe und in der frühen Hämatopoese. In adulten Organen wird HHEX in der Schilddrüse, in der Leber und der Lunge exprimiert. Darüber hinaus hat HHEX eine wichtige Funktion bei der Regulation der adulten Hämatopoese (Soufi und Jayaraman, 2008). Im hämatopoetischen System findet man beim Menschen wie beim Huhn eine HHEX-Expression in B-Zellen und in den Zellen der myeloischen Reihe, jedoch keine Expression in Erythrozyten und in T-Zellen (Ghosh et al., 1999).

\subsection{Vergleich der Ergebnisse des Hex-Expressionsmusters mit anderen Ergebnissen in der Entwicklung}

Die 21-tägige Embryogenese des Hühnchens wurde erstmals durch Keibel und Abraham (1900) in Stadien eingeteilt. Diese Einteilung wurde von Hamburger und Hamilton (1951) übernommen und überarbeitet. Sie legten 46 Stadien in der Hühnerentwicklung fest. Heute existieren nach Starck und Ricklefs (1998) durch Zusammenfassung einiger Entwicklungsstufen 42 Stadien in der embryonalen Hühnerentwicklung. Nach Hamburger und Hamilton (HH) besitzt die Einteilung der Embryogenese nach Stadien anstelle der Inkubationsdauer in Tagen den Vorteil, dass die Embryonen besser vergleichbar sind. Nach Starck und Ricklefs (1998) kann man vier große Abschnitte in der Embryonalentwicklung von Vögeln einteilen:

\section{Entwicklungsstadium 1:}

Dieses Stadium bezieht sich auf die Frühentwicklung des Vogelembryos und reicht von der ersten Furchungsteilung bis zum Erreichen der Körpergrundgestalt (HH-Stadien 1-22).

Entwicklungsstadium 2:

In dieser Phase kommt es zur Ausbildung der Organstrukturen. Außerdem finden erste Gewebedifferenzierungen statt (HH-Stadien 23-33). 
Entwicklungsstadium 3:

Die zunehmende Organdifferenzierung ist das wichtigste Merkmal dieser Phase (HHStadien 34-38).

Entwicklungsstadium 4:

Im letzten Stadium finden Wachstum und Ausreifung statt (HH-Stadien 39-42).

\section{Die Frühentwicklung des Hühnerembryos}

Die Entwicklung des Huhns vom befruchteten Ei bis zum schlupfreifen Küken vollzieht sich in 21 Tagen (Bellairs \& Osmond, 2005). Dabei sind im Hühnerei alle zur embryonalen Entwicklung nötigen Stoffe, wie Nährstoffe und Wasser vorhanden. Lediglich der Sauerstoff und Wärme dringen durch die Kalkschale ein. Der Eidotter entspricht beim Hühnchen der Eizelle, die Vitellinmembran oder Dottermembran, die den Dotter umgibt, der Zona pellucida. Das Eiweiß und die Kalkschale lagern sich erst nach der Wanderung durch den Eileiter an (Drews, 2006). Während der Furchung bildet sich unter der Vitellinmembran der Keimfleck, in dem sich die Furchungsteilungen vollziehen. Die Area pellucida ist der Bereich, in dem Keimscheibe und Vitellinmembran nicht miteinander verwachsen sind, während die Area opaca den Bereich mit festem Kontakt zwischen Keimscheibe und Vitellinmembran darstellt. Bereits vor Bebrütung haben sich innerhalb der Keimscheibe der obere, epitheliale Epiblast und der untere Hypoblast gebildet. Der Primitivstreifen, welcher sich während der Bebrütung nach kranial verlängert, gibt die Lage der späteren Körperachse an. Hier schieben sich Zellen aus dem Epithelverband des Epiblasten nach medial und bilden das definitive Mesoderm und Entoderm. Am kranialen Ende des Primitivstreifens befindet sich der Primitivknoten, der die Organisation des Mesoderms in Chorda, Somiten und Seitenplatten induziert. Das Mesoderm gliedert sich in ein parietales, äußeres und ein viszerales, inneres Blatt. Das Chorion, das als extraembryonale Membran aus Mesoderm und Ektoderm besteht, ist gefäßfrei und wird erst durch Verschmelzung mit der Allantois zur gefäßreichen Chorioallantoismembran, dem Atmungs- und Entsorgungsorgan des Embryos (Drews, 2006).

\subsubsection{Hex in der Leber, im Gallengangssystem und im Pankreas}

Die Entwicklung der Leber lässt sich in mehrere Prozesse gliedern: Die hepatische Induktion im Entoderm des Darmrohrs, die Anordnung der hepatischen Anlage sowie die Proliferation und Reifung der Hepatozyten und Formation der intrahepatischen Gallengänge (Romanoff, 1960). Die Leber wird aus entodermalen und mesodermalen Strukturen im Bereich der Leberbucht, dem Leberdivertikel, gebildet. Die Kupferschen Sternzellen, die 
Zellen der Hämatopoese und die bindegewebigen Anteile der Leber leiten sich vom Mesoderm ab. Im kaudalen Bereich der Leberbucht bildet sich durch Abschnürung aus dem Darmrohr der Ductus hepaticus und der Ductus choledochus sowie Gallenblase und Ductus cysticus (Drews, 2006). Die extrahepatischen Gallengänge leiten sich vom proximalen Teil des Leberdivertikels ab, während die intrahepatischen Gallengänge aus dem distalen Teil stammen (Masaaki et al., 2005). Das Pankreas entwickelt aus einem dorsalen Anteil aus der hinteren Darmwand und zwei ventralen Anlagen nahe des Leberdivertikels. Ab dem Tag 6 fusionieren diese drei Pankreasanlagen (Bellairs \& Osmond, 2005).

Masaaki et al. (2005) untersuchten das Expressionsmuster von Hex an whole-mountHühnerembryonen in der Leber, im Pankreas, in der Gallenblase sowie in den intra- und extrahepatischen Gallengängen in verschieden Stadien der Hühnchenentwicklung. Sie zeigten, dass Hex ab dem HH-Stadium 17 in der Leberknospe und ab dem HH-Stadium 42 in der ventralen Pankreasknospe exprimiert wird. Bei der Entwicklung der Gallengänge ist Hex ab dem Stadium 25 in den extrahepatischen Gallengängen und in dem Ductus cysticus nachweisbar. Im HH-Stadium 39 nimmt das Hex-Signal auch in den intrahepatischen Gallengängen zu. Im Stadium 42 ist Hex-mRNA vor allem im Gallenblasenepithel und in den extrahepatischen Gallengängen ist zu beobachten (Masaaki et al., 2005).

Bislang sind noch viele Zielgene und Funktionen von Hex in der Leber unbekannt. Einige Angriffspunkte des Homeobox-Gens konnten jedoch bereits identifiziert werden. Tanaka et al. (2005) zeigten, dass Hex zur Leberdifferenzierung beiträgt, indem das Gen funktionell mit HNF1 $\alpha$ interagiert. HNF1 $\alpha$ ist ein wichtiger Transkriptionsfaktor für die Leberdifferenzierung. Die Stimulation von HNF1 $\alpha$ ist auf die Homeodomäne und das carboxyterminale Ende von Hex mit der POU-Homeodomäne von HNF1 $\alpha$ zurückzuführen. HNF1 $\alpha$ aktiviert den Promotor der L-Typ Pyruvatkinase, sodass eine Überexpression von Hex in Hepatozyten zu einer Stimulation der L-Typ Pyruvatkinase führt (Tanaka et al., 2005). Zhang et al. untersuchten 2004 die Regulierung der Hex-Expression im zukünftigem Leberbereich des Huhns, dem anterioren lateralen Entoderm. Sie fanden heraus, dass hier die Expression von BMP (Bone morphogenetic protein) mit dem Bereich der HexExpression übereinstimmt und zeigten anschließend, dass im anterioren lateralen Entoderm zur Hex-Expression BMP Signale benötigt werden (Zhang et al., 2004). Des Weiteren konnte im Gallengangssystem ein leberspezifischer $\mathrm{Na}^{+}$-Gallensäure Kotransporter (ntcp) als Ziel des Transkriptionsfaktors Hex identifiziert werden. Dieser Kotransporter hält den 
Gallefluss aufrecht und der Promotor des Gens wird durch Hex reguliert (Denson et al., 2000). Experimente an Mäusen zeigten, dass das Fehlen des Homeobox-Gens Hex wegen fehlender Leberbildung zum Tod des Embryos führt. Es wird zwar eine leberähnliche Knospe angelegt, jedoch wandern keine Hepatoblasten in das Mesoderm des Septum transversum ein (Martinez Barbera et al., 2000). Verschiedene HNF (hepatocyte nuclear factors), die in die Hepatozytendifferenzierung involviert sind, wurden reduziert vorgefunden. Dies deutet darauf hin, dass Hex eine wesentliche Rolle in Vorläuferzellen für das hepatische Entoderm spielt (Keng et al., 2000). Somit wurde Hex als eines der ersten Markergene für eine normale Leberentwicklung identifiziert. Hunter et al. (2007) untersuchten an Mäusen, welche Rolle Hex in späteren Stadien der Leber- und Gallengangsentwicklung spielt. Sie stellten fest, dass eine Hex-Deletion im Leberdivertikulum an Tag 2/3 zum embryonalen Tod und einer kleinen zystischen Leber mit dem Verlust von HNF4 $\alpha$ - und HNF6Expression in den frühen Hepatoblasten führte. Des Weiteren fehlte die Gallenblase, die extrahepatischen Gallengänge konnten nicht identifiziert werden und die intrahepatischen Gallengänge waren irregulär angelegt. Folglich konnte gezeigt werden, dass Hex in Mäusen in mehreren Stadien der hepatobiliären Entwicklung benötigt wird (Hunter et al., 2007). In $\mathrm{Hex}^{-/-}$Embryonen zeigt sich bei offensichtlich unbeeinflusster Genregulation des Pankreas eine Fehlentwicklung der ventralen Pankreasmorphologie. Hex beeinflusst die Pankreasentwicklung, indem das Gen die Proliferation von entodermalen Vorläuferzellen und folglich deren Positionierung reguliert und nicht wie in vielen anderen Organen die gewebeabhängige Genexpression reguliert (Bort et al. 2004). Die Hex-Expression bleibt im adulten Pankreas erhalten, so dass vermutet wird, dass das Gen zusätzliche Funktionen in differenzierten Pankreaszellen hat.

In dieser Arbeit konnte mittels ISH ebenfalls gezeigt werden, dass Hex im HH-Stadium 17 in der Leber von Hühnerembryonen exprimiert wird. Am 3. Entwicklungstag wurde das Entoderm der Leberanlage am Übergang zum Vorderdarm gezeigt, wo eindeutig die Hexpositive entodermale Leberkomponente im Gegensatz zum Hex-negativen Vorderdarm dargestellt ist. Diese Ergebnisse des hepatischen Hex-Epressionsmusters stimmen in der Leber demnach mit denen von Masaaki et al. (2005) überein. Die Hex-Expression bleibt bis zum untersuchten 10. Entwicklungstag in den Hepatozyten erhalten und ist auch im Endothel der Lebersinusoide und der Lebervenen, aber nicht in der glatten Muskulatur nachweisbar. 


\subsubsection{Hex im Gefäßsystem}

Blutgefäße werden aus einer Schicht Endothelzellen, aus Perizyten, Fibrozyten und einer oder mehreren Lagen von glatten Muskelzellen gebildet. Letztere variieren abhängig vom Gefäßtyp (Arterie oder Vene) und von der Gefäßgröße. Intra- und extraembryonale Gefäße werden durch Vaskulogenese und Angiogenese gebildet. Extraembryonal entstehen Blutinseln. Hierbei werden die peripheren Zellen jeder Blutinsel zum Endothel, während sich zentral Stammzellen der Hämatopoese befinden, deren Tochterzellen sich zu Erythrozyten entwickeln. Benachbarte Blutinseln fusionieren miteinander und bilden einen Gefäßplexus, indem Zellkolonnen aussprießen und Kanäle formen (Bellairs \& Osmond, 2005). Die meisten intraembryonalen Blutgefäße bilden sich hingegen auf dem Weg der Vaskulogenese. Endotheliale Vorläuferzellen, die Angioblasten, entwickeln sich hier unabhängig von den hämatopoetischen Zellen zu Endothelzellen und bilden erste primitive Kapillarnetze (Bellairs \& Osmond, 2005). Diese bilden später durch differenziertes Wachstum und Aussprossung ausgereifte Gefäße. Die Endothelzellen induzieren eine Differenzierung von Mesenchymzellen zu glatten Muskelzellen und Perizyten. Die endothelialen Vorläuferzellen leiten sich hauptsächlich vom Splanchnopleuramesoderm ab (Hallaq et al. 2004).

Hex spielt eine wichtige Rolle bei der Entwicklung des Gefäßsystems. Die Entstehung der Blutgefäße verläuft bei $\mathrm{Hex}^{-/-}$Mausembryonen bis zum 8. Entwicklungstag normal, so dass eine normale Angioblastenmigration sowie ihre Differenzierung zu Endothelzellen und die Bildung der ersten Kapillarplexus bei Abwesenheit des Hex-Gens angenommen werden kann (Hallaq et al., 2004). Die ersten Veränderungen im Gefäßsystem werden ab dem 10. Entwicklungstag bei der Maus sichtbar. Die Gefäße haben eine regelrechte Endothelzellschicht, erscheinen jedoch im gesamten Embryo vergrößert und unorganisiert. Somit kann Hex nicht wie angenommen für die Differenzierung von Endothelzellen verantworlich sein, sondern ist notwendig für die Stabilisierung und Umgestaltung der Gefäße. Des Weiteren zeigen $\mathrm{Hex}^{-/-}$Mausembryonen im Gegensatz zu Hex ${ }^{+/+}$-Embryonen eine verminderte oder fehlende Bildung der glatten Gefäßmuskelzellen im kranialen Gefäßsystem, in der dorsalen Aorta, in den intersomitischen Gefäßen und in den Schlundbogengefäßen (Hallaq et al., 2004). Hex wird darüber hinaus als ein negativer Regulator von vaskulogeneseabhängigen Genen beschrieben, was sich durch stark erhöhte Mengen von VEGFmRNA in Gefäßen von $\mathrm{Hex}^{-/-}$Embryonen erklären lässt. Es wird jedoch davon ausgegangen, dass sowohl eine erhöhte als auch eine verminderte Expression des Hex-Gens in gleicher Weise wirkt (Guo et al., 2003). Der Zusammenhang zwischen erhöhten VEGF-A- 
Spiegeln und den beobachteten Gefäßmalformationen ist gut belegt. Zusätzlich beeinflusst VEGF-A die Entwicklung von vaskulären Vorläuferzellen. Somit kann vermutet werden, dass die vaskulären Anomalien in $\mathrm{Hex}^{-/}$Embryonen zum Teil durch erhöhtes VEGF-A hervorgerufen werden (Yamashita et al., 2000). Die Interaktion von Hex mit VEGF-A könnte ein wichtiger Ansatz einer therapeutischen Kontrolle der Vaskulogenese sein (Hallaq et al., 2004).

Ich konnte im Hühnerembryo ab dem 3. Entwicklungstag ebenfalls eine Hex-Expression in der Aorta, in den intersomitischen Gefäßen und in den Viszeralbogenarterien nachweisen. Dies lässt vermuten, dass Hex in diesen Gefäßen im Huhn ähnliche Funktionen hat wie die von Hallaq et al. (2004) herausgestellten Funktionen von Hex in der Maus. Auffällig in meinen Ergebnissen ist die starke Hex-Expression in der Ausflussbahn des Herzens, wo die Teilung in Aorta und Truncus pulmonalis stattfindet sowie die Expression im koronaren Gefäßsystem. Endothelzellen von Gefäßen stammen vom Mesoderm ab. Die glatten Muskelzellen und Perizyten hingegen sind je nach Körperregion unterschiedlicher Herkunft. Die Gefäßmuskelzellen des Vorderhirns, des Gesichts, des Nackens und des Truncus arteriosus leiten sich von der zephalen Neuralleiste ab (Le Lièvre \& Le Douarin, 1975), während die Gefäßmuskelzellen im Herzen und die des Septums, welches die Aorta vom Truncus pulmonales trennt, sowie die Gefäßmuskelzellen der proximalen kardialen Arterien von der kardialen Neuralleiste stammen (Pouget et al., 2006). Es könnte somit ein Zusammenhang zwischen den einwandernden Neuralleistenzellen und der Hex-Expression in den entsprechenden Gefäßen bestehen. In Gefäßen, deren Gefäßmuskelzellen und Perizyten aus der zephalen Neuralleiste einwandern, konnte ich nämlich im Gegensatz zu den übrigen Gefäßen keine Hex-Expression zeigen. Des Weiteren habe ich eine HexExpression in Gefäßen verschiedener Organanlagen beobachtet. Dazu gehören die peritubulären Kapillaren im Mesonephros ab dem 5. Entwicklungstag und auch im Metanephros ab dem 10. Entwicklungstag. Außerdem konnte ich Hex-Expression im Gefäßsystem des Drüsenmagens, der Gonaden, und im Rückenmark beobachten. Sowohl in Venen als auch in Arterien habe ich am 10. Entwicklungstag gezeigt, dass die Hex-Expression nur im Endothel und nicht in der Media zu finden ist. Quantitativ ist die Hex-Expression in beiden Gefäßtypen ähnlich. Das Gen scheint daher keine wesentliche Funktion bei der Differenzierung zu Arterien und Venen zu spielen. 


\section{Die Lymphgefäße}

Die Entwicklung des lymphatischen Systems beginnt im Hühnerembryo später als die der Blutgefäße. Während die ersten Blutgefäße im Embryo bereits am ersten Tag nach Inkubation sichtbar werden (Pardanaud et al., 1987), zeigen sich die ersten lymphatischen Endothelzellen erst am 5. Entwicklungstag (Clark \& Clark, 1920). Vorläuferzellen des lymphatischen Systems können hingegen mittels spezifischen Markermolekülen schon am 3.5. Tag identifiziert werden (Wilting et al., 2007). Es wurde gezeigt, dass sowohl intra- als auch extraembryonale Blutgefäße beim Vogelembryo von Lymphgefäßen begleitet werden (Wilting et al., 2000a). Das lymphatische System leitet sich zum einen von den Lymphsäckchen und zum anderen von mesenchymalen Lymphangioblasten ab (Wilting et al., 2001). Die Lymphangioblasten sind schon lange vor der Bildung der Lymphsäckchen vorhanden und wandern von den Somiten in die Somatopleura ein (Bellairs \& Osmond, 2005). Im Gegensatz zu Venen und der Aorta sind die Lymphsäckchen unregelmäßig geformt, enthalten keine Schicht aus glatter Muskulatur und exprimieren die Vascular Endothelial Growth Factor Rezeptoren (VEGFR) -2 und -3 (Schneider et al., 1999).

In meinen Untersuchungen konnte ich keine sichere Aussage zur Hex-Expression im Lymphendothel machen. Dabei ist zu bedenken, dass Lymphendothelzellen extrem dünn sind und somit eine mRNA-Expression im Zytoplasma nur sehr schwer nachweisbar ist. Am 10. Entwicklungstag kann in manchen Lymphgefäßen ein leichtes Hex-Signal beobachtet werden, in anderen Lymphgefäßen hingegen ist kein Hex-Signal zu finden. Die nur in manchen Lymphgefäßen vorhandene schwache Hex-Expression könnte durch technische Limitation bedingt sein oder im Zusammenhang mit der Entstehung des lymphatischen Systems aus Lymphsäckchen bzw. Lymphangioblasten stehen. In der Literatur ist bislang noch keine Hex-Expression im Lymphendothel beschrieben worden.

\subsubsection{Hex im hämatopoetischen System}

\section{Hämatopoese und hämatopoetische Stammzellen}

Die Hämatopoese beschreibt den in den blutbildenden Organen ablaufenden zellulären Teilungs- und Differenzierungsvorgang, der die Blutzellen hervorbringt. Dabei ist die pluripotente undifferenzierte hämatopoetische Stammzelle die Ausgangszelle. Hämatopoetische Stammzellen werden als Zellen definiert, die sowohl in der Lage sind zu differenzieren als auch sich uneingeschränkt selbst zu erneuern (Siminovitch et al., 1964). Die hämatopoetischen Zellen leiten sich vom mesodermalem Keimblatt ab. Bei der Hünchenentwicklung findet Hämatopoese sowohl intraembryonal als auch extraembryonal statt. Kurz 
nach der Gastrulation werden die ersten primitiven Erythrozyten in den Blutinseln des Dottersacks beobachtet und außerdem wird Blutbildung in der Allantois sichtbar. Anschließend werden hämatopoetische Zellen im intraembryonalen Mesoderm um die dorsale Aorta gefunden und danach in anderen sekundären Geweben wie im Mesonephros, in der Leber und im Knochenmark (Durand \& Dzierzak, 2005). Diese zweite Erythrozytenreihe der embryonalen Entwicklung wird ab dem Tag 5 in embryonalen Organen gebildet (Bellairs \& Osmond, 2005). Die Stammzellen können im Mesenchym entlang der thorakalen und abdominellen Aorta gefunden werden, bevor sie die Leber und das Knochenmark zur Blutbildung besiedeln. Ab dem 10. Tag nach Inkubation findet Blutbildung in der Milz statt, obwohl hier schon ab dem 4. Tag hämatopoetische Zellen vorhanden sind (Bellairs \& Osmond, 2005).

Die ersten Blut- und Endothelzellen bilden sich in Blutinseln im extraembryonalen Mesoderm des Dottersacks. Die eng assoziierte Entwicklung führte 1920 erstmals zu der Hypothese, dass die Endothelzellen und die hämatopoetischen Zellen von einem gemeinsamen Vorläufer, dem Hämangioblasten, abstammen (Sabin, 1920). Die Hypothese wurde durch die Tatsache unterstützt, dass in Endothelzellen und hämatopoetischen Zellen eine Vielzahl der exprimierten Gene wie zum Beispiel VEGFR-2 und die Tyrosinkinasen Tie1 und Tie2 identisch sind (Yano et al., 1997). Die Existenz eines Hämangioblasten wird außerdem durch die Zebrafischmutante cloche unterstützt. Hier konnte gezeigt werden, dass durch knock-out des Gens cloche sowohl die Differenzierung von Endothelzellen als auch die der hämatopoetischen Zellen verhindert wird (Stainier et al., 1995). In in-vitro-Experimenten zeigte man eine gemeinsame Ursprungszelle mit Hilfe der Embryoid Bodies (EB). EB sind dreidimensionale Strukturen aus embryonalen Stammzellen, in denen verschiedene Zelltypen, wie hämatopoetische Zellen, neuronale Zellen, Muskelzellen und andere Zellen ausdifferenzieren können (Keller, 1995). Die Vorgänge in den EB spiegeln die natürlichen Entwicklungsabläufe im Dottersack wieder. In den EB wurde eine Zellpopulation, die Blastenkolonie-bildenden Zellen (BL-CFC), identifiziert, die die Charakteristika eines Hämangioblasten aufweist (Huber et al., 2004). Genanalysen haben gezeigt, dass die BLCFC unter anderem die Gene CD34 und VEGFR-2 exprimieren, die sowohl auf hämatopoetischen Zellen als auch auf Endothelzellen zu finden sind (Kennedy et al., 1997). Zudem konnte bewiesen werden, dass sich aus den BL-CFC durch Zugabe von hämatopoetischen bzw. endothelialen Wachstumsfaktoren primitive definierte hämatopoetische Zellen bzw. Endothelvorläuferzellen entwickeln (Choi et al., 1998; Kennedy et al., 1997). Die En- 
dothelzellen, die sich aus den Blastenkolonien gebildet hatten, waren adhärent und wurden mittels charakteristischer Marker detektiert (Choi et al., 1998). Die hämatopoetischen Zellen blieben in Suspension und konnten mittels spezfischer Genexpression identifiziert werden. Mit Hilfe kinetischer Analysen zeigte man, dass die BL-CFC eine transiente Zellpopulation in EB darstellt, die sich früh entwickelt und schnell wieder verschwindet (Choi et al., 1998). Alle diese Ergebnisse sprechen dafür, dass es sich bei den BL-CFC um den lange gesuchten Hämangioblasten handelt (Choi et al., 1998). Primitive Erythrozyten der fetalen Hämatopoese differenzieren sich somit im Dottersack aus Hämangioblasten. Differenzierte Blutzellen aller Zellreihen entwickeln sich aus hämatopoetischen Stammzellen, die das Knochenmark besiedeln. Dieses wird oft als adulte oder definitive Hämatopoese bezeichnet (Speck \& Gilliland, 2002). Die genetischen Kaskaden der Differenzierung vom Hämangioblasten in hämatopoetische Zellen und Endothelzellen sind noch weitgehend ungeklärt (Guo et al., 2003).

\section{$\underline{\text { Hex in der Hämatopoese }}$}

Homeobox-Gene spielen in der Hämatopoese eine wichtige Rolle und ihre Expression wird strikt reguliert. Sowohl die Gruppe der HOX-Gene als auch die der Non-HOX-Gene sind an der Hämatopoese beteiligt. HOX-Gene der Cluster A, B und C werden in unreifen CD34 ${ }^{+}$Progenitorzellen exprimiert, während HOX-Gene des Clusters D in diesem Progenitorpool nicht zu finden sind (Buske \& Humphries, 2000). Im reifen Kompartiment fehlt die Expression von HOX-Genen oder ist deutlich herunterreguliert (Giampaolo et al., 1995; Lawrence et al., 1996). Dies deutet darauf hin, dass HOX-Gene eine größere Rolle in primitiven hämatopoetischen Zellen spielen.

Die Funktion des Hex-Gens bei der Hämatopoese ist Gegenstand vieler Untersuchungen. Dabei konnte gezeigt werden, dass das Gen nicht für die Entwicklung der Hämangioblasten, jedoch dosisabhängig für die Differenzierung der Zellen zu definitiven hämatopoetischen Vorläuferzellen wichtig ist (Chan et al., 2006). Hex steuert die Stammzelldifferenzierung in verschiedenen Entwicklungsstadien, wobei die Aktivität zwischen Aktivierung und Suppression variiert (Kubo et al., 2005). Kubo et al. (2005) untersuchten die Rolle von Hex in der hämangioblatischen, hämatopoetischen und endothelialen Entwicklung in $\mathrm{Hex}^{-/-}$ EB (embryoid bodies). BL-CFC/Hämangioblasten und Endothelzellen werden in $\mathrm{Hex}^{-/-} \mathrm{EB}$ am 4. bzw. 6. Entwicklungstag in einer erhöhten Zahl vorgefunden. MakrophagenVorläuferzellen und multipotente Vorläuferzellen zeigen hingegen in $\mathrm{Hex}^{-/-} \mathrm{EB}$ an den 
folgenden Entwicklungstagen herabgesetzte Zellzahlen. Primitive Erythrozytenvorläufer bleiben unbeeinflusst (Kubo et al., 2005). Eine herabgesetzte Zahl von Hämangioblasten in Hex-überexprimierten EB weist darauf hin, dass Hex als negativer Regulator der Hämangioblastentwicklung fungiert und wichtig für die Anzahl dieser Vorläufer in vivo ist (Kubo et al., 2005). Außerdem konnten Kubo et al. (2005) in Hex ${ }^{-/-}$EB im Vergleich zu Wildtyp EB ein reduziertes Proliferationspotential von Endothelzellen nachweisen. Vorherige Studien zeigten bereits die große Bedeutung von Hex bei der Entwicklung und Reifung der Endothelzelllinie, wobei seine exakte Rolle hierbei noch immer kontrovers ist (Kubo et al. 2005). Guo et al. (2003) fanden aber in $\mathrm{Hex}^{-/-}$Embryoid Bodies eine niedrigere Anzahl von Gefäßendothelzellen. Diese Diskrepanzen könnten die verschiedenen Funktionen des Homeobox-Gens in den verschiedenen Stadien der Gefäßentwicklung reflektieren (Kubo et al., 2005). Hex könnte initial eine Funktion als Repressor der endothelialen Entwicklung und Proliferation besitzen. Möglicherweise stellt dies einen Mechanismus dar, um die Balance zwischen Endothelzellen und glatten Muskelzellen der Gefäße zu gewährleisten. In späteren Stadien könnte Hex dann jedoch eine Rolle als positiver Regulator der Endothelzellreifung und Organisation annehmen, so wie es die Versuche von Guo et al. (2003) zeigten. Des Weiteren konnte in den Versuchen von Kubo et al. (2005) gezeigt werden, dass Hex für die Etablierung einer normalen Zahl von Makrophagen-Vorläufern und multipotenten Vorläufern benötigt wird, was man dem Anstieg dieser Zelllinien in $\mathrm{Hex}^{-/-} \mathrm{EB}$ entnehmen kann. Die primitiven Erythrozyten bilden sich in $\mathrm{Hex}^{-/-} \mathrm{EB}$ unverändert im Vergleich zu Hex-Wildtyp EB. Dies deutet darauf hin, dass Hex nicht auf die primitiven Erythrozyten wirkt (Kubo et al., 2005). Dass die primitive Hämatopoese in $\mathrm{Hex}^{-/-} \mathrm{EB}$ unbeeinflusst bleibt, wurde bereits von Guo et el. (2003) dargestellt. Demnach sei Hex nur dosisabhängig für die Transition des definitiven Hämangioblasten zu definitiven hämatopoetischen Stammzellen notwendig (Guo et al., 2003).

Hex wird in den Zellen der myeloischen Reihe sowie in B-Zellen exprimiert, jedoch nicht in T-Zellen (Manfioletti et al., 1995). Folglich scheint die Herunterregulation von Hex ein frühes Ereignis in der T-Zellentwicklung zu sein, kurz nachdem sich die lymphatischen Vorläufer in die B-Zell und T-Zell Linien aufteilen (Manfioletti et al., 1995). Es wurde gezeigt, dass für eine normale T-Zellentwicklung nicht nur die Hochregulation von lymphoidspezifischen Transkriptionsfaktoren von Bedeutung ist, sondern auch die gleichzeitige Herunterregulation von myeloidspezifischen Transkriptionsfaktoren wie Hex (Mack et al., 2002). Hex besitzt in der Hämatopoese unabhängig von seiner Rolle als Transkriptions- 
faktor eine inhibierende Funktion auf eIF4E (eukaryotic translation initiation factor 4E). EIF4E ist ein Modulator des Zellwachstums. Es vermittelt den Transport von speziellen Transkripten, die eine transformierende Aktivität besitzen, vom Nukleus in das Zytoplasma (Topisirovic et al., 2003a). Hex inhibiert in myeloischen Zellen den durch eIF4F vermittelten nukleozytoplasmatischen Transport von mRNA und somit die transformierende Aktivität von eIF4E. Auch diese Funktion von Hex scheint für die normale Blutzelldifferenzierung wichtig zu sein (Topisirovic et al., 2003a).

In meiner Arbeit konnte ich eine Hex-Expression in hämatopoetischen Zellen im Mesenchym zeigen. Bei diesen könnte es sich um Leukozyten, bzw. Makrophagen handeln, da sie einen sehr großen runden Zellkern besitzen. Die Expression von Hex in diesen Zellen könnte die Funktion des Homeobox-Gens, die Differenzierung von Hämangioblasten zu definitiven hämatopoetischen Stammzellen, wiederspiegeln. In Erythrozyten konnte hingegen keine Hex-Expression beobachtet werden, was zu den bereits beschriebenen Ergebnissen passt, dass Hex keinen Einfluss auf die Erythrozytenentwicklung hat.

\section{Hämatopoese in der Allantois}

Die Allantois, als embryonale Harnblase des Vogels ist eine extraembryonal gelegene Ausstülpung der Kloake und besteht aus Entoderm und gefäßreichem viszeralem Mesoderm. Nach dem Verschmelzen mit dem Chorion übernimmt sie als Chorioallantoismembran ab dem 10. Bebrütungstag die Atmungsfunktion vom Dottersack (Drews, 2006). Die Allantois zeigt ein Bild, welches durch die Expression von vielen typischen hämangioblastären Genen im Mesoderm charakterisiert ist. Zudem differenzieren Blutinsel ähnliche Strukturen, welche denen im Dottersack gleichen und sowohl CD $45^{+}$Leukozyten enthalten als auch Zellen, die Hämoglobin anreichern (Caprioli et al., 2001). Diese Beobachtungen unterstützen erneut die Hypothese von der Existenz des Hämangioblasten, dem gemeinsamen Vorläufer der endothelialen und hämatopoetischen Zellen und sprechen gegen die Vermutung, dass zwei verschiedene Zelllinien aus der Allantois das Knochenmark besiedeln (Jaffredo et al., 2005; Eichman et al., 2005).

Ich konnte in meinen Untersuchungen eine starke Hex-Expression in den Blutinseln der Allantois in den HH-Stadien 17 und 18 (3. Entwicklungstag) finden. Am 4. Entwicklungstag ist das Hex-Signal in diesen Blutinseln im Vergleich zum Vortag vermindert. Dieses passt zeitlich zu der in der Allantois stattfindenden Hämatopoese und lässt vermuten, dass 
Hex in der Hämatopoese in der Allantois involviert ist. Das Hex-Gen könnte in der Allantois des Hühnerembryos für die Differenzierung der Hämangioblasten zu definitiven hämatopoetischen Vorläuferzellen notwendig sein.

\section{Aorta-assoziierte Hämatopoese}

Dieterlein-Lievre (2005) untersuchte die Paraaortale Splanchnopleura (P-Sp) im 5-10 Somitenstadium von Hühnerembryonen. Diese Region enthält Entoderm, Mesoderm (Splanchnopleura) und die zwei Anlagen der Aorta. Sie konnte zeigen, dass sich aus den Zellen der P-Sp myeloische und lymphatische Zellkolonien differenzieren, während im Dottersack nur Zellen der myeloischen Reihe gebildet werden. Die intraembryonalen hämatopoetischen Stammzellen haben also ein breiteres Potential als die hämatopoetischen Zellen des Dottersacks (Dieterlein-Lievre, 2005). Auch zu späteren Entwicklungsstadien (35-40 Somiten), in denen die Aorta-Gonaden-Mesonephros-Region (AGM-Region) untersucht wurde, konnte gezeigt werden, dass sich aus diesen Zellen pluripotente hämatopoetische Stammzellen entwickeln (Ling \& Dzierzak, 2002). Die Region um die Aorta wurde demnach beim Vogel als Ort der Produktion von hämatopoetischen Stammzellen identifiziert. Dabei werden während der Entwicklung sequentiell zwei verschiedene Aspekte der Hämatopoese sichtbar. Zum einen die intraaortalen Cluster, die kleine, fest mit dem Endothel assoziierte Gruppen von hämatopoetischen Zellen darstellen. Diese erscheinen am 3.-4. Entwicklungstag und ragen in das Lumen der Aorta hinein (Dieterlein-Lievre \& Martin, 1981; Jaffredo et al., 1998). Zum anderen gibt es paraaortale Foci, die am 6.-9. Entwicklungstag als Ort der diffusen Blutbildung im Mesenterium ventral des Aortenbodens in Erscheinung treten (Dieterlein-Lievre \& Martin, 1981). Die intraaortale und paraaortale Hämatopoese leitet sich, wie Dieterlein-Lievre \& Martin (1981) zeigten, nicht von Vorläuferzellen aus dem Dottersack ab. Die maximale Aktivität der paraaortalen Hämatopoese überschneidet sich zeitlich mit der ersten Kolonisation von sekundären hämatopoetischen Organen wie Leber und Milz, so dass vermutet wurde, dass dieser Ort Ursprung der hämatopoetischen Stammzellen ist (Dunon et el., 1998; 1999). Bei der intraaortalen Hämatopoese entstehen durch einen Switch aus Endothelzellen der ventralen Aortenwand hämatopoetische Stammzellen (Pouget et al., 2005). Vor diesem Switch zeigen diese Zellen typische endotheliale Funktionen und eine für Endothelzellen typisches Genexpression (Jaffredo et al., 1998). Diese Hämangioblasten sollten nach Jordan's (1916) Terminologie besser als hämogenes Endothel bezeichnet werden. Sobald der Vorgang der Hämatopoese beginnt verlieren die Zellen ihren endothelialen Phänotyp und erlangen ein Hämatopoese- 
spezifisches Genexpressionsmuster (Jaffredo et al., 2005). Die Zellen werden entweder in die Blutzirkulation freigesetzt oder dringen in das ventrale Mesenterium ein (Jaffredo et al. 1998), bevor sie die sekundären hämatopoetischen Organe besiedeln.

Es konnte anhand von Transplantationsversuchen gezeigt werden, dass die Endothelzellen des Embryos aus zwei verschieden mesodermalen Anlagen stammen (Pardanaud et al., 1996). Das endotheliale Gefäßsystem der Viszeralorgane stammt vom splanchnischen Mesoderm ab und diese Zellen haben sowohl das Potential zu Endothelzellen als aus zu hämatopoetischen Zellen zu differenzieren (Pardanaud et al., 1996). Die zweite mesodermale Anlage stammt von den Somiten, hat nur endotheliales Potential, besiedelt die Somatopleura und bildet das Gefäßsystem der Körperwand (Pardanaud et al., 1996), der Nieren und der lymphatischen Gefäße (Wilting et al. 2000b). Das Endothel der Aorta hat eine duale Herkunft. Das Dach und die Seiten leiten sich von den Somiten ab, während der Boden von der Splanchnopleura stammt (Pardanaud et al., 1996). Da nur aus der Splanchnopleura hervorgehende Endothelzellen hämogenes Potential haben, sind die intraaortalen Cluster auf den ventralen Bereich der Aorta begrenzt. Das komplette Endothel der Aorta wird innerhalb der ersten vier Entwicklungstage erneuert und das hämogene Endothel ist demnach nur eine transiente Erscheinung (Pouget et al., 2006). Die Aorta durchläuft während der ersten Tage der embryonalen Entwicklung insgesamt folgende Veränderungen (Pouget et al., 2005):

1) Vor der Hämatopoese wird die Aorta, welche ursprünglich vollkommen splanchnomesodermaler Herkunft ist, von Endothelzellen der Somiten besiedelt. Hierbei bilden sich ein neues Dach und neue Seiten, während der Aortenboden aus Endothelzellen splanchnomesodermaler Herkunft bestehen bleibt.

2) Während die Hämatopoese abläuft, beginnen Endothelzellen aus den Somiten auch den Aortenboden zu besiedeln und werden neben den hämatopoetischen Stammzellanhäufungen gefunden.

3) Nach der Hämatopoese verschwinden die aortalen hämatopoetischen Stammzellen und werden durch Endothelzellen somitischer Herkunft ersetzt. In diesem Stadium leitet sich also das ganze Aortenendothel aus somitischen Zellen ab.

4) Eine neue Zellpopulation aus den Somiten, die glatten Muskelzellen der Gefäße, erscheint in der Aortenwand. Diese stammen nicht, wie ursprünglich angenommen von Endothelzellen ab, sondern, wie eindeutig gezeigt werden konnte, von einer anderen Zellpopulation somitischer Herkunft. 
In meiner Arbeit konnte ich mit Hilfe der WMISH eine Hex-Expression im Aortenboden am 3. Entwicklungstag (Stadium 17 und 18 nach HH) zeigen. Des Weiteren kann in diesem Stadium ein Hex-Signal im Endothel der paarigen Aortenanlage beobachtet werden. Am 4. Entwicklungstag ist weiterhin eine Hex-Expression im Boden der Aorta sichtbar. In Kryoschnitten ist außerdem Hex-Genexpression im Bereich der AGM-Region zu finden. Diese Hex-Expression im AGM-Bereich ist auch noch am 5. Entwicklungstag zu beobachten. In späteren Entwicklungsstadien kann ich das deutliche Signal im Endothel der Aorta nicht mehr beobachten. Das Hex-Signal im Endothel der Aorta könnte durch eine Anfärbung der intraaortalen Cluster verursacht werden, während das Hex-positive Signal im Bereich des Aortenbodens durch die paraaortalen Cluster verursacht sein könnte. Dieses ließe eine Funktion von Hex bei der frühen Aorta-assoziierte Hämatopoese vermuten. Darüber hinaus scheint das Homeobox-Gen eine Funktion bei der Hämatopoese im Bereich der AGM-Region zu haben, da die Hex-Expression in diesem Bereich zeitlich mit der Hämatopoese in der AGM-Region am 4. und 5. Entwicklungstag übereinstimmt. Das fehlende Hex-Signal im Endothel der Aorta in späteren Entwicklungsstadien könnte dadurch erklärt werden, dass das hämogene Endothel der Aorta nur eine transiente Erscheinung der ersten 4 Entwicklungstage ist und Hex in den Endothelzellen somitischer Herkunft nicht mehr exprimiert wird. Insgesamt scheint Hex eine Funktion bei der Aorta-assoziierten Hämatopoese zu haben. Das Gen könnte auch hier essentiell für eine regelrechte Blutzelldifferenzierung sein.

\subsubsection{Hex im Herzen und im AV-Kanal}

Das Herz entsteht im frühen Embryo aus zwei symmetrischen Gebieten im Bereich des viszeralen Seitenplattenmesoderms aus den Vorläufern der Kardiomyozyten und Endokardzellen. Die primären Herzfelder wandern zur Mittellinie und bilden dort eine bilaterale Struktur. Anschließend konfluieren die beiden Endokardschläuche. Der fusionierte Herzschlauch zeigt deutlich das innere Endokard und das äußere Myokard (Bellairs \& Osmond, 2005). Bei der Entwicklung des Herzens findet ein anterior-posteriorer Ablauf statt, was zur Folge hat, dass sich zuerst der spätere Truncus arteriosus, dann der Ventrikel, das Atrium und zuletzt der Sinus venosus ausbildet. Die Septierung des Herzens erfolgt beim Vogel in den HH-Stadien 16-20. Es projizieren sich zwei Atrioventrikularkissen (AV-Kissen) von dorsal und ventral in das Lumen des Atrioventrikularkanals (AV-Kanal). Diese werden vorerst aus einer azellulären Gallerte aus Glycosaminoglycanen und Glycoproteinen gebildet. Endokardzellen wandern in die Gallerte ein und die epithelio-mesenchymale Transiti- 
on dieser Zellen wird initiiert. Am 4. Tag nach Inkubation fusioniert zum einen das interatriale Septum mit den AV-Kissen und zum anderen fusionieren die beiden AV-Kissen miteinander. Das Ergebnis sind zwei getrennte Vorhöfe. Die Umwandlung des singulären Ventrikels in einen rechten und einen linken Ventrikel vollzieht sich ab dem Tag 3/4. Am 5. Tag gliedert sich der proximale Teil des Truncus arteriosus in den rechten Ventrikel ein, während sich der distale Teil durch Wachstum des aortopulmonalen Septums in die Aorta und die beiden Pulmonalarterien teilt. Das aortopulmonale Septum entsteht aus verdichteten Neuralleistenzellen auf Höhe der Ohrplakode bis zum posterioren Teil des 3. Somiten (Bellairs \& Osmond 2005).

In $\mathrm{Hex}^{-/-}$Mausembryonen konnten beachtliche Veränderungen in der Herz- und Gefäßentwicklung beobachtet werden. Dazu gehören eine Hypoplasie des rechten Ventrikels sowie die starke Vergrößerung der AV-Kissen und der Endokardkissen, welche die rechtsventrikuläre Ausflussbahn bilden. Des Weiteren treten Ventrikelseptumdefekte, Anomalien des Ausflusstraktes und AV-Klappendysplasien auf. Das Myokard ist fehlentwickelt und die Ventrikelwand sehr dünn bei fast vollständigem Fehlen des Trabekelsystems. Das Epikard ist erhalten (Hallaq et al., 2004). Die starke Vergrößerung der Endokardkissen bei Abwesenheit von Hex ist auf die reduzierte Apoptose und die Dysregulation der epitheliomesenchymalen Transition zurückzuführen. Des Weiteren ist in Herzen von $\mathrm{Hex}^{-/-} \mathrm{Mau}-$ sembryonen wie auch in Gefäßen die VEGF-A-Expression stark erhöht, so dass man auch hier von einem hemmenden Einfluss des Hex-Gens auf VEGF-A ausgehen kann. Die defekte Endokardkissenentwicklung (mit erhöhter Zellmigration) wird zumindest zum Teil durch das erhöhte VEGF-A verursacht (Hallaq et al., 2004). Im Myokard wird Hex während der gesamten kardialen Entwicklung nicht exprimiert, so dass die morphologischen Veränderungen am Herzen Folge der Abwesenheit von Hex im frühen Entoderm oder im Endokard sein müssen. Die Interaktion zwischen dem kardialen Mesoderm mit angrenzendem Entoderm ist entscheidend für die regelrechte Kardiomyozytenentwicklung. Dabei besitzt das anteriore Entoderm die Fähigkeit, herzspezifische Genexpression, wie z.B. BMPs (bone morphogenetic protein) zu induzieren (Denson et al., 2000). Das Entoderm scheint außerdem einen Einfluss auf die Endokardentwicklung zu haben. VEGF-A wird im definitiven Darmentoderm exprimiert, um ferner im Myokard und im Endokard exprimiert zu werden. Später beschränkt sich die VEGF-A Expression im Endokard auf die Zellen, welche die epithelio-mesenchymale Transition durchlaufen, also auf den Ausflusstrakt und den AV-Kanal. Demzufolge kann entweder eine Deletion von Hex im Darmentoderm oder 
im Endokard zu Veränderungen der AV-Kissen und Anomalien des Ventrikelmyokards führen (Hallaq et al., 2004).

In meinen Ergebnissen kann ich in Hühnerembryonen ebenfalls eine Hex-Expression im AV-Kanal und in der Herzausflussbahn finden. Das Hex-Signal im Ausflusstrakt ist bereits ab dem 3. Entwicklungstag sichtbar, während das Signal im AV-Kanal ab dem 4. Entwicklungstag zu beobachten ist. Des Weiteren habe ich die Hex-Expression im Ventrikelendokard ab dem 3. Entwicklungstag dargestellt. Im Myokard kann ich, in Übereinstimmung mit den Ergebnissen von Hallaq et al. (2004) an Mausembryonen, keine Hex-Expression beobachten. Im Herzen habe ich außerdem noch Hex-Expression im koronaren Gefäßsystem darstellen können. In die AV-Kissen, welche in den HH-Stadien 16-20 vorerst aus azellulärer Gallerte bestehen, wandern Endokardzellen nach epithelio-mesenchymale Transition ein. Das Hex-Gen könnte demnach durch Expression in den einwandernden Endokardzellen am 4. Entwicklungstag im AV-Kanal ein positives Signal zeigen und dort wie auch im Mausembryo eine Funktion bei der epithelio-mesenchymalen Transition oder der Regulation von Proliferation und Apoptose besitzen. Die Expression von Hex in der Herzausflussbahn könnte auch hier im Zusammenhang mit der epithelio-mesenchymalen Transition stehen. Die Zellen, welche die Teilung des Ausflusstraktes in Aorta und Pulmonalarterien bewirken, wandern aus der Neuralleiste ein. Hex könnte demnach in den einwandernden Zellen exprimiert werden und somit zur Teilung der Ausflussbahn beitragen. Insgesamt sind meine Ergebnisse der Hex-Expression im Herzen von Hühnerembryonen dem beschriebenem Hex-Expressionsmuster in Herzen von Mausembryonen sehr ähnlich. $\mathrm{Hex}^{-/-}$Hühnerembryonen könnten daher ähnliche Defekte in der Herzentwicklung aufweisen wie die von Hallaq et al. (2004) beschriebenen Herzdefekte im Mausembryo. Die Expression von Hex im koronaren Gefäßsystem ist bislang aber nicht beschrieben worden. Da es dort bereits bei jungen Menschen zu Intimaproliferationen kommt, könnte dies von klinscher Bedeutung sein.

\subsubsection{Hex in der Schilddrüse}

Die Schilddrüsenknospe bildet beim Vogel sich während des 2. und 3. Entwicklungstages aus einer Ausstülpung des Pharynx in das unterliegende Mesoderm auf Höhe der zweiten Schlundtaschen. Während des 6. Entwicklungstages degeneriert der Ductus thyroglossus, die beiden Schilddrüsenlappen verzweigen sich weiter und das Organ wird aus Ästen der Arteriae subcalviae stark vaskularisiert. Die Schilddrüse besteht ursprünglich aus Epithel 
entodermalen Ursprungs, bis sie am Tag 6 von Mesenchym durchdrungen wird (Bellairs \& Osmond, 2005).

Verschiedene Studien haben belegt, dass Hex für die normale Schilddrüsenentwicklung essentiell ist (Martinez Barbera et al., 2000). Bei $\mathrm{Hex}^{-/-}$Maus-Mutanten ist die Schilddrüsenanlage hypoplastisch oder aplastisch und in späteren Entwicklungsstadien gar nicht mehr auffindbar. Dabei wird in $\mathrm{Hex}^{-/-}$Mäusen der Schilddrüsen Marker NKX2-1 frühzeitig abgeschaltet. Das Homeobox-Gen NKX2-1 codiert für den thyroidalen Transkriptionsfaktor 1 (TTF-1), welcher essentiell für die Morphogenese der Schilddrüse ist (Martinez Barbera et al., 2000). Es wurden bereits mehrere thyreoidspezifische Transkriptionsfaktoren, darunter TTF-1, TTF-2, Pax8 und Hex, identifiziert (Pellizzari et al., 2000). Die Gene werden vom Beginn der Schilddrüsenentwicklung bis zum differenzierten Stadium exprimiert und Inaktivierung dieser Gene verursacht bei Mäusen Defekte bei der Bildung und Differenzierung des Organs (Martinez Barbera et al., 2000). Außerdem führen inaktivierende Mutationen dieser Gene beim Menschen zu kongenitaler Hypothyreose (Macchia, 2000). Die thyreoidspezifischen Transkriptionsfaktoren interagieren funktionell miteinander. So konnte gezeigt werden, dass die Hex-Promotor-Aktivität durch TTF-1 und durch das HexProtein selber gesteigert wird (Puppin et al., 2003). Das Ergebnis dieser Beobachtung und der, dass in $\mathrm{Hex}^{-/-}$Mausmutanten TTF-1 in der Schilddrüsenanlage fehlt, deutet darauf hin, dass es einen positiven Feedback Mechanismus zwischen TTF-1 und Hex geben muss (Puppin et al., 2003; Martinez Barbera et al., 2000). Weiterhin fanden Pellizzari et al. (2000) heraus, dass Hex bei Ratten in den Regulationsmechanismus von TSH und Thyroglobulin eingreift. TSH hemmt die Hex-Expression, während Hex die Thyroglobulin Expression supprimiert. Somit führt eine über TSH induzierte Herunterregulation von Hex zu einem Anstieg von Thyroglobulin (Pellizari et al., 2000).

In meinen Untersuchungen konnte ich ein Hex-Signal in der Schilddrüsenanlage des Hühnchens erstmal ab dem 4. Entwicklungstag nachweisen. Am 3. Entwicklungstag hingegen ist Hex-Expression in der Schilddrüsenanlage noch nicht zu beobachten. Das deutlich positive Signal zeigt sich weiterhin am 5. Entwicklungstag, am 10. Entwicklungstag habe ich die Schilddrüse nicht mehr untersucht. Die starke Hex-Expression am 4. und 5. Entwicklungstag erhärtet die Vermutung, dass das Homeobox-Gen Hex beim Huhn auch wie bei der Maus eine wesentliche Rolle bei der Schilddrüsenbildung und ihrer Differenzierung spielt. 


\subsubsection{Hex in den Extremitäten und in Hautanhangsgebilden}

Die Regionen der zukünftigen Extremitäten werden beim Vogel im HH-Stadium 15 als sich langsam verdickende Leisten des somatischen Lateralplattenmesoderms sichtbar. Die Flügelknospen bilden sich etwas früher als die Beinknospen. Jede Extremitätenknospe besteht an Tag 3 der Inkubation aus einem Kern aus Mesoderm, welcher von Ektoderm umhüllt wird. Das Somatopleura-Mesoderm bildet die Sehnen, das Skelett und die Dermis, während aus den Somiten die Muskelvorläuferzellen einwandern. In den frühen Stadien ist die Entwicklung der Flügel- und Beinknospen gleich, ab dem HH-Stadium 24 beginnen sie aber ihre individuellen Charakteristika zu entfalten (Bellairs \& Osmond, 2005). Die Extremitätenknospen werden von Angioblasten besiedelt, die sich aus den Somiten ableiten (Dieterlein-Lievre 2005). Epitheliale Anhänge wie z. B. Federn, Haare und Krallen werden durch epithelio-mesenchymale Interaktionen induziert und geformt. Ein induktives dermales Signal initiiert die Bildung einer epidermalen Plakode und führt zur Kondensation in der unterliegenden Dermis (Obinata \& Akimoto, 2005).

\section{$\underline{\text { Hex in der Extremitätenentwicklung }}$}

Die Haut der Extremitäten besteht aus der Epidermis, welche sich vom Ektoderm ableitet, und der unterliegenden Dermis, welche vorwiegend mesodermaler Herkunft ist. Während der Entwicklung der Haut und der Hautanhangsgebilde ist die Interaktion zwischen dem Epithel und dem Mesenchym von großer Bedeutung. Eine transiente Expression des HexGens konnte in der sich entwickelnden Haut nachgewiesen werden. Die dermale Expression korreliert dabei mit der proliferativen Aktivität der epidermalen Basalzellen. Die epidermale Hex-Expression hingegen bedingt eine Suppression der epidermalen Differenzierung (Obinata et al., 2002). Beim Hühnerembryo konnte am 11. Entwicklungstag HexExpression in der tarsometatarsalen Haut in den epidermalen Basalzellen und in der Dermis nachgewiesen werden. Während der Bildung der Hornschuppen am 13. Tag ist in diesen Bereichen, in denen eine aktivere Zellproliferation stattfindet, eine starke Expression in den epithelialen Basalzellen zu beobachten und in der Dermis nimmt die Hex-Expression ebenfalls zu. Mit Beginn der Verhornung, einhergehend mit einer Abnahme der Proliferation epithelialer Basalzellen am 15. Entwicklungstag, zeigt sich weniger Hex-Expression in den Basalzellen. Nach dem 19. Entwicklungstag, wo die epidermale Proliferation gering ist, verschwindet die dermale Hex-Expression. Diese Ergebnisse lassen vermuten, dass Hex in der Dermis für die Zellproliferation verantwortlich ist und dass eine verminderte Expression für den Ablauf der Verhornung essentiell ist (Obinata et al., 2002). 
Beim Huhn wurde die Hex-Expression in den Extremitätenanlagen in frühen Stadien der Entwicklung bislang noch nicht beschrieben. Ich konnte Hex-Expression in den Extremitätenanlagen ab dem 4. Entwicklungstag beobachten. Zuerst zeigen dabei die Gefäße in den Extremitätenanlagen Hex-positive Signale. Am 5. Entwicklungstag hingegen ändert sich das Expressionsmuster und wechselt zu einer Hex-Expression im interdigitalen Mesenchym und im Mesenchym des Zeugopodiums. Dabei ist in der vorderen Extremität im Vergleich zur hinteren Extremität ein anderes Muster der Hex-Expression zu beobachten. Dies könnte im Zusammenhang mit der unterschiedlichen Morphologie des Skelettsystems der vorderen und hinteren Extremität stehen, so dass Hex eine Funktion bei der Gestaltbildung der Extremitäten haben könnte.

\subsubsection{Hex im Gliom auf der CAM}

Die Chorioallantoismembran (CAM) gehört zu den extraembryonalen Organen des Vogelembryos. Aufgabe der Allantois ist die Lagerung von Stoffwechselendprodukten. Sie besteht aus viszeralem Mesoderm und Entoderm und verschmilzt bis zum 10. Entwicklungstag mit dem Chorion (Drews, 2006). Von da an übernimmt sie bis kurz vor dem Schlupf als sehr gefäßreiche Chorioallantoismembran die Atmungsfunktion und steht breitflächig mit der inneren Eischalenmembran in Kontakt. Allein die Allantoisgefäße stellen die Verbindung der CAM zum Embryo her, da das Chorion selbst gefäßfrei ist (Drews, 2006).

Die CAM des Huhns wird häufig verwendet, um Angiogenese und ihre Hemmung zu untersuchen. Mittels des CAM-Systems wurde bereits die Angiogenese in normalem, inflammatorischem und Tumorgewebe untersucht. Darüber hinaus wurden zahlreiche lösliche Faktoren mit angiogenen und antiangiogenen Effekten über diese Methode identifiziert (Ribatti et al., 1996). Außerdem können CAM-Versuche genutzt werden, um das Invasionsverhalten von malignen Tumoren abzuschätzen und Wachstumskinetiken dieser Tumoren zu erstellen (Laurin et al., 2004). Von großer Bedeutung ist bei den CAM-Versuchen, dass der Embryo noch keine Immunkompetenz besitzt und es dadurch nicht zur Abstoßung der transplantierten Zellen kommt. Die CAM des Hühnerembryos bietet somit aufgrund ihres Gefäßreichtums, fehlender Immunkompetenz, einfacher Handhabung und idealen Beobachtungsbedingungen (Borges et al. 2003) sehr gute Vorrausetzungen zur Untersuchung der Tumorangiogenese. 


\section{Die Tumorangiogenese}

Das Wachstum und die Progression maligner Tumoren und Metastasen ist stark angiogeneseabhängig (Folkmann, 1989). Physiologisch stehen die Endothelzellen unter strenger Kontrolle von endogenen Angiogenesestimulatoren und -inhibitoren. Dadurch findet im normalen Gewebe, mit Ausnahme des Endometriums und bei der Wundheilung, nur der notwendige Zellumsatz, jedoch kein quantitativer Zellzusatz statt (angiogene Balance) (Denekamp, 1993). Die Entartung von Körperzellen zu Tumorzellen ist nicht angiogeneseabhängig und anfangs wächst der Zellklon angiogeneseunabhängig (avaskuläre Phase). Die Versorgung mit Sauerstoff und Nährstoffen wird zu diesem Zeitpunkt durch Diffusion aufrecht erhalten. Ab einer bestimmten Größe reicht die Versorgung der Tumorzellen mittels Diffusion auf Grund der weiten Diffusionsstrecke nicht mehr aus, so dass eine Angiogeneseaktivierung durch den Tumor bei weiterer Größenzunahme beobachtet wird (Denekamp, 1993). An dieser Stelle durchlaufen die Tumorzellen den so genannten angiogenen switch, so dass der Tumorzellklon die Fähigkeit bekommt, Angiogenese zu stimulieren. Folglich kommt es zu Endothelzellproliferation und Gefäßwachstum. Zum einen kann dies über gesteigerte Freisetzung angiogenesestimulierender Faktoren kommen und zum anderen über die Hemmung der Sekretion von Angiogeneseinhibitoren (Hanahan \& Folkmann, 1996). Die angiogene Kaskade beginnt mit der Auflösung der extrazellulären Matrix wie der vaskulären Basalmembran durch Proteasen. Anschließend wandern Endothelzellen in Richtung des angiogenen Stimulus aus, proliferieren und bilden gefäßähnliche Strukturen (Klagsbrun \& Moses, 1999). Die Endothelzellen haben zusätzlich zu dem nutritiven Effekt durch Produktion von Wachstumsfaktoren einen parakrinen stimulierenden Effekt auf die Tumorzellen (Hanahan \& Folkmann, 1996), so dass diese in der vaskulären Phase exponentiell proliferieren (Rak et al., 1995).

Bei der Untersuchung von Hex im experimentellen Gliom auf der CAM habe ich am 10. Tag nach Inkubation Gliomzellen von Ratten auf die CAM des Hühnerembryos pippetiert. 7 Tage nach Tumorwachstum konnte ich eine Expression von Hex im Gefäßsystem des Tumors feststellen. Hex wird dabei, wie in embryonalen Gefäßen, im Endothel der Tumorgefäße exprimiert. Somit scheint das Homeobox-Gen Hex bei der Tumorangiogenese eine Rolle zu spielen. Ob Hex dabei die Sekretion von angiogenesestimulierenden Faktoren fördert oder hemmt oder über Hemmung von Angiogeneseinhibitoren in die Tumorangiogenese eingreift, ist bislang ungeklärt. Die Funktion von Hex in der Tumorangiogenese 
wurde bislang in der Literatur noch nicht detailliert beschrieben und könnte ein zukünftiger Angriffspunkt in der Antiangiogenesetherapie bei Tumoren darstellen. Dabei muss aber bedacht werden, dass nur ein kleiner Teil der Gefäße in den experimentellen Gliomen Hexpositiv war.

\subsection{Bedeutung für den Menschen; Pathologien}

In der Literatur sind verschiedene Krankheitsbilder beschrieben worden bei denen das Homeobox-Gen HHEX von Bedeutung ist.

Hex bei malignen epithelialen Tumoren

Abate-Shen (2002) stellte heraus, dass die Homeobox Genexpression in Karzinomen in den meisten Fällen einer einfachen Regel folgt: Die Gene, welche normalerweise in undifferenzierten Zellen exprimiert werden, sind in Karzinomen hochreguliert, während die Homeobox-Gene, die normalerweise in differenzierten Geweben exprimiert werden, in Karzinomen herunterreguliert werden. In epithelialen Malignomen wie dem Mamma- und dem Schilddrüsenkarzinom ist das HHEX-Gen von Bedeutung. In der Brustdrüse kann HHEX-Expression im Kern und im Zytoplasma der Drüsenzellen detektiert werden. Sowohl im duktalen als auch im lobulären Adenokarzinom der Brust wird eine stark reduzierte nukleäre $H H E X$-Expression beobachtet, während in der laktierenden Brust die nukleäre HHEX-Expression stark ansteigt. Dies deutet darauf hin, dass HHEX in der Differenzierung der epithelialen Brustdrüsen eine wichtige Rolle zukommt (Puppin et al., 2006). Ein ähnliches Phänomen der HHEX-Expression wurde auch bei humanen Schilddrüsentumoren beobachtet. HHEX-Expression bleibt in allen als differenziert geltenden benignen und malignen Schilddrüsentumoren erhalten und im Gegensatz zu PAX-8 und TTF-1 auch in der Mehrheit der undifferenzierten Schilddrüsentumoren. In malignen Tumoren beschränkt sich die HHEX-Expression jedoch, anders als in benignen Schilddrüsenadenomen, auf das Zytoplasma (D'Elia et al., 2002).

\section{$\underline{H H E X}$ bei malignen hämatopoetischen Erkrankungen}

Eine Dysregulation von Homeobox-Genen wird in vielen malignen hämatopoetischen Erkrankungen beobachtet. Divergente Homeobox-Gene (non-HOX Gene) wurden dabei als Kofaktoren und/oder als Beschleuniger der Leukämie identifiziert (Owens \& Hawley, 2002). Experimente an Mäusen zeigten, dass Hex die Entstehung von malignen hämatolo- 
gischen Tumoren induzieren kann, wenn es in hämatopoetischen Progenitorzellen missexprimiert wird. Bei Mäusen führt eine außerplanmäßige Hex-Expression in B-Zellen zu B-Zell-Leukämien (Hansen \& Justice, 1999). In manchen Fällen, der adulten akuten myeloischen Leukämie (AML) und in der Blastenkrise der chronischen myeloischen Leukämie (CML) konnte ein erhöhter eIF4E (eukaryotic translation initiation factor 4E) abhängiger mRNA-Transport nachgewiesen werden. Dieses ist unter anderem auf den Verlust von HHEX, dem negativen Regulator von eIF4E, in diesen Zellen zurückzuführen. Studien zeigten, dass HHEX eIF4E nur hemmen kann, wenn es im Nukleus lokalisiert ist. Daher könnte der Verlust von nukleär lokalisiertem HHEX und damit die fehlende eIF4E Suppression eine wichtige Rolle in der Entwicklung von menschlichen Malignomen spielen. Abhängig vom Zelltyp und vom Entwicklungsstadium kann sowohl eine Hochregulation als auch eine Herabregulation von HHEX zur neoplastischen Transformation führen (Topisirovic, 2003b).

George et al. (2003) untersuchten an Mäusen, ob eine Missexpression des Hex-Gens in lymphozytären Vorläuferzellen zu einer veränderten Differenzierung oder einer neoplastischen Transformation dieser Zellen führt. Es konnte gezeigt werden, dass eine stark erhöhte Hex-Expression in lymphozytären Vorläuferzellen die Differenzierung zu reifen Blutzelllinien inhibiert. Eine schwache Hex-Überexpression hingegen verursacht Lymphome, die sich von unreifen T-Lymphozyten ableiten. Diese Ergebnisse deuteten darauf hin, dass Hex in lymphatischen T-Zellen als Onkogen fungieren kann (George et al., 2003).

\section{$\underline{H H E X}$ bei der lymphozytären Choriomeningitis}

Das lymphozytäre Choriomeningitis-Virus (LCMV) gehört zur Familie der Arenaviridae. Die Infektion von Primaten mit dem WE-Stamm des lymphozytären ChoriomeningitisVirus (LCMV-WE) führt zu einer Krankheit, die dem Lassa Fieber bei Menschen ähnelt. Die Infektion mit dem LCM-Virus involviert verschiedene Organsysteme; das zentrale Nervensystem, das respiratorische und das hämatopoetische System sowie die Leber, welche den Ort der höchsten Virusreplikationsrate darstellt (Djavani et al., 2005). Der Hauptüberträger des LCM-Virus ist die Hausmaus. Bei dieser kommt es wie bei anderen Nagetieren zu persistierenden Infektionen. Die LCMV-Übertragung auf den Menschen erfolgt durch direkten Kontakt mit Nagerexkrementen (Schwarz, 2005). Beim Menschen reicht die klinische Symptomatik von der asymptomatischen Infektion bis hin zum klassischen ZNS Befall. Bei der neurologischen Verlaufsform entwickelt sich eine aseptische Meningitis 
und zum Teil eine Enzephalopathie. Von besonderer Bedeutung ist die LCMV-Infektion bei Schwangeren, da die Übertragung auf den Fetus mit einem Hydrozephalus internus assoziiert ist (Schwarz, 2005). Djavani et al. (2005) untersuchten die Effekte des LCMVWE auf die HHEX-Expression, Lokalisation und Funktion in Hepatozyten. Sie fanden heraus, dass $H H E X$-mRNA, Protein und Funktion herunterreguliert werden, während das LCMV-WE sich in der Leber repliziert. Somit ist das Virus in der Lage den antiproliferativen Effekt von HHEX zu eliminieren und damit die Leberzellteilung zu förden. Als Korrelat zeigt sich während der akuten Infektion mit dem virulenten Arenavirus eine Hepatozytenproliferation. Djavani et al. (2005) gehen davon aus, dass das Virus eine Leberdysfunktion verursacht, indem es die physiologischen Reparationsprozesse inhibiert. HHEX wird sowohl in der Hämatopoese als auch in der Leber für Differenzierungs- und Reparationsprozesse benötigt. Die Interaktion des Arenavirus mit dem Homeodomain Protein deutet auf virale teratogene Effekte hin und erklärt die gewebeabhängige Manifestation der lymphozytären Choriomeningitis (Djavani et al., 2005).

\section{$\underline{H H E X}$ beim Diabetes mellitus Typ 2}

Der genaue Mechanismus der Entwicklung und des Fortschreitens des Diabetes mellitus Typ 2 ist noch nicht geklärt. Es werden Kombinationen aus genetischen und umweltbedingten Faktoren in Betracht gezogen, an der Pathogenese des Typ 2 Diabetes mellitus mitzuwirken. So ist auch das Homeobox-Gen HHEX aktuell Gegenstand vieler Untersuchungen zur Pathogenese dieser Erkrankung. Mittlerweile sind 18 Genloci bekannt, welche mit Typ 2 Diabetes mellitus assoziiert werden. Darunter sind Gene, die den Zellzyklus kontrollieren, Ionenkanäle und Transkriptionsfaktoren wie HHEX. Die meisten dieser Gene beeinflusssen die Insulinsekretion (Perry \& Frayling, 2008). Grarup et al. (2008) konnten validieren, dass besonders bei Personen mittleren Alters Veränderungen im HHEXGen stark mit einer erniedrigten akuten Insulin Antwort im oralen Glukose Toleranztest assoziiert sind. Außerdem wurde bei jungen gesunden Probanden eine erniedrigte Insulinfreisetzung nach intravenöser Gabe von Tolbutamid beobachtet. Somit wurde eine BZelldysfunktion bei Veränderungen im HHEX-Gen vermutet (Grarup et al., 2008). 


\section{Zusammenfassung}

Das Homeobox-Gen Hex reguliert bei Vertebraten eine Vielzahl von Entwicklungsprozessen. Das Gen steuert dabei die Zellproliferation und Differenzierung, ist verantwortlich für die Bildung der Körperachse, des hämatopoetischen und vaskulären Systems und für die Ausbildung vieler lebenswichtiger Organe. Das DNA-bindende Hex-Protein führt über unterschiedliche Mechanismen zur Hemmung oder Aktivierung der Transkription. Des Weiteren beeinflusst Hex die Genexpression auf translationaler Ebene, indem es den nukleären Transport von bestimmten mRNAs reguliert.

Aufgrund der großen klinischen Bedeutung von Mutationen des HEX-Gens habe ich in meiner Arbeit neben dem Hex-Expressionsmuster in der Frühphase der Entwicklung auch das Expressionsmuster in späteren Entwicklungsstadien bei Hühnerembryonen untersucht. Dabei habe ich besonderen Wert auf neue Erkenntnisse der Hex-Expression und auf das Expressionsmuster des Homeobox-Gens in Gefäßen und hämatopoetischen Zellen gelegt. Ich konnte erstmals eine Hex-Expression im koronaren Gefäßsystem darstellen, was hinsichtlich der klinischen Bedeutung von Intimaproliferationen, die bereits bei jungen Menschen auftreten, von Interesse sein könnte. Außerdem konnte ich in meiner Arbeit neue Beobachtungen über die Hex-Expression in den Extremitätenanlagen machen. Hier zeigen zuerst die Gefäße Hex-positive Signale und später wird Hex im interdigitalen Mesenchym und im Mesenchym des Zeugopodiums exprimiert. Zur Expression des Homeobox-Gens Hex im Lymphendothel konnte ich in meinen Untersuchungen keine sichere Aussage machen, was durch technische Limitationen bei der Darstellung des extrem dünnen Lymphendothels bedingt sein könnte. Des Weiteren konnte ich Hex-Expression in manchen Tumorgefäßen eines experimentellen Glioms auf der Vogel-Chorioallantoismembran beobachten. Dabei sind die Hex-positiven Signale, wie auch bei den intraembryonalen Arterien und Venen, im Endothel zu finden. Das Hex-Gen könnte eine Funktion bei der Tumorangiogenese besitzen, was ein wichtiger Angriffspunkt bei der Therapie maligner Tumoren sein könnte. Die Herausforderung wird in der Zukunft darin liegen, weitere Funktionen des Homeobox-Gens Hex zu erforschen, in der Hoffnung, Erkenntnisse für die Therapie und das Verständnis humaner Pathologien zu gewinnen, die durch Mutationen des HEXGens hervorgerufen werden. 


\section{Abkürzungsverzeichnis}

AGM-Region

AML

Anti-Dig-AP

APAAP

BCIP

BL-CFC

BMP

CAM

CML

DEPC

DEPC

DIG

Dig-11-UTP

DMEM

DNA

EB

EDTA

eIF4E

ESM-1

FA

FISH

$\mathrm{H}_{2} \mathrm{O}$-bidest

Hex

$\mathrm{HH}$

HNF

$\mathrm{HTH}$

ISH

LCMV

mRNA

NBT

NK

NKX2-1

ntcp

PAP

PAX8

PBS

PFA
Aorta-Gonade-Mesonephros-Region

akute myeloische Leukämie

Anti-Digoxigenin-Antikörper konjugiert mit

Alkalischer Phosphatase

Alkalische-Phosphatase-Anti-Alkalische-Phosphatase

5-Brom-4-chlor-3-indolylphosphat (Substrat der AP)

blast colony-forming cell

bone morphogenetic protein

Chorioallantoismembran

chronische myeloische Leukämie

Diethylpyrocarbonat (RNase Inhibitor)

Diethylenpyrocarbonat

Digoxigenin

Digoxigenin-11-Uraciltriphosphat

Dulbecco`s Modified Eagle's Medium

Desoxyribonukleinsäure

embryoid body

Ethylendiamintetraacetat

eukaryotic translation initiation factor $4 \mathrm{E}$

endothelial cell-specific molecule-1

Formaldehyd

Fluoreszenz-in-situ-Hybridisierung

Bidestilliertes Wasser

hematopoietically-expressed homeobox

Hamburger \& Hamilton

hepatocyte nuclear factor

Helix-Turn-Helix

in-situ-Hybridisierung

lymphozytäres Choriomeningitis-Virus

messenger-RNA

Nitroblautetrazolium

nuclear body-associated kinase

Homeobox-Gen NK2 homeobox 1

$\mathrm{Na}^{+}$-taurocholate cotransporting polypeptide

Peroxidase-Anti-Peroxidase

paired-box-protein 8

phosphate bufferd saline (Phosphatgepufferte Salzlösung)

Paraformaldehyd 
PRH

P-Sp

RNA

RT

SDS

SDS

SSC

TBP

TBS

TRIS

tRNA

TSH

TTF

Tween 20

VEGF-A

WM prolin-rich-homeodomain

paraaortale Splanchnopleura

Ribonukleinsäure

Raumtemperatur

Natriumdodecylsulfat, Emulgator und Denaturierungsmittel

Natriumdodecylsulfat

standard sodium citrate (NaCl-Citrat Puffer)

TATA-box-binding protein

Tris-buffered saline

Trishydroxymethyl-aminomethan

transfer-RNA

Thyroidea stimulierendes Hormon

thyroidaler Transkriptionsfaktor

Polyoxyethylensorbitanmonolaurat

vascular endothelial growth factor-A

whole-mount 


\section{Literaturverzeichnis}

Abate-Shen C (2002): Deregulated homeobox gene expression in cancer: cause or consequence? Nat Rev Cancer 2(10): 777-85

Bellairs R, Osmond M: The Atlas of Chick Development. 2. Auflage; Elsevier Academic Press, San Diego 2005

Bogue CW, Ganea GR, Sturm E, Ianucci R, Jacobs HC (2000): Hex Expression suggests a role in the development and function of organs derived from foregut endoderm. Dev Dyn 219: 84-89

Borges J, Tegtmeier FT, Padron NT, Müller MC, Lang EM, Stark B (2003): Chorioallantoic Membrane Angiogenesis Model for Tissue Engineering: A New Twist on a Classical Model. Tissue Eng 9(3): 441-450

Bort R, Martinez-Barbera JP, Beddington RS, Zaret KS (2004): Hex homeobox gene-dependent tissue positioning is required for organogenesis of the ventral pancreas. Development 131: 797-806

Buske C, Humphries RK (2000): Homeobox genes in leukemogenesis. Int J Hematol 71(4): 301-8

Caprioli A, Jaffredo T, Drevon C, Eichmann A, Dierterlein-Lievre F, Jaffredo T (2001): Hemangioblast commitment in the avian allantois: cellular and molecular aspects. Dev Biol 238: 64-78

Chan RJ, Hromas R, Yodas MC (2006): The role of Hex in hemangioblast and hematopoetic development. Mol Biol 330:123-33

Choi K, Kennedy M, Kazarov A, Papadimitriou JC, Keller G (1998): A common precursor for hematopoietic and endothelial cells. Development 125(4):725-32

Clark ER, Clark EL (1920): On the origin and early development of the lymphatic system of the chick. Contr Embryol 9: 447-82

Cong R, Jiang X, Wilson CM, Hunter MP, Vasavada H \& Bogue CW (2006): Hhex is a direct repressor of endothelial cell-specific molecule 1 (ESM-1) Biochem Biophys Res Commun 346(2): 535-545

D’Elia AV, Tell G, Russo D, Arturi F, Puglisi F, Manfioletti G, Gattei V, Mack DL, Cataldi P, Filetti S, Di Loreto C, Damante G (2002): Expression and Localization of the Homeodomain-Containing Protein HEX in Human Thyreoid Tumors. J Clin Endocrinol Metabol 87(3): 1376-1383

Denekamp J (1993): Angiogenesis, neovascular proliferation and vascular pathophysiology as target for cancer therapy. Br J Radiol 6ㅜ: 181-196

Denson LA, Karpen SJ, Bogue CW, Jacobs HC (2000): Divergent Homeobox gene Hex regulates promoter of the Na+-dependent bile acid cotransporter. Am J Physiol Gastrointest Liver Physiol 279(2): 347-355

Dieterlein-Lievre (2005): Commitment of hematopoietic stem cells in avian and mammalian embryos: an ongoing story. Int J Dev Biol 49: 125-130

Dieterlein-Lievre F, Martin C (1981): Diffuse intraembryonic hemopoiesis in normal and chimeric avian development. Dev Biol $\underline{88}: 180-191$

Djavani M, Topisirovic I, Zapata JC, Sadowska M, Yang Y, Rodas J, Lukashevich IS, Bogue CW, Pauza CD, Borden KLB, Salvato MS, (2005): The Proline-Rich Homeodomain (PRH/HEX) Protein Is DownRegulated in Liver during Infection with Lymphocytic Choriomeningitis Virus. Virologie 79(4): 2461-2473.

Drews U (2006): Taschenatlas der Embryologie. 2. Auflage; Georg Thieme Verlag, Stuttgart 2006

Dunon D, Allioli N, Vainio O, Ody C, Imhof BA (1998): Renewal of thymocyte progenitors and emigration of thymocytes during avian development. Dev Comp Immunol 22: 279-287 
Dunon D, Allioli N, Vainio O, Ody C, Imhof BA (1999): Quantification of T-cell progenitors during ontogeny: Thymus colonization depends on blood delivery of progenitors. Blood 93: 2234-2243

Durand C, Dzierzak E (2005): Embryonic beginnings of adult hematopoietic stem cells. Heamatologica 90: $100-108$

Ensembl Gen-Datenbank, http://www.ensembl.org (21.05.2009)

Eichmann A, Yuan L, Moyon D, Lenoble F, Pardanaud L, Breant C (2005): Vascular development: from precursor cells to branched arterial and venous network. Int J Dev Biol 49:259-267

Folkmann J (1989): What is the evidence that tunors are angiogenesis dependent? J Natl Cancer Inst $\underline{82}$ : 4-6

Gall JG, Pardue ML (1969): Formation and detection of RNA-DNA hybrids in cytological preparations. Genetics 63: 378-383

Gehring WJ, Affolter M, Burglin T (1994): Homeodomain proteins. Annu Rev Biochem 63: 487-526

Geisha-Hühner in-situ-Hybridisierungen, http://geisha.arizona.edu (15.05.2009)

George A, Morse HC, Justice MJ (2003): The homeobox gene Hex inducs T-cell-derived lymphomas when overexpressed in hematopoeietic precursor cells. Oncogene 22: 6764-6773

Ghosh B, Jacobs HC, Wiedemann LM, Brown A, Bedford FK, Nimmakayalu MA, Ward DC, Bogue CW (1999): Genomic structure, cDNA mapping, and chromosomal localization of the mouse homeobox gene, Hex. Mamm Genome 10: 1023-1025

Ghosh B, Ganea GR, Denson LA, Iannucci R, Jacobs HC, Bogue CW (2000): Immunocytochemical characterization of murine Hex, a homeobox-containing protein. Pediatr Res 48(5): 634-638

Giampaolo A, Pelosi E, Vatieri M, Montesoro E, Sterpetti P, Samoggia P, Camagna A, Mastroberardino G, Gabbianelli M, Testa U (1995): HOXB gene expression and functin in differentiating purified in hematopoetic progenitors. Stem Cells 13(1): 90-105

Guo Y, Chan R, Ramsey H, Li W, Xie X, Shelley WC, Martinez-Barbera J-P, Bort B, Zaret K, Yoder M, Hromas R (2003): The homeoprotein Hex is required for hemangioblast differentiation. Blood 102: 2428-35

Hallaq H, Pinter E, Enciso J, Mc Grath J, Zeiss C, Brueckner M, Madri J, Jacobs HC, Wilson CM, Vasavada H, Jiang X, Bogue CW (2004): A null mutation of the Hhex results in abnormal cardiac development, defective vasculogenesis und elevated Vegfa levels. Development 131: 5197-5209

Hamburger V, Hamilton HL (1951): A series of normal stage in the development of the chick embryo. J Morphol $\underline{88}, 49-92$.

Hanahan D, Folkmann J (1996): Pattern and emerging mechanisms of the angiogenic switch during tumorigenesis. Cell $\underline{86}$ : 353-364

Hansen GM, Justice MJ (1999): Activation of Hex and mEg5 by retroviral insertion may contribute to mouse B-cell leukemia. Oncogene 18(47): 6531-6539

Huber TL, Kouskoff V, Fehling HJ, Palis J, Keller G (2004): Haemangioblast commitment is initiated in the primitive streak of the mouse embryo. Nature $\underline{432}$ : 625-30

Hunter MP, Wilson CM, Jiang X, Cong R, Vasavada H, Kaestner KH, Bogue CW (2007): The homeobox gene Hhex is essential for proper hepatoblast differentiation and bile duct morphogenesis. Dev Biol 308(2): 355-367

Jaffredo T, Gautier R, Eichmann A, Dieterlein-Lievre F (1998): Intra-aortic hemopoietic cells are derived from endothelial cells during ontogeny. Development 125:4575-4583 
Jaffredo T, Boolerot K, Sugiyama D, Gautier R, Drevon C (2005): Tracing the hemangioblast during embryogenesis: developmental relationship between endothelial and hematopoeitic cells. Int J Dev Biol 49: 269277

John HA, Birnstiel ML, Jones KW (1969): RNA-DNA hybrids at the cytological level. Nature 223: 582-587

Jordan HE (1916): Evidence of hemogenic capacity of endothelium. Anat Rec 10: 417-420

Keller GM (1995): In vitro differentiation of embryonic stem cells. Curr Opin Cell Biol. 7(6):862-9

Keng VW, Yagi H, Ikawa M, Nagano T, Myint Z, Yamada K, Tanaka T, Sato A, Muramatsu I, Okabe M, Sato M, Noguchi T (2000): Homeobox Gene Hex is essential for onset of Mouse embryonic liver development and Differentiation of the monocyte lineage. Biochem Biophys Res Commun. 276(3): 1155-61

Kennedy M, Firpo M, Choi K, Wall C, Robertson S, Kabrun N, Keller G (1997): A common precursor for primitive erythropoiesis and definitive hematopoiesis. Nature (London) 386: 488-493

Klagsbrun M, Moses MA (1999): Molecular angiogenesis. Chem Biol 6: R217-R224

Krumlauf R (1994): Hox genes in vertebrate development. Cell 78(2): 191-201

Kubo A, Chen V, Kennedy M, Zahradka E, Daley GQ, Keller G (2005): The hemeobox gene HEX regulates proliferation and differentiation of the hemangioblasts and endothelial cells during ES cell differentiation. Blood 105: 4590-4597

Langer PR, Waldrop AA, Ward DC (1981): Enzymatic synthesis of biotin-labeled polynucleotides: novel nucleic acid affinity probes. Proc Natl Acad Sci USA $\underline{78}$ : 6633-6637

Laurin T, Schmitz U, Riediger D, Frank HG, Stoll C (2004): Chorioallantoic membrane of fertilized avian eggs as a substrate for assessment of cancerous invasiveness. Mund Kiefer Gesichtschir 8(4): 223-228

Lawrence H J, Sauvageau G, Humphries R K, Largman C (1996): The role of HOX homeobox genes in normal and leukemic hematopoiesis. Stem Cells 14(3): 281-291

Le Lièvre CS, Le Douarin NM (1975): Mesenchymal derivatives of the neural crest: analysis of chimaeric quail and chick embryos. J Embryol Exp Morphol 34: 125 -154

Leitch AR, Schwarzacher T,Jackson D: In-Situ-Hybridisierung. Spektrum-Akademischer Verlag Heidelberg 1994

Ling KW, Dzierzak E (2002): Ontogeny and genetics of the hemato/lymphopoietic system. Curr. Opin. Immunol 14: 186-191

Luttmann W, Bratke K, Küpper M, Myrtek D: Der Experimentator Immunologie. 1. Auflage; SpektrumAkademischer Verlag Heidelberg 2004

Macchia PE (2000): Recent advances in understanding the molecular basis of congenital hypothyreoidism. Mol Med Today $\underline{6}:$ 36-42

Mack DL, Leibowitz DS, Cooper S, Ramsey H, Broxmeyer HE, Hromas R (2002): Down-regulation of the myeloid homeobox protein Hex is essential for normal T-cell development. Immunology 107(4): 444-51

Manfioletti G, Gattei V, Buratti E, Rustighi A, De luliis A, Aldinucci D, Goodwin GH, Pinto A (1995): Differential expression of a novel proline-rich homeobox gene (Prh) in human hematolymphopoietic cells. Blood 85:1237-45

Martinez Barbera JP, Clements M, Thomas P, Rodriguez T, Meloy D, Kioussis D, Beddington RS (2000): The homeobox gene Hex is required in definitive endoderm tissues for normal forebrain, liver and thyroid formation. Development 127(11): 2433-45

Masaaki Y, Norifumi T, Endo F, Yokouchi Y (2005): Analyses of gene expression patterns in the developing chick liver. Dev Dyn 233: 1116-1122 
Mülhardt C: Der Experimentator: Molekularbiologie/Genomics. 4. Auflage; Spektrum-Akademischer Verlag Heidelberg 2003

NCBI Gendatenbank, http://www.ncbi.nlm.nih.gov (15.05.2009)

Obinata A, Akimoto Y (2005): Expresssion of HEX during feather bud development. Int J Dev Biol 49: 953960

Obinata A, Akimoto Y, Omoto Y, Hirano H (2002): Expression of Hex homeobox gene during skin development: ncrease in epidermal cell proliferation by transfecting the Hex to the dermis. Dev Growth Differ 44(4): 281-292

Owens BM, Hawley RG (2002): HOX and non-HOX Homeobox genes in leukemic hematopoiesis. Stem Cells 20(5): 364-379

Papoutsi M, Siemeister G, Weindel K, Tomarev SI, Kurz H, Schächtele C, Martiny-Baron G, Christ B, Marme D, Wilting J (2000): Active Interactionof human A375 melanoma cells with the lymphatics in vivo. Histochem Cell Biol 114:373-385

Pardanaud L, Altmann C, Kitos P, Dieterlen-Lièvre F (1987): Vasculogenesis in the early quail blastodisc as studied with a monoclonal antibody recognizing endothelial cells. Development 100: 339-49

Pardanaud L, Luton D, Prigent M, Bourcheix L.-M, Catala M, Dieterlen-Lièvre F (1996): Two distinct endothelial lineages in ontogeny, one of them related to hemopoiesis. Development 122:1363 -1371

Pellizzari L, D’Elia A, Rustighi A, Manfioletti G, Tell G, Damante G (2000): Expression and function of the homeodomain-containing protein Hex in thyreoid cells. Nucleic Acids Res 28(13): 2503-2511

Perry JR, Frayling TM (2008): New gene variants alter type 2 diabetes risk predominantly through reduced beta-cell function. Curr Opin Clin Nutr Metab Care 11(4): 371-377

Pouget C, Teillet MA, Gautier R, JAffredo T (2005): From the primitive to the definitive aorta: angioblasts and hemangioblasts during aorta-associated haematopoiesis. J Soc Biol 199(2): 85-91

Pouget C, Gautier R, Teillet M-A, Jaffredo T (2006): Somite-derived cells replace ventral aortic hemangioblasts and provide aortic smooth muscle cells of the trunk. Development 133: 1013-1022

Puppin C, D'Elia AV, Pellizzari L, Russo D, Arturi F, Presta I, Filetti S, Bogue CW, Denson LA, Damante G (2003): Threoid-specific transcription factors control Hex promoter activity. Nucleic Acids Res $\underline{31(7)}$ : 18451852

Puppin C, Puglisi F, Pellizzari L, Manfioletti G, Pestrin M, Pandolfi M, Piga A, Di Loreto C, Damante G (2006): Hex expression and localization in normal mammary gland and breast carcinoma. BMC Cancer $\underline{6}$ : 192

Rak JW, St Croix BD, Kerbel RS (1995): Consequences of angiogenesis for tumor progression, metastasis, and cancer therapy. Anticancer Drugs 6 : 3-18

Ribatti D, Vacca A, Roncali L, Dammacco F (1996): The chick embryo chorioallantoic membrane as a model for in vivo research on angiogenesis. Int J Dev Biol 40: 1189-1197

Romanoff AL: The avian embryo, structural and functional development. Macmillan Company New York 1960

Sabin FR (1920): Studies on the origin of blood vessels and of red corpuscles as seen in the living blastoderm of the chick during the second day of incubation. Contrib Embryol 9:213-62

Schneider M, Othman-Hassan K, Christ B, Wilting J (1999): Lymphangioblasts in the avian wing bud. Dev Dyn 216:311-19

Schwarz TF (2005): Lymphozytäre Choriomeningitis - eine vergessene Infektion? Impf Dialog 4: 196-198 
Siminovitch L, Till JE, McCulloch EA (1964): Decline in colony-forming ability of marrow cells subjected to serial transplantation into irradiated mice. J Cell Physol 64: 23-31

Smith J, Burt DW (1998): Parameters of the chicken genome (Gallus gallus). Anim Genet 29:290-294

Soufi A, Jayaraman PS (2008): PRH/HEX: an oligomeric transcription factor and multifunctional regulator of cell fate. Biochem J 123(3): 399-413

Soufi A, Gaston K, Jayaraman PS (2006): Purification and characterisation of the PRH homeodomain: Removel of the N-terminal domain of PRH increases the homeodomain-DNA interaction. Int J Biol Macromol 15;39(1-3): $45-50$

Speck NA, Gilliland DG (2002): Core-binding factors in haematopoiesis and leukaemia. Nat Rev Cancer $\underline{2}$ : $502-513$

Stainier DY, Weinstein BM, Detrich HW, Zon LI, Fishman MC (1995): Cloche, an early acting zebrafish gene, is required by both the endothelial and hematopoietic lineages. Development 121(10): 3141-3150

Starck JM, Ricklefs RM: Avian Growth and Development. Oxford University Press, New York 1998

Tanaka H, Yamamoto T, Ban T, Satoh S-I Tanaka T, Shimoda M, Miyazaki J-I, Noguchi T (2005): Hex stimulates the hepatocyte nuclear factor 1a-mediated activation of transcription Arch Bichem Biophys 442(1): 117-124

Topisirovic I, Culjkovic B, Cohen N, Perez JM, Skabanek L, Borden K (2003a): The proline-rich homeodomain protein, $\mathrm{PRH}$, is a tissue- specific inhibitor of eIF4E-dependent cyclin D1 mRNA transport and growth. EMBO J 22(3): 689-703

Topisirovic I, Guzman ML, McConnell MJ, Licht JD, Culjkovic B, Neering SJ, Jordan CT, Borden KLB (2003b): Abberant Eukaryotic Translation Initiation Factor 4E-Dependent mRNA Transport Impedes Hematopoietic Differentiation and Contributes to leukemogenesis. Mol Cell Biol 23(24): 8992-9002

Tupler R, Perini G, Green MR (2001): Expressing the human genome. Nature 409: 832-833

Wilting J, Schneider M, Papoutski M, Alitalo K, Christ B (2000a): An avian model for studies of embryonic lymphangiogenesis. Lymphology 33:77-80

Wilting J, Papoutsi M, Schneider M, Christ B (2000b): The lymphatic endothelium of the avian wing is of somitic origin. Dev Dyn 217: 271 -278

Wilting J, Paptoutsi M, Othman-Hassan K, Rodriguez-Niedenführ M, Pröls F, Tomarev SI, Eichmann A (2001): Development of the avian lymphatic system. Microsc Res Tech 55: 81-91

Wilting J, Papoutsi M, Buttler K, Becker J (2007): Embryonic development of the lymphovascular system and tumor lymphangiogenesis. Cancer Treat Res 135:17-24

Yamashita J, Itoh H, Hirashima M, Ogawa M, Nishikawa S, Yurugi T, Naito M, Nakao K (2000): Flkpositive cells derived from embryonic stem cells serve sa vascular progenitors. Nature $\underline{408}$ : $92-96$

Yano M, Iwama A, Nishio H, Suda J, Takada G, Suda T (1997): Expression and function of murine receptor tyrosine kinases, TIE and TEK, in hematopoetic stem cells. Blood $\underline{89}$ : 4317-4326

Yatskievych TA, Pascoe S, Antin PB (1999): Expression of the homebox gene Hex during early stages of chick embryo development. Mech Dev $\underline{\text { 80(1): } 107-9}$

Zhang W, Yatskievych TA, Baker RK, Antin PB (2004): Regulation of Hex gene expression and initial stages of avian hepatogenesis by Bmp and Fgf signalling. Dev Biol 286(2): 312-326 


\section{Lebenslauf}

Am 14. Oktober 1983 wurde ich als Tochter von Elisabeth Terwelp, geb. Kirschner, und Michael Terwelp in Cloppenburg geboren.

\section{Schulische Ausbildung}

In den Jahren 1990 bis 1994 besuchte ich die Grundschule St. Augustinus in Cloppenburg. Im Anschluss daran folgte der zweijährige Besuch der Orientierungsstufe am Cappelner Damm. 1996 wechselte ich auf das Liebfrauengymnasium Cloppenburg, wo ich im Juli 2003 die Allgemeine Hochschulreife erwarb.

\section{Hochschulstudium}

Im Herbst 2003 begann ich das Studium der Humanmedizin an der Georg-AugustUniversität Göttingen und legte dort im Jahr 2005 den ersten und 2009 den zweiten Abschnitt der ärztlichen Prüfung ab. Mein Praktisches Jahr (2008 bis 2009) verbrachte ich mit dem Wahlfach Hals- Nasen- Ohrenheilkunde in Oldenburg und Bozen (Italien).

Ende des Jahres 2005 begann ich in der Abteilung Anatomie und Zellbiologie der Medizinischen Fakultät der Universität Göttingen meine Dissertation zum Erwerb des Doktorgrades der Humanmedizin.

\section{Berufliche Ausbildung}

Seit April 2010 arbeite ich als Assistenzärztin in der Hals- Nasen- Ohrenheilkunde im Evangelischen Krankenhaus in Oldenburg.

Cloppenburg, den 10.10.2010 